\title{
Evaluation of concrete median barrier delineation under poor visibility conditions
}

Kari A. French

West Virginia University

Follow this and additional works at: https://researchrepository.wvu.edu/etd

\section{Recommended Citation}

French, Kari A., "Evaluation of concrete median barrier delineation under poor visibility conditions" (2003). Graduate Theses, Dissertations, and Problem Reports. 1373.

https://researchrepository.wvu.edu/etd/1373

This Thesis is protected by copyright and/or related rights. It has been brought to you by the The Research Repository @ WVU with permission from the rights-holder(s). You are free to use this Thesis in any way that is permitted by the copyright and related rights legislation that applies to your use. For other uses you must obtain permission from the rights-holder(s) directly, unless additional rights are indicated by a Creative Commons license in the record and/ or on the work itself. This Thesis has been accepted for inclusion in WVU Graduate Theses, Dissertations, and Problem Reports collection by an authorized administrator of The Research Repository @ WVU. For more information, please contact researchrepository@mail.wvu.edu. 
Evaluation of Concrete Median Barrier Delineation Under Poor Visibility Conditions

\author{
Kari A. French \\ Thesis submitted to the \\ College of Engineering and Mineral Resources at \\ West Virginia University \\ In partial fulfillment of the requirements for the degree of \\ Master of Science \\ In \\ Civil and Environmental Engineering
}

\author{
David Martinelli, Ph.D., Chair \\ Darrell Dean, Ph.D. \\ Michael H. Dufalla, P.E.
}

Department of Civil and Environmental Engineering

Morgantown, WV

2003

Keywords: delineation, visibility, adhesive 


\section{ABSTRACT \\ Evaluation of Concrete Median Barrier Delineation Under Poor Visibility Conditions}

\section{Kari A. French}

A nationwide survey, durability test, and visibility test were conducted for concrete median barrier delineation. PENNDOT was encountering with delineators becoming detached due to harsh conditions in the roadside areas, as well as visibility problems in spot locations prone to fog. From the results of the research it was recommended that in areas prone to poor visibility conditions, PENNDOT consider decreasing the longitudinal spacing and providing delineation lower on the barrier than shown in the standards. With respect to the durability, in instances where the "peel-nstick" delineators are comparable in price to obtaining the delineator and adhesive separately, that special consideration should be given to the "peel-n-stick" delineators. Their installation time was found to be less, and their durability was perfect over the one year period monitored. They should also be given special consideration in instances where traveler delay due to the traffic control set up to install the delineators is critical. Finally, the literature review revealed that the ultimate solution to delineation under poor visibility conditions is light-emitting delineation and should be considered as a long term solution. 


\section{ACKNOWLEDGEMENTS}

I would like to express my most sincere appreciation to Mr. Michael Dufalla, the district engineer at PENNDOT 12-0, for his support and encouragement during this research project. Without his time and guidance this project would not have been possible.

I would also like to thank Dr. David Martinelli for his guidance and assistance throughout my graduate program. Likewise, I extend my gratitude to my supervisors at PENNDOT for their encouragement and patience.

Finally, I would like to extend a special thanks to my brother Jim for his hard work and direction, and setting such a great example throughout my entire college career. 


\section{Table of Contents}

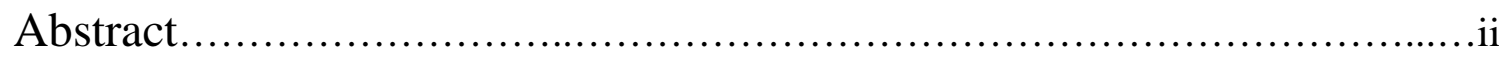

Acknowledgements...................................................ii

Table of Contents....................................................

Chapter 1 Introduction

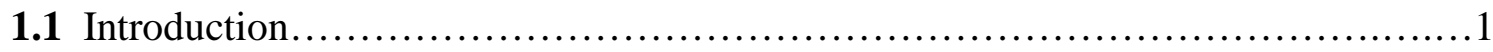

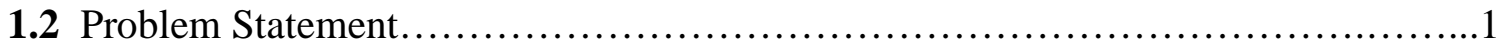

Chapter 2 Literature Review

2.1 Principles of Delineation and Traffic Control Devices............................5

2.1.1 The General Principles of Traffic Control Devices.......................5

2.1.2 Principles Specific to Delineators.......................................

2.2 Key Components of Delineation........................................... 11

2.2.1 Elements of Delineation Design.....................................11

2.2.2 Retroreflection........................................................

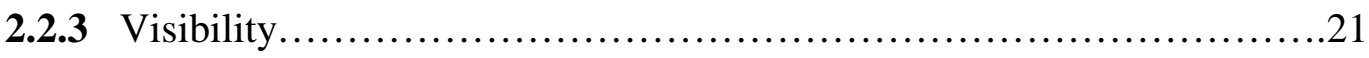

2.2.4 Driving Task ........................................................... 30

2.2.5 Environmental Considerations...........................................33

2.3 Current Issues and Research in Concrete Median Barrier Delineation...............36

2.4 State of Practice Survey of Concrete Median Barrier Delineation...................37

2.4.1 Current PennDOT Standards and Practices..............................38

2.4.2 Delineator Standards from Other States................................45 


\section{Chapter 3 Durability Test}

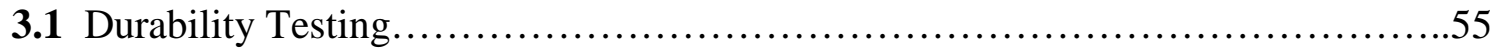

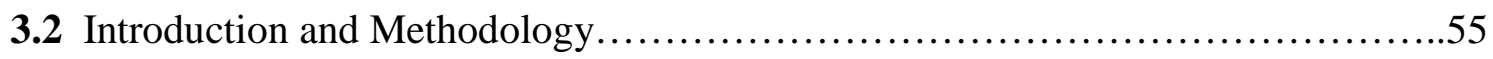

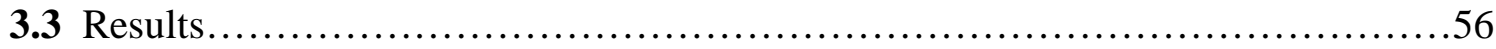

3.3.1 Application Rate..................................................56

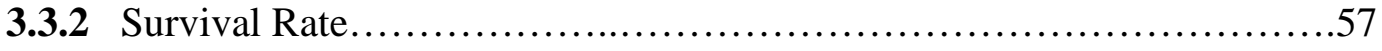

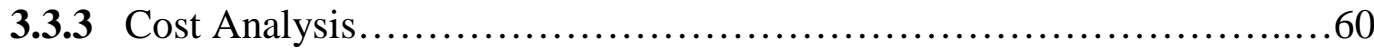

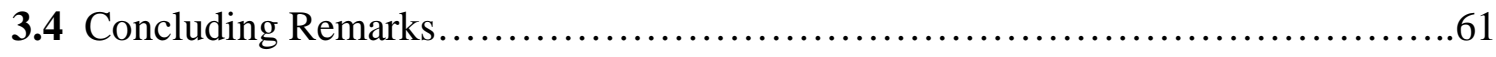

Chapter 4 Visibility Test

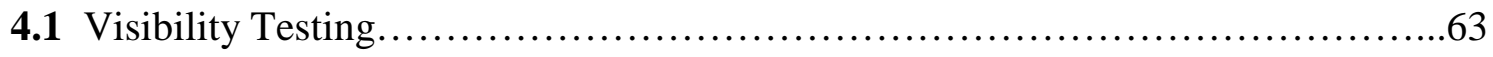

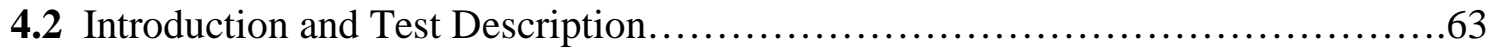

4.3 Phase I - Baseline Conditions...............................................67

4.4 Phase II - High vs Low Side-Mounted Delineators..............................68

4.5 Phase III - Low vs Three Side-Mounted Delineators.............................72

4.6 Phase IV - Halved Spacing .................................................. 75

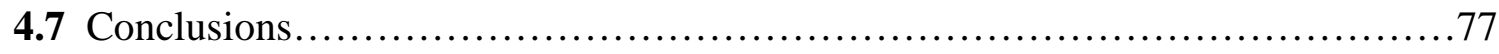

Chapter 5 Summary and Conclusions

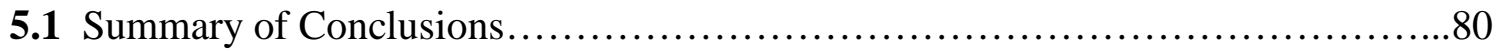

5.2 Literature Review and State of Practice Survey ...............................8 80

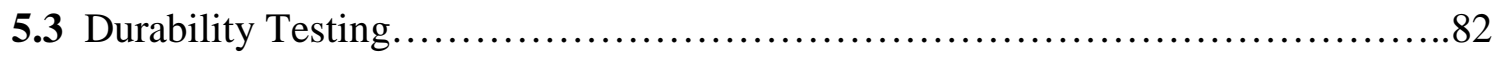

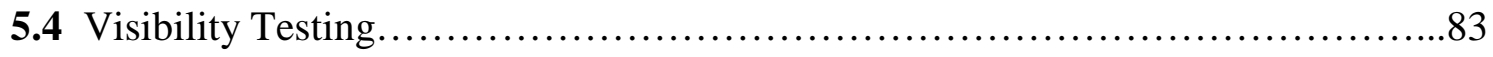

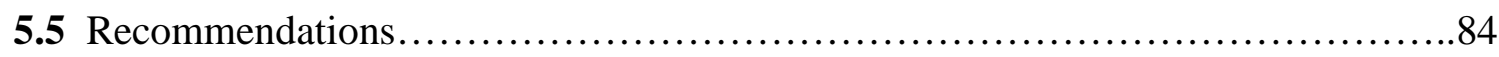

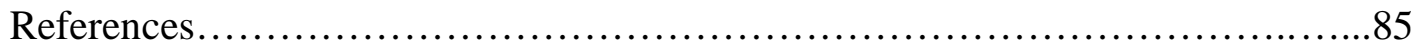


Appendix A - Standards and Specifications from Other States................A-1

Appendix B - Durability Test Calculations...................................

Appendix C - Visibility Test - Baseline Conditions....................... -1

Appendix D - Visibility Test - High vs Low Side-Mounted Delineators........... D-1

Appendix E - Visibility Test - Low vs Three Side-Mounted Delineators.........E-1

Appendix F - Visibility Test - Halved Spacing $\ldots \ldots \ldots \ldots \ldots \ldots \ldots \ldots \ldots \ldots \ldots \ldots$ F-1 


\section{List of Tables}

Table

Page

3-1

Application Rates Associated With Each Adhesive

57 Type

Arrangement of Delineators in the Durability Test Sections

Actual Mean Temperature vs Normal Mean

Temperature $-9 / 01$ to $9 / 02$

Phase II 


\section{List of Figures}

Figure

Page

I

Different Types of Reflection

13

II

Comparison of Perfect Retroreflectors to Roadway

14

Retroreflector

III

Observation and Entrance Angles

16

IV

Typical Delineator with Prismatic Retroreflective

17 Sheeting

V

How Prismatic Retroreflectors Reflect Light

18

VI

PennDOT's Standard Drawing for Concrete Median

40

Barrier Delineation (TC-7604)

VII

PennDOT's Previous Standard Delineators

41

VIII

Three Side Row Delineation Configuration

44

IX

Visibility Test Section Layout

65

$\mathrm{X}$

Phase II Configuration

69

XI

Phase III Configuration

73

XII

Preliminary Configuration for PENNDOT Standard

79 


\section{Chapter 1 Introduction}

\subsection{Introduction}

Concrete median barrier delineators are reflective or light-emitting devices that are placed in series on a median barrier divider between opposing directions of traffic. The specific type of median barrier addressed in this research is the safety-shaped, also known as the F-shaped or "jersey" barrier. Delineation of these barriers is of interest to the Pennsylvania Department of Transportation (PENNDOT) because:

(1) Due to durability problems caused by vandalism and the affects of adverse environmental conditions in the roadside area where they are mounted, this delineation causes a significant maintenance problem for the Department.

(2) During poor visibility conditions, particularly fog and snow, there is a perceived increase in the frequency of side-swipe collisions with the barrier.

(3) In response to the above-mentioned problems, different entities within PENNDOT have tried various delineation designs, without any scientific feedback on the effectiveness of the strategies.

In order to adequately evaluate the effectiveness of concrete median barrier delineation, particularly under poor visibility conditions, background information regarding this issue was required. A comprehensive literature review was conducted in order to understand delineation, the principles of retroreflectivity and visibility, and the effects of poor atmospheric conditions on visibility and the driving task. This review also focused on the deterioration and damage 
incurred by the delineator due to its location in the roadside environment, which is generally very close to the traveling lanes. Finally, current research and issues in the area were identified.

In addition, a survey of standards and specifications for concrete median barrier delineation from other states was conducted. A survey was also conducted of PENNDOT personnel to determine strategies that they have tried in the past.

\subsection{Summary of Results and Proposed Field Tests}

There is an opportunity for updating the PENNDOT standard for concrete median barrier delineation to make it more effective in areas prone to poor visibility conditions. Field experiments that are proposed to this end and are as follows:

1. Test the effect of delineator configuration on driving performance under poor visibility conditions for barrier that is close to the traveling lane, as measured by driving performance indicated by speed.

Test Overview: Four 1500-foot to 1800 -foot long test sections will be established on SR 40 just west of the crest of Summit Mountain near Uniontown, Pennsylvania. Two of the sections will be in the upgrade direction and the other two will be in the opposing lanes in the downgrade direction. Speed data will be collected at each test section under good visibility conditions to validate the suitability of the test sections and provide a baseline for driving performance in the area. During Phase I of the configuration testing, the following configurations will be tested: 
- Delineator on top and side near the top - Current PENNDOT standard

- Delineator on top and side near the bottom

During Phase II of the configuration testing, the following configurations will be tested:

- Delineator on top and one on the side (either top or bottom, to be determined as a result of the Phase I testing)

- Delineator on top and three on the side

Speed measuring traffic counters will be placed in each section. Speed comparisons will be made. For each section, a test of statistical significance will be conducted between speed data collected (1) in the adjacent sections, (2) between the two configurations, and (3) between the speed data collected under poor visibility conditions and good visibility conditions.

2. Test the effect of delineator spacing on driving performance under poor visibility conditions for barrier that is close to the traveling lane, as measured by speed.

Test Overview: One of the above-mentioned delineator configurations will be selected to test the influence of spacing on driver performance. In both the upgrade and downgrade direction, one of the test sections will have the delineators spaced at the standard rate and the other will have spacing that is half the standard rate. Speed data 
will be used as in (1) to determine the effect on driving performance. A test of statistical significance will be conducted between speed data in the two sections.

3. Measure the rate of delineator installation and survival for two mounting techniques: typical adhesives and adhesive used with Sun Labs adhesive.

Test Overview: The following three delineator applications will be tested to determine their installation and survival rate: (1) typical adhesive commonly used at PENNDOT, (2) a different, yet similar adhesive to the first type, (3) adhesive used with Sun Labs products having a butyl pad backing. Three test sections will be established, each section using a different application type. For each section, the rate of mounting and survival after one year will be measured. These will be used to perform a benefit-cost study of each application type. Each test section will contain approximately 17 delineators. Delineators will be mounted on the top and on the side near the bottom.

The outcomes of the testing will determine whether updates to the current standard should be proposed. 


\section{Chapter 2 Literature Review}

\subsection{Principles of Delineation and Traffic Control Devices}

In this section, first some general principles of traffic control devices are reviewed and related to the specific function of delineation, particularly concrete median barrier delineation. Second, some of the documented principles and requirements specific to delineation are identified.

\subsubsection{The General Principles of Traffic Control Devices}

Delineators, in the most general sense, are traffic control devices. The purpose of traffic control devices is addressed in the Manual on Uniform Traffic Control Devices (MUTCD) (FHWA, 2000),

The purpose of traffic control devices, as well as the principles for their use, is to promote highway safety and efficiency by providing for the orderly movement of all road users on streets and highways throughout the nation.

Traffic control devices notify road users of regulations and provide warning and guidance needed for the safe, uniform, and efficient operation of all elements of the traffic stream.

The primary purpose of delineators is to provide guidance information to assist the driver in following the roadway alignment. According to the Roadway Delineation Practices Handbook (Migletz, Fish and Graham, 1994), “delineation” is: 
"any method of defining the roadway operating area for the driver...(and) is defined as one, or a combination of devices (excluding guide signs), that regulate, warn, or provide tracking information and guidance to the driver."

The guidance provided by delineators is useful to the driver in particularly difficult driving circumstances, such as night-time driving, in adverse weather, and locations where the alignment might be confusing or unexpected. However, it is also useful and typically used for more general purposes, regardless of whether special circumstances exist. In the case of concrete median barrier delineation, it also marks the location of the median barrier, which can assist the driver in avoiding collisions with it. Because it is color coded to match the adjacent pavement marking it also provides some regulatory information.

According to MUTCD (FHWA, 2000), there are five fundamental requirements for traffic control devices to be effective. As traffic control devices, these are generally applicable to delineators and specifically concrete median barrier delineation. The requirements are as follows:

1. Fulfill a need.

2. Command attention.

3. Convey a clear, simple meaning.

4. Command respect of road users.

5. Give adequate time for response. 
All of these requirements are important to concrete median barrier delineation. Relative to the first requirement, if there is no need for the delineation, then it is wasteful to place and maintain the devices in the field. Unlike other traffic control devices, where their unneeded use leads to violation and disrespect of that particular device and all devices in general, unneeded delineators are likely to be simply ignored by the driver and become a maintenance burden for the Department of Transportation.

Relative to the second requirement, the key to commanding attention is proper size and placement. The delineator must have an appropriate amount of reflective (or other means of emitting light) area to catch the drivers' attention. Furthermore, it must be located in the drivers' cone of vision. Finally, since concrete median barrier delineators are primarily reflectors mounted on the barrier for use during nighttime driving, they must also be located in cone of light emitted by the headlight. Note that as will be discussed later, the attention commanded by delineators is different than that commanded by other devices, such as signs, in that delineators convey information on a more subliminal level.

The third requirement can have implications for the layout of delineators at a fixed point along the highway. There are several known configurations of concrete median barrier delineation either currently or previously in use. For example, a reflector may or may not be placed on top of the barrier. Zero, one, two, or even three or more reflectors can be placed on the sides of the barrier. The configuration of a series of delineators along a route may be uniform, alternating, or varying in some other way. In the case of concrete median barrier delineation, the delineation must convey the alignment of the roadway, and also to a certain extent, it must convey the location of the barrier to allow the driver to identify it. 
The concept of commanding respect is generally tied to other traffic control devices, most typically warning signs. For example, setting up work zone traffic control devices when there is no work being performed degrades driver respect for work zone traffic control the next time it is encountered. One problem caused by the lack of respect for concrete median barrier delineation is vandalism of top-mounted reflectors.

Adequate time for response to concrete median barrier delineation is directly tied to spacing of the delineators, and indirectly tied to the configuration, type, and size of the delineators. This is particularly important during adverse environmental conditions, when the driver may be depending solely on the delineation for guidance information. If the spacing is too large, the driver may lose sight of the delineation for a period of time, causing them to deviate from the proper driving path. The spacing required is a direct function of the visibility of the delineators. The greater the visibility of the delineation, the larger the spacing that can be accommodated.

The Policy on Geometric Design of Highways and Streets (AASHTO, 2001) also briefly addresses the needs for delineation. In the discussion on "Signing and Marking", AASHTO identifies delineators as a "marking", noting:

"Where removal (of physical obstructions near the roadway) is impractical, such objects should be adequately marked by painting or by use of other high-visibility material...Postmounted delineators are (a) type of marking device used to guide traffic, particularly at night. Reflector units are installed at certain heights and spacings to delineate the roadway where alignment changes may be confusing and not clearly defined." 
This discussion reinforces the role of delineators in guiding traffic. Although the MUTCD is hesitant to accept the role of delineation in marking a hazard, the AASHTO publication does mention this function.

Furthermore, delineators are classified as a specific type of traffic control device in the MUTCD (FHWA, 2000), namely a "marking." According to the MUTCD (FHWA, 2000), the function of a marking is to provide "guidance and information for the road user ... while allowing minimal diversion of attention from the roadway."

Again, this is a reinforcement of the role of the delineator in guiding traffic. It also raises an important point to be made about the way in which delineators much accomplish this function. Its role is generally supplementary. It must provide information to aid the driver without becoming a primary focus.

\subsubsection{Principles Specific to Delineators}

The MUTCD (FHWA, 2000) also has a specific section devoted to delineation. This section provides more specific guidance on the function and application of delineation. The key points relevant to concrete median barrier delineation:

- Delineators are retroreflective devices, primarily used as an aid in nighttime driving and during adverse weather. It was noted that the 1988 version of the MUTCD did not mention aiding drivers during adverse weather. This was newly added for the 2000 edition.

- They are mounted above the roadway surface and along the side of the roadway in a series to 
indicate roadway alignment, and as such are considered guidance devices rather than warning devices.

- An important advantage of delineators is that they remain visible when the roadway is wet or snow-covered. (FHWA, 1988) This clause was removed between the 1988 and 2000 editions of the MUTCD.

Six key requirements of delineators relevant to concrete median barrier delineation were also noted (FHWA, 2000):

1. Delineators shall consist of reflector units capable of clearly reflecting light under normal atmospheric conditions from a distance of 1000 feet when illuminated by the upper beam of standard automobile lights.

2. Reflective elements for delineators shall have a minimum dimension of 3 inches

3. The color of delineators shall, in all cases, conform to the color of edgelines.

4. The top of the highest retroreflector is 4 feet above the near roadway edge.

5. They should be in line with a roadside barrier that is 8 feet or less outside the outer edge of the shoulder.

6. The closest delineator spacing recommended for any condition (curvature, facility type, etc.) was 20 feet, corresponding to a 50-foot radius curve.

The MUTCD (FHWA, 2000) also provides general delineation requirements for horizontal curves, freeways and expressways and their interchanges and truck escape ramps. 
Delineators should be spaced 200 to 530 feet apart on mainline tangent sections, 100 feet apart on ramp tangent sections, and 20 to 90 feet in curved sections, depending on the curvature. There was no guidance specific to either (1) concrete barrier delineation or (2) delineation during adverse weather conditions.

\subsection{Key Components of Delineation}

In this section, some of the key principles related to delineation design are presented. Section 2.2.1 presents definitions of some of the key variables in delineation design. Sections 2.2.2 and 2.2.3 present the important principles of retroreflectivity and visibility as they relate to delineation. Section 2.2.4 discusses the driving task, and in particular the portions relying on delineation. Section 2.2.5 concludes this section with an investigation of the environmental conditions present in the roadside area that have an impact on delineator performance and life.

\subsubsection{Elements of Delineation Design}

This purpose of this subsection is to briefly define the key variables in delineation design and layout.

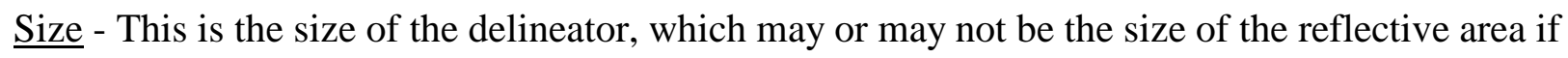
it does not cover the entire delineator.

Spacing- The distance between delineators, measured longitudinally along the roadway. 
Reflective Area - The area containing the retroreflective sheeting or element.

Configuration - How delineators are positioned on a transverse cross-section of the barrier.

Delineators are typically positioned either on the top only, side only, or both top and side. There can be several rows on the side.

Mounting - How the delineators are fixed to the barrier, usually through bolting or gluing.

\subsubsection{Retroreflection}

Except for the few delineators that emit light, delineators function by reflecting light from vehicle headlamps back to the driver. Thus, the reflectivity properties of delineators are crucial to their operations. Delineators, like most traffic control devices that use reflected light for nighttime visibility, are retroreflective. Retroreflection is defined as the ability of a surface to reflect incoming, or incident, light predominately in the direction of the source (Migletz, Fish and Graham, 1994). In the context of driving, this means that the light from the vehicle headlamps is redirected back towards the vehicle, thus making the delineator visible to the driver.

Retroreflection is unlike the reflection of light off a mirrored surface, which directs light at an angle that is equal and opposite to the direction of its source. The perfect retroreflector reflects light in the exact reverse direction of the light incident upon it, which in highway applications would be directly back at the headlamps. Thus, drivers would not be able to see a perfect retroreflector because none of the light would be directed towards their eye. In highway use, however, retroreflectors are not perfect. Some of the light is absorbed by the reflector, and the remainder of the light is scattered in all directions predominately in the direction of the source, in 
this case the headlamps. In this way, some of the reflected light reaches the eye of the driver. Figure I shows different types of reflection and Figure II shows the comparison of a perfect retroreflector to actual roadway retroreflector.

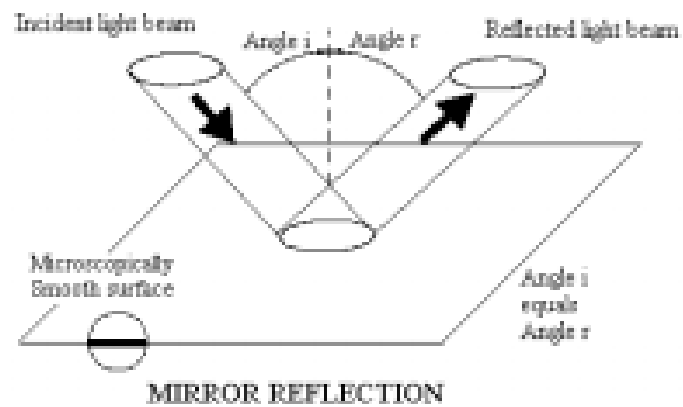

MIRTOR REFLECTION
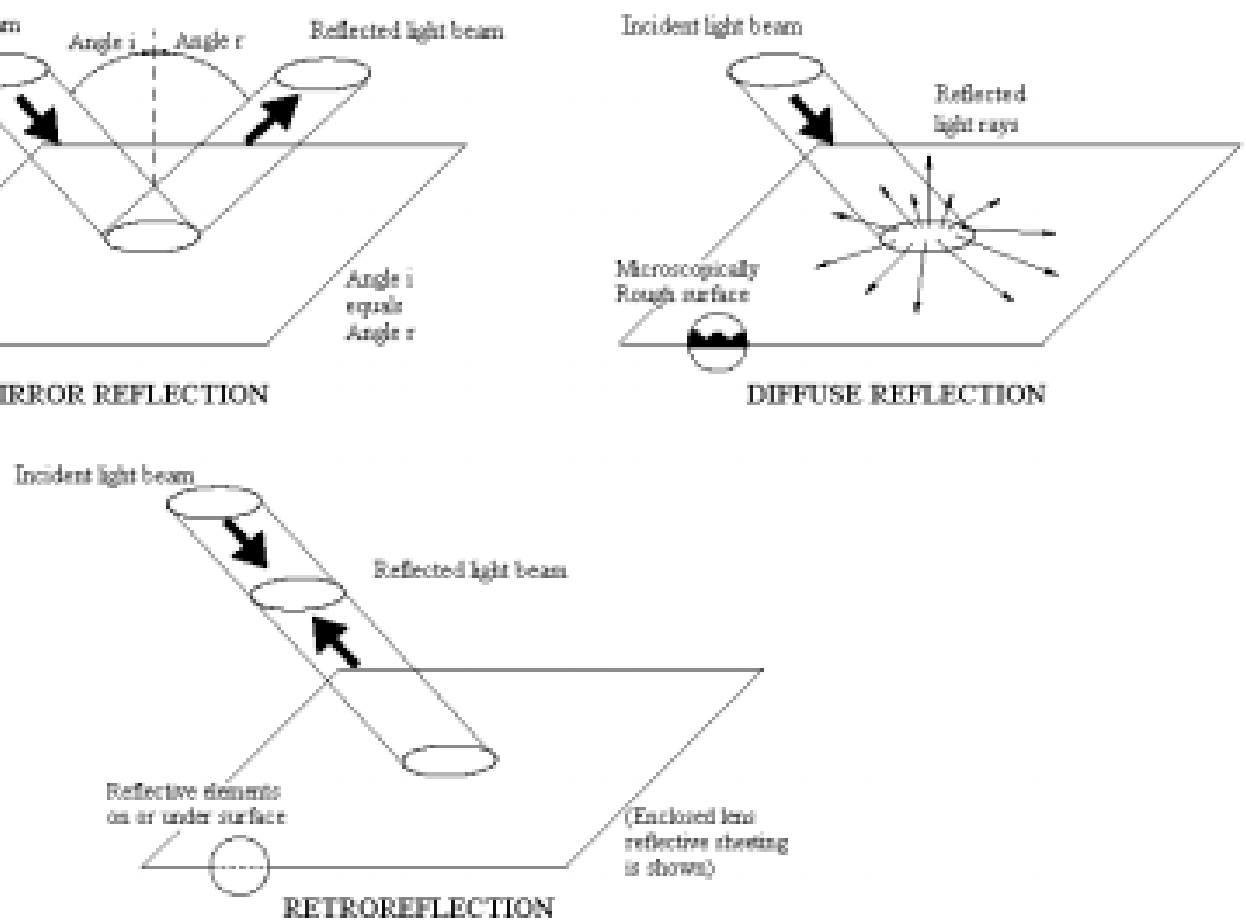

Figure I - Different Types of Reflection, (Migletz, Fish and Graham, 1994) 

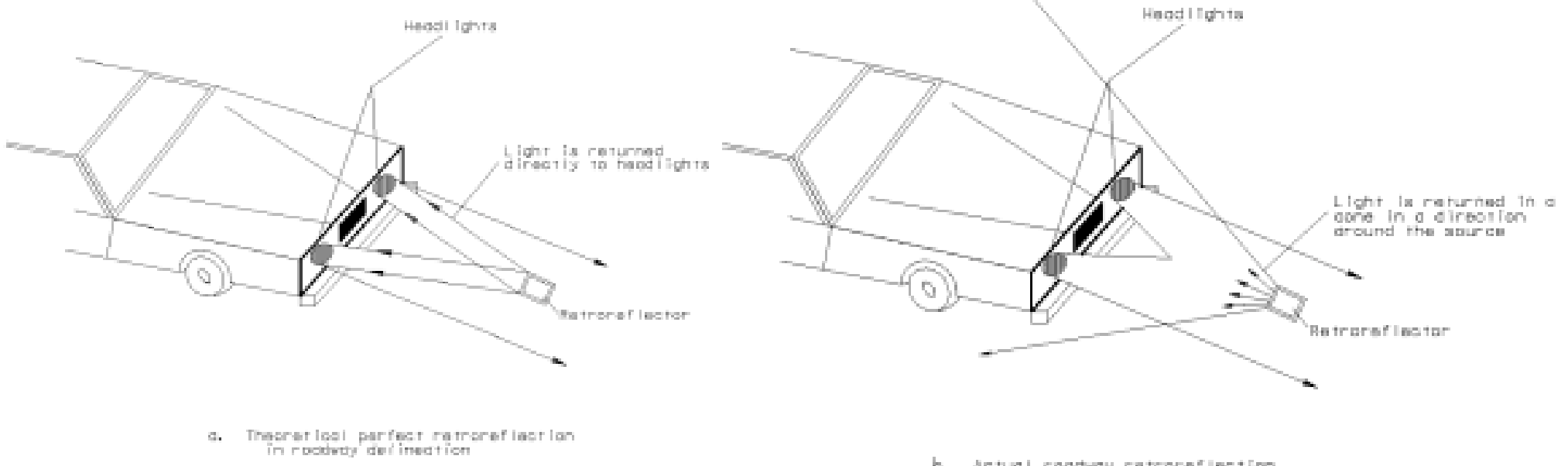

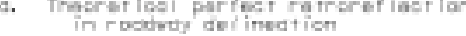

5. Agtual rogdeay retrerefiestion

Figure II - Comparison of Perfect Retroreflectors to Roadway Retroreflector, (Migletz, Fish and Graham, 1994)

In this section, some of the principles related to retroreflectivity are explained, and the general classes of retroreflective sheeting are presented. Please note that the most common and significant retroreflective traffic control device is the sign. As such, much of the material presented in this section was detailed in work related to signs. However, with a few exceptions, the principles are transferable from one to other.

An understanding of the principles of retroreflectivity begins with an understanding of the terms and units of measurement related to light and retroreflectivity. Light, from vehicles headlamps, is measured in terms of candlepower (cp), or the metric candela (cd). Illuminance, measured in foot-candles (fc) or metric lux (lx) is a measure of the amount of light falling onto a surface. Once the light is reflected from the surface to the driver it is termed luminance. This is what the driver actually sees. Luminance is measured in candelas per square foot $\left(\mathrm{cd} / \mathrm{ft}^{2}\right)$ or square meter $\left(\mathrm{cd} / \mathrm{m}^{2}\right)$. Reflectivity is measured as the coefficient of retroreflected luminance, RL, which is defined as the ratio of the luminance of a surface to the normal illuminance on the 
surface (Migletz, Fish and Graham, 1994). This is basically the amount of light leaving the retroreflective material per the amount of light striking it from the source. It is given the English units of candelas per foot-candle per square foot $\left(\mathrm{cd} / \mathrm{fc} / \mathrm{ft}^{2}\right)$ or the metric equivalent of candelas per lux per square meter $\left(\mathrm{cd} / \mathrm{lx} / \mathrm{m}^{2}\right)$.

The ability of a retroreflective material to direct light back to its source is also described by another property, its angularity. In the case of delineators, angularity is defined by the angle at which light is directed towards the delineator (known as the entrance angle) and the angle at which light is returned to the driver (known as the observation angle.) In terms related to the driving population, these are the angles at which the light from the headlight strikes the delineator perpendicular to its surface, entrance angle $(\phi)$, and the angle between the incoming light and the reflected light as it is seen by the motorist on its return from the delineator, observation angle $(\theta)$. The observation angle is a function of the difference in elevation between the driver's eye and the headlamp, while the entrance angle is a function of the horizontal distance between the delineator and the vehicle. See Figure III. A small change in the observation angle can have a large impact on the amount of light reflected back to the driver. 


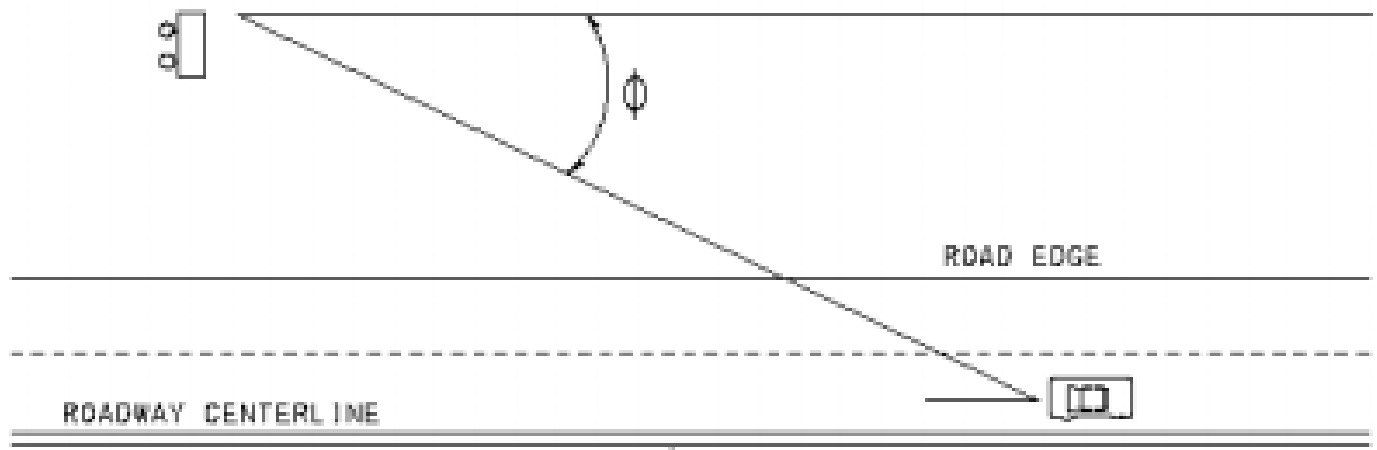

a.) Entrance Angle (0) For Roadsids Sign

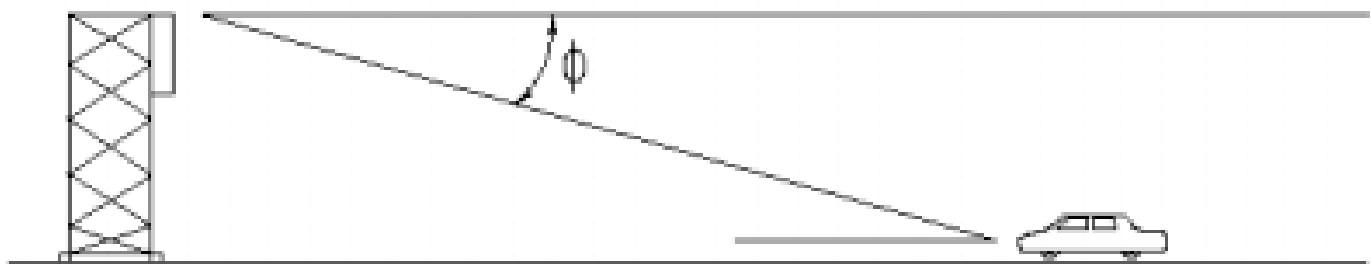

b.) Entranes Angle $\phi$ For Overhacd stan

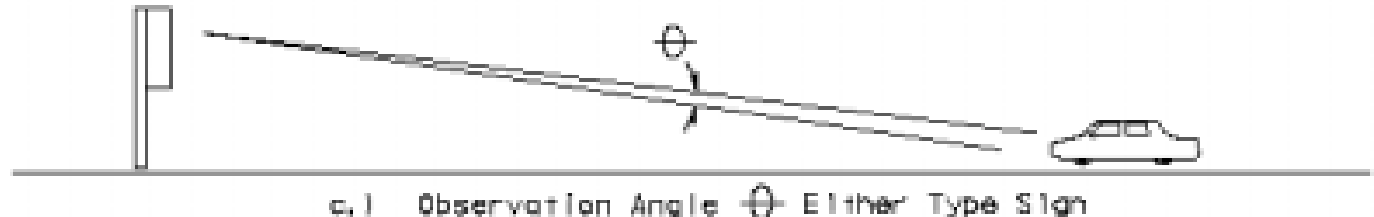

Figure III - Observation and Entrance Angles, (Migletz, Fish and Graham, 1994)

Retroreflective delineator materials return a spreading cone of light over a range of observation angles. As a vehicle approaches a delineator, the observation angle increases, thus narrowing the cone of light reflected to the driver. The light at the center of the cone is most intense and gradually dissipates as the distance from the source is increased. This spreading of the cone is what allows motorists at varying observation angles to see the retroreflected light. 
Retroreflection for delineators is most commonly accomplished through the use of retroreflective sheeting. Most retroreflective sheeting is composed of either glass beads with a reflecting surface behind them or prismatic reflectors. Prismatic retroreflection is the result of internal reflection, as light enters it is reflected off the first surface to the rear surface which then reflects the light to the last surface and then back to the source. Figure IV shows a typical delineator with prismatic retroreflective sheeting. Figure $\mathrm{V}$ shows how prismatic retroreflectors reflect light.

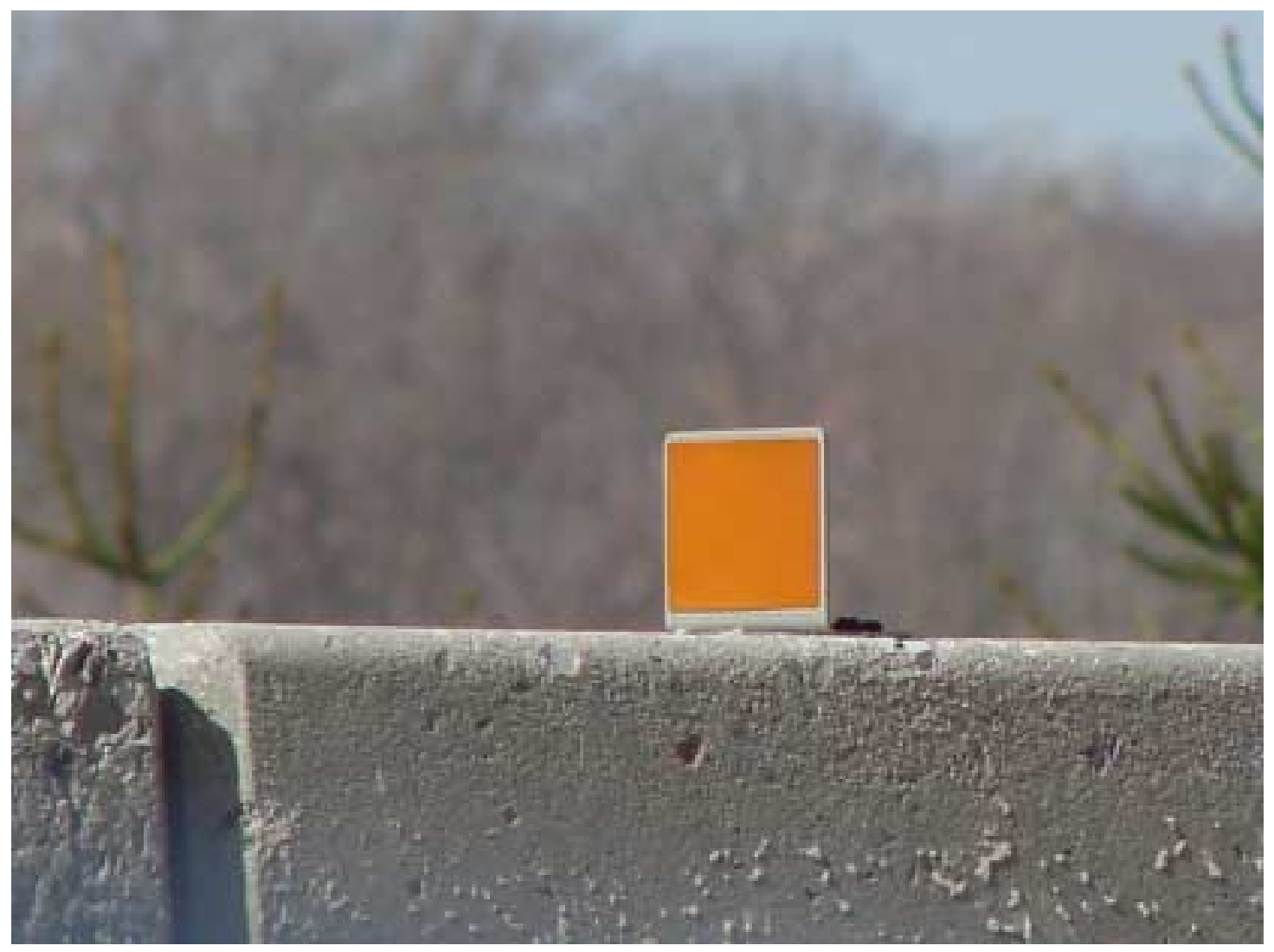

Figure IV - Typical Delineator with Prismatic Sheeting 


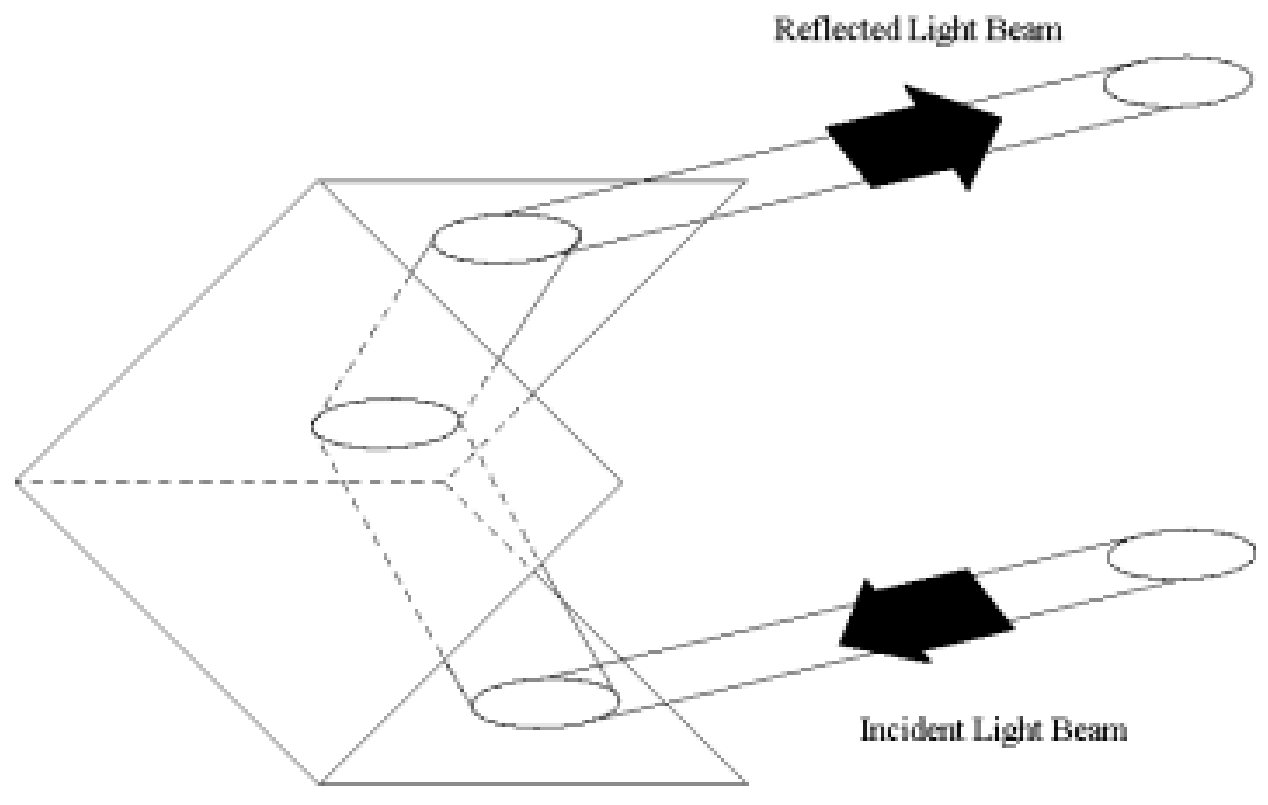

Figure V - How Prismatic Retroreflectors Reflect Light, (Migletz, Fish and Graham, 1994)

According to the ASTM Standards Specifications for Retroreflective Sheeting for Traffic Control, D 4956-95 there are six categories of retroreflective sheeting material that apply to delineators:

- Type I: A medium-intensity retroreflective sheeting referred to as "engineering grade" and typically enclosed lens glass-bead sheeting.

- Type II: A medium-high-intensity retroreflective sheeting sometimes referred to as "super-engineering grade" and typically enclosed lens glass-bead sheeting.

- Type III: A high-intensity retroreflective sheeting that is typically encapsulated glass-bead or prismatic retroreflective material.

- Type IV: A high-intensity retroreflective sheeting that is typically and unmetallized microprismatic retroreflective element material. 
- Type V: A super-high-intensity retroreflective sheeting that is typically an abrasion-resistant metallized microprismatic retroreflective element material.

- Type VI: An elastometric-high-intensity retroreflective sheeting without adhesives. This sheeting is typically a vinyl microprismatic retroreflective material.

PENNDOT also has two additional categories of retroreflective sheeting. They are the following types:

- Type VII: A super-high-intensity retroreflective sheeting sometimes referred to as "Diamond Grade" and typically a resin-filled prismatic retroreflective material.

- Type VIII: A fluorescent high-intensity retroreflective sheeting that is typically encapsulated glass-bead unmetallized microprismatic or resin-filled prismatic retroreflective material.

Since this research will not deal with reflective sheeting, this topic will not be covered in depth. However, a few facts about the sheeting, which may be pertinent, include:

- In general, the sheeting types are generally more reflective and more expensive as grade increases. For example, Type IV is seven times as bright as and four times the cost of Type I sheeting. (Moeur, 1999) Diamond Grade sheeting can be up to 14 times as bright as and five times the cost of Type I sheeting. (Moeur, 1999). The service life also increases slightly, from approximately seven years for Type I to ten years for Types IV and VI (Moeur, 1999). All grades can be and generally are used for signs. However, Types V and VI have special applications and Type VIII is an emerging issue given the recently approved applications of fluorescent-colored signs. 
- PENNDOT currently specifies Type V sheeting for delineators. The typical use of Type V sheeting is in delineators and raised pavement markers, although it can also be used in signs (Moeur, 1999). Its service life is approximately $5 \frac{1}{2} 2$ years (Moeur, 1999). The $5 \frac{1}{2} 2$ year service life is not typically an important consideration, as other aspects of the delineator life cycle, such as vandalism or falling off the barrier typically dictate their service life.

However, if these elements become neutralized, the service life of the reflective material would become an issue.

- Prismatic retroreflectors, which includes Type V, generally appear brighter than glass bead retroreflectors because prismatic retroreflectors gather and return light in a narrower beam (Wright, 1996).

- Microprismatic sheeting contains many units of "minute corner-cubed prisms per square inch that are embossed into a clear and durable sheeting material" according to the Traffic Engineering Handbook. (ITE, 1992)

- The properties of the retroreflective sheeting do not remain constant with time. There are many ways in which the sheeting can degrade and reduce the amount of light that is returned to the driver. The amount of exposure to solar radiation, high temperatures, abrasion from debris, and other forces of nature significantly reduce the service life of a delineator. The original quality of the sheeting has also been cited as a cause of degradation. These effects will be discussed in more detail in Section 1.2.5. 


\subsubsection{Visibility}

In this section, some of theoretical aspects of visibility are reviewed, particularly as it relates to traffic control devices and adverse environmental conditions. The section concludes with some pertinent research findings related to visibility, delineation, and adverse environmental conditions that were found during the literature review.

\section{$\underline{\text { Visibility Criteria }}$}

The criteria that determine the visibility of delineators are luminance, contrast, conspicuity and the prevailing weather and atmospheric conditions. Each will be discussed below.

As previously mentioned, luminance is the amount of light reflected from a surface, in this case, a delineator. The overall amount of delineator luminance is important, and a major contributor to whether the delineator can be comfortably seen. However, the distribution of luminances in the driver field of vision is of crucial importance for visibility.

There are many ways to define relative luminances, the most common procedure is to specify the ratio of two luminances that exist side by side. This ratio is known as contrast. Contrast, in the context of delineation, is provided in the equation below: 
$\mathrm{C}=\frac{\mathrm{L}_{\mathrm{D}}-\mathrm{L}_{\mathrm{B}}}{------}$

where:

$\mathrm{C}=$ Contrast

$\mathrm{L}_{\mathrm{D}}=$ Luminance of the delineator

$\mathrm{L}_{\mathrm{B}}=$ Background luminance

Contrast determines how clearly an object stands out from its background and is therefore a better measure of a delineator's visibility than luminance. In general, the greater the contrast, the better the visibility. Note that contrast, and hence delineator visibility, can be negatively affected not only by a decrease in the luminance from the delineator, but also from an increase in the background luminance. As will be seen, in many cases this is the reason for visibility problems.

The concept of contrast can also be related to median barrier / road surface visibility. Because these are often constructed from the same or similar material having similar colors, the contrast between the median barrier and the road surface can be low. This situation exists during the daytime as well as the night, although the need for contrast decreases under daytime conditions.

Conspicuity is defined as the likelihood that a driver will notice a certain target at a given distance (Migletz, Fish and Graham, 1994). Unlike luminance and contrast, conspicuity is not easily determined and is dependent upon many factors, some of which are very unpredictable. 
Generally speaking, however, it is probably the best measure of visibility. The factors that affect how conspicuous a traffic control device will appear to the driver are given below (McGee and Mace, 1987):

- Eccentricity

- Degree of expectation

- Visual complexity of the background area

- Size

Before a discussion of these items, note that the concept of conspicuity is not applied to delineators like other traffic control devices, such as signs. Part of function of delineation is to indicate the roadway alignment without being a distraction. The information provided by delineators should be accepted and processed on a more subliminal level than, for example, a stop sign, which requires specific driver decisions and responses. In short, delineators should clearly appear in the driver field of vision without attracting too much attention.

Eccentricity is a measure of how far away the driver's line of sight can be in order for the delineator to remain detectable. For near guidance information, it is logical to assume that the further the delineation is from the line of sight, the less likely it is that the delineator will be detected. However, since the field of vision converges towards the center, a certain amount of eccentricity is tolerable for far guidance purposes. As will be seen, some states have warrants for placing delineation on concrete median barrier that is based on the distance from the barrier to the traveling lane. 
Driver expectancy is an important factor in determining how conspicuous a traffic control device will appear. If the driver is seeking the device, it will appear much more conspicuous. However, given the steady and repeating nature of delineation, the concept of expectancy is not applied like it might be for single device, such as a stop sign. Expectancy is important in delineation in that drivers following the path marked by it build up an expectance relative to its path. They expect that following the delineation path coincides with following the road. Missing delineators or other inappropriate changes in delineation design, particularly in curves, could cause problems.

Visual complexity is not easily understood or measured. However, it can have an extreme effect on the conspicuity of some traffic control devices. In situations where there is high complexity the traffic control device must compete with the distractions and visual clutter of its surroundings. Concrete median barrier delineators generally have only the median barrier and oncoming traffic for competition. While the median barrier provides a good background, oncoming traffic, particularly their headlamps, can have a significant affect on conspicuity.

The size of a delineator affects how much it stands out from its surroundings. A larger delineator will have more reflective area and will better compete with background clutter. However, it is interesting to note that in fog visibility research, it was determined that the visibility of a luminous source--an automobile tail light--was dependent on the intensity of the light and not size. (Institute of Transportation and Traffic Engineering, 1969) In contrast, in research on pavement markings, it was determined that a wider pavement marking of less brightness was as visible as a narrower marking of greater brightness (Hoffman and Firth, 1985). 
Neither of these was concerned strictly with delineators, so neither is definitive on the topic. This is an issue worth pursuing specifically as it relates to the size of delineators under poor visibility conditions.

There is no numerical measure for conspicuity. Assessing it involves a qualitative evaluation of the above-mentioned factors. The most pertinent point related to conspicuity of delineators is that it can be controlled by adjusting the above-mentioned factors. However, it must be remembered that more conspicuity will not always lead to a better driving condition.

\section{Visibility Under Adverse Environmental Conditions}

It is well known that climate and weather conditions can contribute to the ineffectiveness of delineation because of degradation of visibility. Specific conditions that could have an adverse effect on the visibility of delineation are rain, snow, fog and particulate matter.

Rain

Rain can have a great impact on the visibility of a delineator. In general, rain reduces the driver's ability to see the surroundings, particularly if it accumulates on the windshield at a rate faster than it can be removed. At night, the combination of glare from oncoming headlights reflecting off the film of water on the road surface increases background luminance levels and erodes delineator contrast. Also retroreflectivity is lost due the film of water directly on the delineator and the dispersement of light as it comes in contact with the droplets of airborne 
water. As the light beam hits the water particles, the light is dispersed and refracted, therefore shifting the light rays from the delineator in different directions. Very few light rays are reflected back to the driver. In addition, water lying on the delineator can affect the angle at which light enters and exits the delineator, which is a key to retroreflection. The increase in background luminance, coupled with the decrease in the delineator luminance, decreases the contrast of and the ability to see the delineator. As will be seen, the reduction in visibility during snow and fog conditions is also caused by the reduction in contrast. However, it is more dramatic in these situations.

Rain does not have a great impact on the durability of delineators. However, they are subject to splashing from wet highways, which may cover them with dirt or degrade their retroreflectivity. This will be discussed in Section 1.2.5.

Snow

The effect of snow on visibility is two-fold. First, all types of markings, concrete median barrier delineators included, can become snow-covered and thus not visible. The most susceptible marking to snow cover is the pavement marking. However, depending on the size and shape of the delineator and the intensity of the snowfall, delineators mounted on concrete median barrier can also become snow-covered. It would seem that the further the delineator sticks out from barrier, the less likely it would be to become covered by accumulating snow. However, this is not necessarily so, as snow can accumulate on vertical surfaces (delineator) without the need to build up from a horizontal surface (barrier). 
Second, snow affects driver visibility. Visibility is most affected by the reflection of head lamp light off the snowflakes back towards the driver. This increases the background luminance relative to the delineator. As with rain, the increase in background luminance, coupled with the dramatic decrease in the delineator luminance, greatly decreases contrast of and the ability to see the delineator. The effect of an intense snowfall is more likely to effect visibility than an intense rain. Snowplowing activity and deicing salts also have a detrimental effect on the delineator. This will be discussed in Section 2.2.5

Generally speaking, rain and snow conditions both obliterate other markings providing guidance information faster than delineators. Pavement markings for example, can be obliterated in a matter of seconds under these conditions. During these times, delineators take on added importance in providing guidance information. There are times when the only traffic control device providing guidance information are delineators.

Fog

Fog also greatly reduces a driver's visibility. Fog is a ground level cloud composed of water droplets varying in diameter from 2 to 50 microns with concentrations between 20 and 500 droplets per cubic centimeter of air. Fog becomes denser in areas of high particulate matter, commonly referred to as smog.(FHWA, 1990) Research performed in the late 1970s indicated that driver performance is not seriously degraded until visibility drops below 600 feet in daylight. (Heiss, 1976). 
As with rain, the light from the head lamps is reflected, refracted, and generally dispersed, making the amount of reflected light reaching the driver minimal. At the same time, because the water droplets are smaller and more concentrated, the dispersed light in the fog, particularly the light reflected back to the driver, greatly increases the background luminance relative to clear

conditions. As with snow conditions, the increased background luminance coupled with reduced delineator luminance drastically reduces the delineator contrast making it difficult and many times impossible to see.

\section{Particulate Matter}

Particulate matter, such as dust or smoke, can be significant problems in different parts of the country, where dust or sand storms occur. Only limited research was found on this topic, but one source did document occurrences of zero (0) visibility during a dust storm. (Blackledge and Burritt, 1977) It is likely that these airborne particles differ from water droplets in their ability to reflect, refract, and disperse light. It is more likely that visibility problems under these conditions are caused by a masking of the roadway environment, with minor contributions from light dispersion. However, this statement is highly dependent on the constituency of the particulate matter and atmospheric conditions.

Particulate matter also has a damaging effect on the delineators, as they are subject to abrasion from the airborne particles. This will be discussed later Section 1.2.5. 


\section{Pertinent Research Findings}

The following are miscellaneous findings related to visibility of delineators that were found during the literature review.

Driver Visibility Findings From by the Roadway Delineation Practices Handbook (Migletz, Fish and Graham, 1994):

- Drivers 65 and older may require four times as much light to see as well as a 39-year-old.

- Older drivers adopt less flexible searching strategies.

- Driver perception-reaction time continually increases with age.

- Recommendations were made to double the value of luminance contrast to account for older or impaired drivers.

- Two (2) seconds of preview time is required for short-range guidance and a minimum of three (3) seconds is required for long-range guidance. At $40 \mathrm{~km} / \mathrm{h}(25 \mathrm{mi} / \mathrm{h})$, delineation must be visible at least $34 \mathrm{~m}(110 \mathrm{ft})$ ahead; at $90 \mathrm{~km} / \mathrm{h}(55 \mathrm{mi} / \mathrm{h})$, delineation must be seen at least $76 \mathrm{~m}(250 \mathrm{ft})$ ahead.

- Optimal contrast levels and, therefore, the required reflectivity to allow for processing at a higher level must account for conditions (such as fog, rain, dew, glare) that could alter a minimum contrast achieved in clear, dry weather. 


\section{Driver Visibility Findings From Other Sources:}

- There was evidence that after 11 months raised pavement markers (RPMs) retained operational effectiveness with respect to near delineation but that their effectiveness as a far delineator was degraded (Krammes and Tyer, 1991).

Note: RPMs are delineators much like concrete median barrier delineators. However, RPMs are subject to wear from traffic, whereas concrete median barrier delineators are not.

- New prismatic RPMs in clear weather had a threshold visibility distance of $243 \mathrm{~m}$ (790 ft) when dry and 198 m (660 ft) when wet. New prismatic RPMs in fog had a threshold visibility distance of $109.8 \mathrm{~m} \mathrm{(360} \mathrm{ft)} \mathrm{when} \mathrm{dry} \mathrm{and} 100.6 \mathrm{~m}$ (330 ft) when wet (Blaauw and Padmos, 1982).

Note: To a certain extent, this demonstrates visibility reduction of delineators under rain conditions.

- Traffic-worn RPMs in clear weather had a threshold visibility distance of $131.5 \mathrm{~m}$ (430 ft) when dry and $140.3 \mathrm{~m}$ (460 ft) when wet. Worn corner-cube RPMs in fog had a threshold visibility distance of $70.2 \mathrm{~m}(230 \mathrm{ft})$ when dry and $109.8 \mathrm{~m}(60 \mathrm{ft})$ when wet (Blaauw and Padmos, 1982).

Note: While not subject to wear directly from traffic, delineators are subject to the abrasive effects of airborne road debris such as anti-skid material for winter maintenance. 


\subsubsection{Driving Task}

It has been stated that the primary function of delineation is providing guidance information. This section reviews a popular conceptual framework of the driving task, and focuses on information gathered and processed at the guidance level.

The information gathered and processed in driving a motor vehicle may be grouped into three levels (Allen, Lunenfield, and Alexander, 1971):

\section{- Control}

- Guidance

- Navigation

Control is related to the physical operation of the vehicle. Tasks such as steering and speed control fall into this category. The consequence of inability to execute at this level can lead to a crash. Guidance is a higher level of the driving task, as it combines the elements of controlling the vehicle to follow the appropriate path. For example, the ability to steer and control speed are applied to follow the road alignment, change lanes when necessary, select headways, execute desired turns, etc. Errors at this level can also lead to crashes. The highest level of the driving task is navigation. Navigation is related to planning and executing a trip. It involves knowing the route between the origin and the selected destination, and the ability to follow the appropriate path(s) through the highway network to successfully complete the trip. Driver errors at this level generally only lead to the driver losing their way and becoming lost. The basic relationship 
between these levels is that the lower the level, the more critical it is to safe vehicle operation.

This has a direct relationship on driver information processing. In cases where the driver is overloaded with information, the driver will process the information from the lower level in lieu of a higher level. A classic example is navigation information placed amidst confusing or difficult geometric conditions. The information needed to control or guide the vehicle will take precedence over the navigation information, and the navigation information may be missed, causing the driver to miss a route needed to reach the destination.

This review is specifically interested in the guidance level since this is the level at which delineation contributes information to the driver. The following is a more detailed explanation of the guidance level.

Guidance level of driver performance refers to the driver's task of selecting a safe speed and path on the highway. While performance at the control level is overt action, performance at the guidance level is a decision process. The driver must evaluate the immediate situation, make appropriate speed and path decisions, and translate these decisions into control actions needed to survive in the traffic stream. Activities include decisions to relating lane positioning, overtaking, and passing...(Alexander and Lunenfield, 1975)

The role of markings and delineators was specifically addressed relative to the guidance level in the Users Guide to Positive Guidance (Post, Alexander and Lunenfield, 1981).

Markings and delineators...provide messages to the driver, which are often redundant or coded. Some messages are redundant in that they give the same information but in a different form than given by the highway itself.... Coding is an important aspect of... their color... and position. Whether markings are redundant, coded or carry discrete information not carried elsewhere, they are an extremely important class of information carrier. 
Delineation contributes information to this level primarily in the area of path selection. The delineation marks the alignment of the road, albeit by marking a parallel path. As such, consistency in delineation is important since changes in delineation can be perceived by the driver as a change in the path that must be followed. Inconsistency can lead to crashes. In addition, since control level information will take precedence over guidance information, a steady, consistent stream of delineation will insure that the information is present when the driver needs it and is mentally capable to process it. Lastly, providing clear, concise guidance information contributes to better information processing at the navigation level, since less of the drivers capacity will need to be contributed to the lower levels of information processing.

\subsubsection{Environmental Considerations}

As previously mentioned overall climate and environmental conditions in the intermediate roadside area have a great impact on the physical condition and life of a delineator. Passersby can also cause damage. Snow, particularly plowed snow, vandalism, abrasives, sunlight, and temperature extremes all negatively impact the physical condition of delineators. Rain is one of the few environmental conditions that improve the physical condition of delineators. Each of these effects is described below. 
Snow

Although the actual snow itself does not do much damage to the delineator, snowfall indirectly affects the life of a delineator. With the event of significant snowfall comes the responsibility of keeping the roadway clear for vehicles. A few ways in which the roads are kept clear are de-icing materials, anti-skid materials and snowplowing, or some combination. The anti-skid material, in its nature, is required to be very abrasive to provide traction for traveling vehicles. This abrasive material has a deteriorating effect as it is thrown or splashed onto the delineator from passing vehicles. Likewise, the de-icing material is made from chemicals that are known to deteriorate delineators. These de-icing materials often mix with snow on the road and create slush that is splashed onto the delineators, placed near the bottom of the barrier, by passing vehicles. This is a major concern for PENNDOT, as it was voiced as one of the primary reasons for poor visibility. Similarly, as snowplows are clearing the roadway, delineators can be impacted by either the plow blade or plowed snow, either of which can break the delineator or knock it off of the barrier.

\section{Vandalism}

Occasionally damage done to the delineators can be caused by vandalism, particularly to the large (12" high) top-mounted delineators. The delineators attract attention from passersby and are easily knocked off the barrier simply by contacting them in some way at the prevailing traveling speed. At 80-foot spacing (the maximum spacing in Pennsylvania) and $45 \mathrm{mph}, 50$ of 
these delineators can be knocked off the barrier in one minute. It is unknown if this can be prevented through use of smaller delineators. However, it is logical that smaller delineators could be less attention grabbing and a smaller target, while still achieving the same effect on driving.

Blowing Dust

Dust and particulate matter accumulates on and along side of the road. As this dust gets blown around by the draft from passing cars and wind, it can come in contact with the delineator, causing an abrasive effect. Over time this dust and particulate matter can erode the surface of the delineator, reducing the effectiveness and life of the delineator. This problem is significant enough that special abrasive resistive Type V sheeting has been developed.

Rain

Generally speaking rain does not have an adverse effect on delineators, which are known to be cleaned by the rain. However, when it rains, there is a tendency for mud puddles to form on the side of the road. As traveling vehicles drive over these puddles, the dirt is thrown onto the delineator, and over time can have an abrasive effect on the delineator. California, for example, specifies that delineators be placed outside a "splash zone." 
Sunlight

Ultraviolet rays from the sun have an impact on the effectiveness of a delineator. Prolonged exposure to the sun results in color fading of the delineator and overall deterioration.

Extreme Temperatures

Temperature is also an issue when it comes to the life of a delineator. The thermoplastic material that delineators are made from is created to withstand specific temperature extremes. This is why the material used for these delineators vary in certain regions. For example, a thermoplastic delineator formulated for the southwestern U.S. would not be appropriate for the northeast and vise versa. Also, in colder climates, delineators have had problems with the freezethaw cycle. This freezing and thawing effect causes early failure by weakening the delineators bond to the barrier.

\subsection{Current Issues and Research in Concrete Median Barrier Delineation}

Other than this project, there is currently not much attention being devoted to delineators in the transportation research community. Major research in traffic control devices is currently being focused on the use of fluorescent colors, older drivers, minimum in-service retroreflectivity 
guidelines and special ITS-based needs. However, research has been performed in the past on delineators and similar devices. The following discussion highlights some of the results.

Sun Labs in Uniontown, Pennsylvania, recently conducted research on an improved flexible hinge between delineator base and mounting area for the retroreflective sheeting (Tshaped delineators, with the base as the cross-member and retroreflective sheeting mounted on

the stem). According to Sun Labs, this hinge was more flexible than other hinges under extreme cold conditions, making it less susceptible to plowed snow and vandalism. They, as well as numerous other companies, have also developed delineators that emit light. Cost and battery life are known issues with these devices.

Another research report documented a preliminary field evaluation using ultraviolet headlights in conjunction with fluorescent pavement markers. It was found that visibility was increased $47 \%$ over the standard delineators and headlights. While the usage of fluorescent materials is on the increase in the United States, it is uncertain if the usage of ultraviolet headlights is on the increase or will ever be significant enough to guide the design of delineation.

\subsection{State of Practice Survey of Concrete Median Barrier Delineation}

For this purposes of this study, the state-of-the-practice can be defined as the way concrete median barrier delineation is currently being implemented. The duty of delineating median barrier typically falls at the state level, as such, it was desired to review the standards, specifications, and other practices of state DOT officials relative to this topic. In this section, the 
standards, specifications, and practices of PENNDOT and other states are reviewed to define the state of the practice in concrete median barrier delineation. A thorough review was conducted for Pennsylvania, as the first section is devoted entirely to it. The second section deals with what was found for the remainder of the states.

\subsubsection{Current PENNDOT Standards and Practices}

The current PENNDOT standard for concrete median barrier delineation is number TC7604, page 2 of 4 (adopted 12/15/99). The standard is shown in Figure VI. In short, the median barrier has two retroreflective units at each location, one on top of the barrier and one on the side placed 26" above the roadway surface. Both delineators must have Type V (ASTM) retroreflective sheeting. The reflective area of the delineator on the side has a vertical dimension of at least 3" but not more than 4.5". The horizontal dimension is at least 3.5" but not more than 4". There are three varieties of acceptable top-mounted retroreflective units. They are labeled Type $\mathrm{P}, \mathrm{R}$, and $\mathrm{S}$ in the standard. Type $\mathrm{P}$ and $\mathrm{R}$ are flat rectangular delineators, both of which have horizontal dimensions of 3". They differ in that the reflective area of Type P is 5" in height, while Type $\mathrm{R}$ is $4 "$ ". In addition, the reflective area of the Type $\mathrm{P}$ reflector is 3 " removed from the top of the barrier. The reflective area for the Type $\mathrm{R}$ delineator is only 0.5 " removed from the barrier top. The Type $\mathrm{R}$ delineator is unique in that the vertical portion of the delineator (portion with the reflective sheet) is connected to the base portion via a flexible hinge. This is because delineators are subject to horizontal forces that bend them parallel to the barrier. These forces come from a variety of sources, primarily vandals, plowed snow, and wind. 
The Type $\mathrm{S}$ delineator is much larger than the Types $\mathrm{P}$ and $\mathrm{R}$, and it is not flat. It is paddle- shaped and requires a separate base to secure it to the barrier top. The reflective sheeting measures 3 " horizontally by 12 " vertically. The bottom of the reflective sheeting is 2.5 " removed from the top of the barrier.

In the notes section of the standard, a maximum horizontal spacing of 80 feet for tangent sections and 40 feet for curve sections with a radius less than 1000 feet is specified. The means of securing the delineator to the barrier, as documented in the specifications (Pub. 408), is epoxy or manufacturer-approved adhesive.

The standards for concrete median barrier delineators have changed numerous times in the past. Two types of delineators that were installed under previous standards that are no longer installed are as follows:

- Circular reflector mounted on a square bracket - also referred to as a "center-mount"

- Trapezoidal-shaped reflector for use on the sides of barriers. This type of delineator had severe durability problems

These delineators are shown in Figure VII - Previous Standard Delineators. 

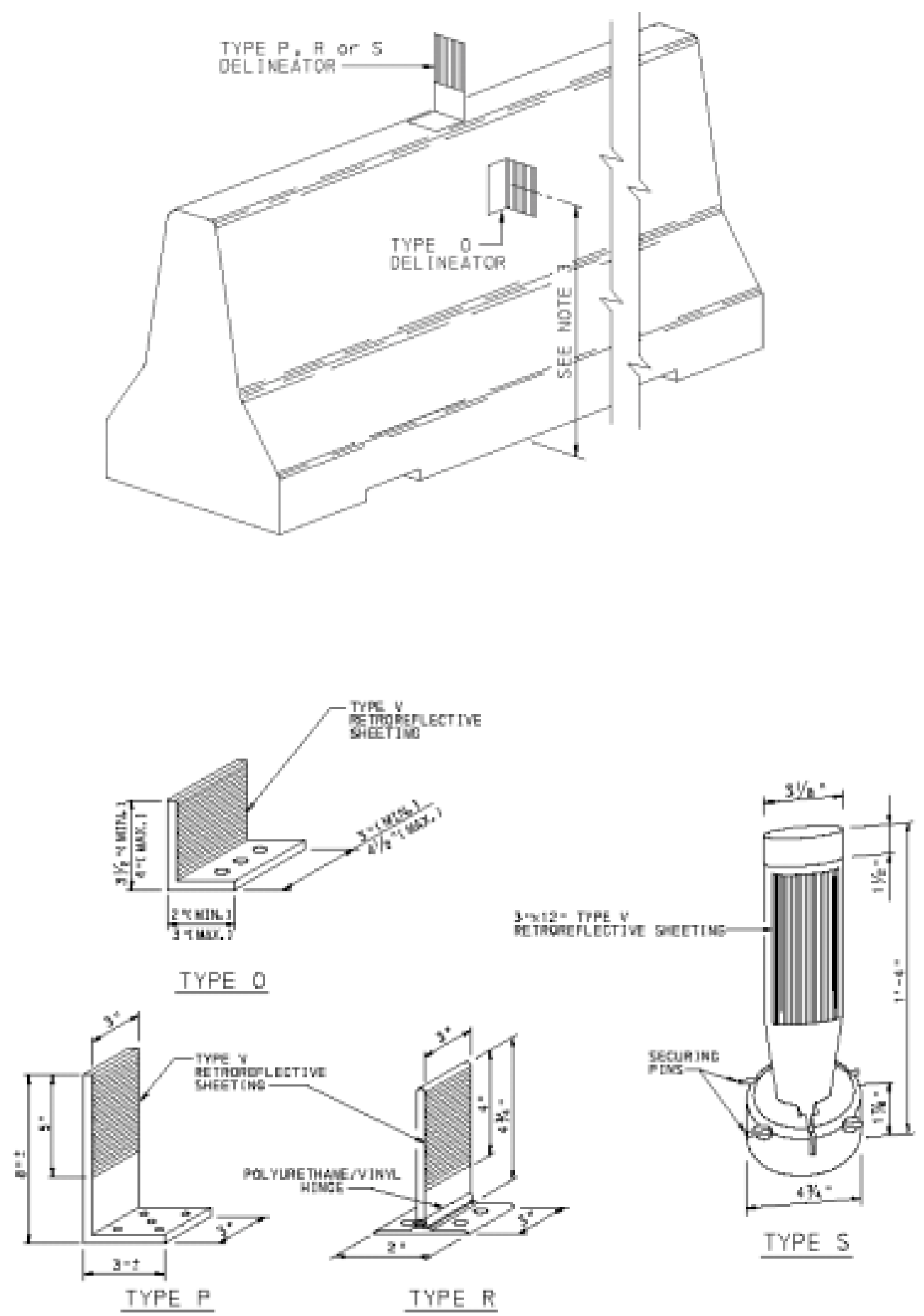

NOTE 3: SIDE MOUNTED DELINEATORS SHALL BE LOCATED 26 INCHES FROM THE PAVEMENT TO THE CENTER OF THE DELINEATOR.

Figure VI - PENNDOT's Standard Drawing for Concrete Median Barrier Delineation (TC-7604) 

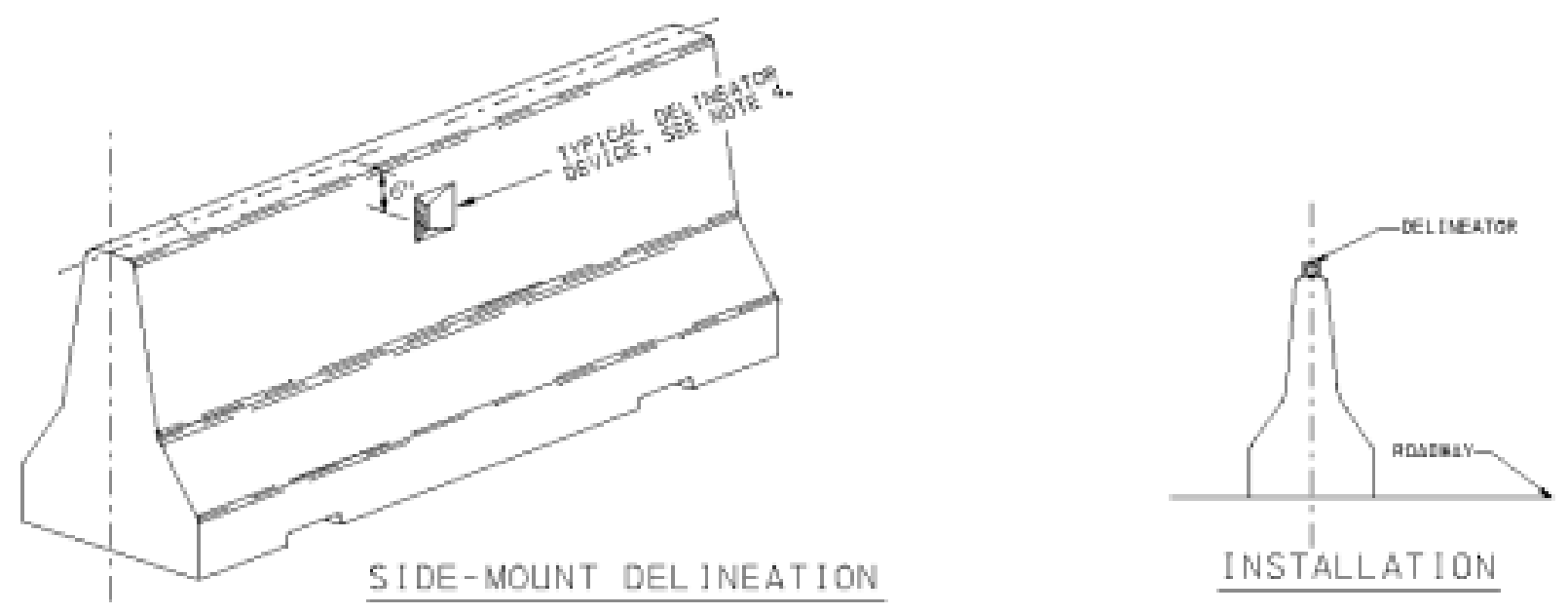

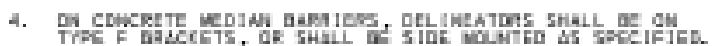

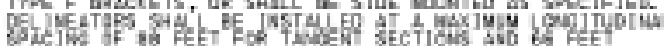

Fon

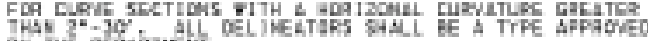

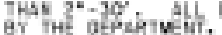
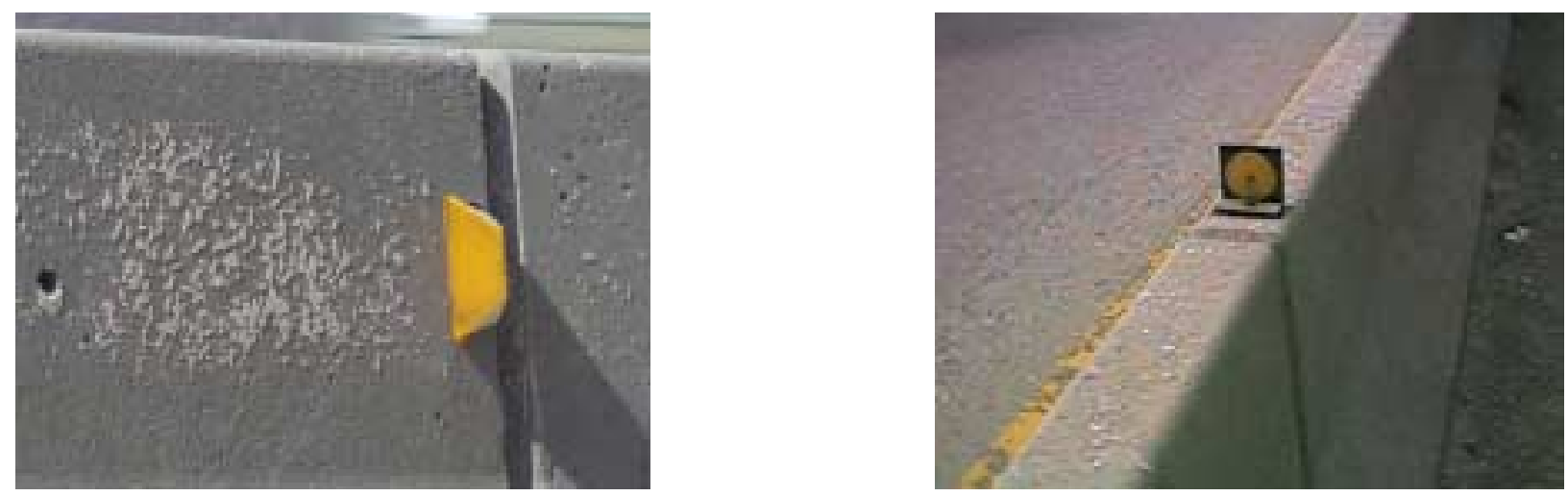

Figure VII - PENNDOT's Previous Standard Delineators

Various PENNDOT District and County Maintenance personnel have also tried different methods of delineation in response to particular durability, maintenance, or reflective problems that were encountered. A survey of each District Traffic Unit was conducted to determine these special applications. A few county maintenance personnel were also contacted at the referral of the respective District Traffic Unit. The following is a synopsis of the discussions that took place. 
First, it was noted through these discussions that maintenance of concrete median barrier delineation is a significant problem that is being faced statewide. Almost all Districts reported that maintaining the delineators is a major effort that often times they cannot keep up with. Broken delineators and their tendency to fall off of the barrier were the most cited reasons for the maintenance problems. These two reasons point to the delineator durability and method of mounting as areas where improvements should be considered.

A few Districts reported using raised pavement markers (RPMs) in place of the standard delineators. This was to counteract the durability problem. RPMs are designed to be much tougher than delineators because they are subject to traffic loads. The RPMs that are used for mountable islands were used because they are smaller and lighter than other types of RPMs. The larger RPMs, while providing more reflective area, were also heavier and much less likely to stay glued to the barrier. The RPMs, with their prismatic retroreflective design, are generally more effective at reflecting light than delineators, which use microprismatic sheeting. This partially compensates for the smaller reflective area.

A few of the Districts also reported staggering the top and side-mounted delineators so that they did not align vertically, as shown in the standard. The spacing between the top and side delineators was kept at the standard distance of 80 feet. However, since they were staggered, a delineator was encountered by the driver at half of the standard distance (every 40 feet).

Some of the Districts also reported adding side-mounted delineators in response to specific circumstances. One District halved the spacing between delineators in problem areas. Another District placed a second row of side-mounted delineators on the high (6 foot) median barrier. The first row was placed at the standard height of 26 inches. The second row was placed 
at the midpoint between the first row and the top of the barrier. Another District reported using three rows of delineators. They were using RPMs in place of the standard delineators and wanted to compensate for the difference of reflective area between the standard delineator and a single RPM. The arrangement of the three rows of delineators is shown in Figure VIII. In their observation of this arrangement under traffic, they noted that drivers tended not to shy away from the barrier to the normal extent because the bottom row of delineators more clearly locates the bottom of the barrier to the driver. This is because the bottom row is placed on the widest portion of barrier, which is at the bottom. The arrangement shown in Figure VIII is currently used for all concrete median barrier applications in the District where it originated.

Three approaches were taken to counteract the problem of delineators falling off the barrier. One District reported using different adhesives, including a Tite Bond Concrete Adhesive that they believe works better than the normal epoxy and/or "Liquid Nails" that most Districts reported using. One county maintenance office reported using a heavier dosage of the typical epoxy to glue the delineators onto the barrier. He noted that they coat the barrier with epoxy, then put an approximately 1/2" thick layer of epoxy on the delineator, and push the delineator on until the epoxy seeps out through the holes in the plate. They then mash the epoxy that seeps out through the holes to form an anchor. They have had good success with this approach. A second county maintenance office reported attaching the top-mounted delineators with lag bolts. Holes were drilled in the top of the barrier (or bridge parapet) using an electric powered hammer drill or "hilti drill". The hole was approximately 1.5" deep. An anchor was then place in the hole, and delineator attached with a lag bolt and flat washer. The manager of 
this operation reported that a crew of three persons--one drilling and two attaching the delineators--could place up to approximately 14 delineators in an hour.

Finally, during the discussions a few ideas came up which have not actually been put into practice, but should be mentioned for future consideration. The usage of "inlaid" delineators and reflective tape in lieu of delineators were mentioned to counteract the damage caused by forces such as vandalism and plowed snow. Two districts were interested in solar-powered lightemitting delineators for areas with poor visibility conditions. One person had a specific type in mind and a second indicated that he knew of a company that made a "blinking" variety, but that PENNDOT requires the device to burn steady. Lastly, for temporary work zone barrier, an upside-down U-shaped bracket that fits over the top of the barrier that reflectors could be mounted to was mentioned as a way of quickly mounting and dismounting reflectors for temporary situations.
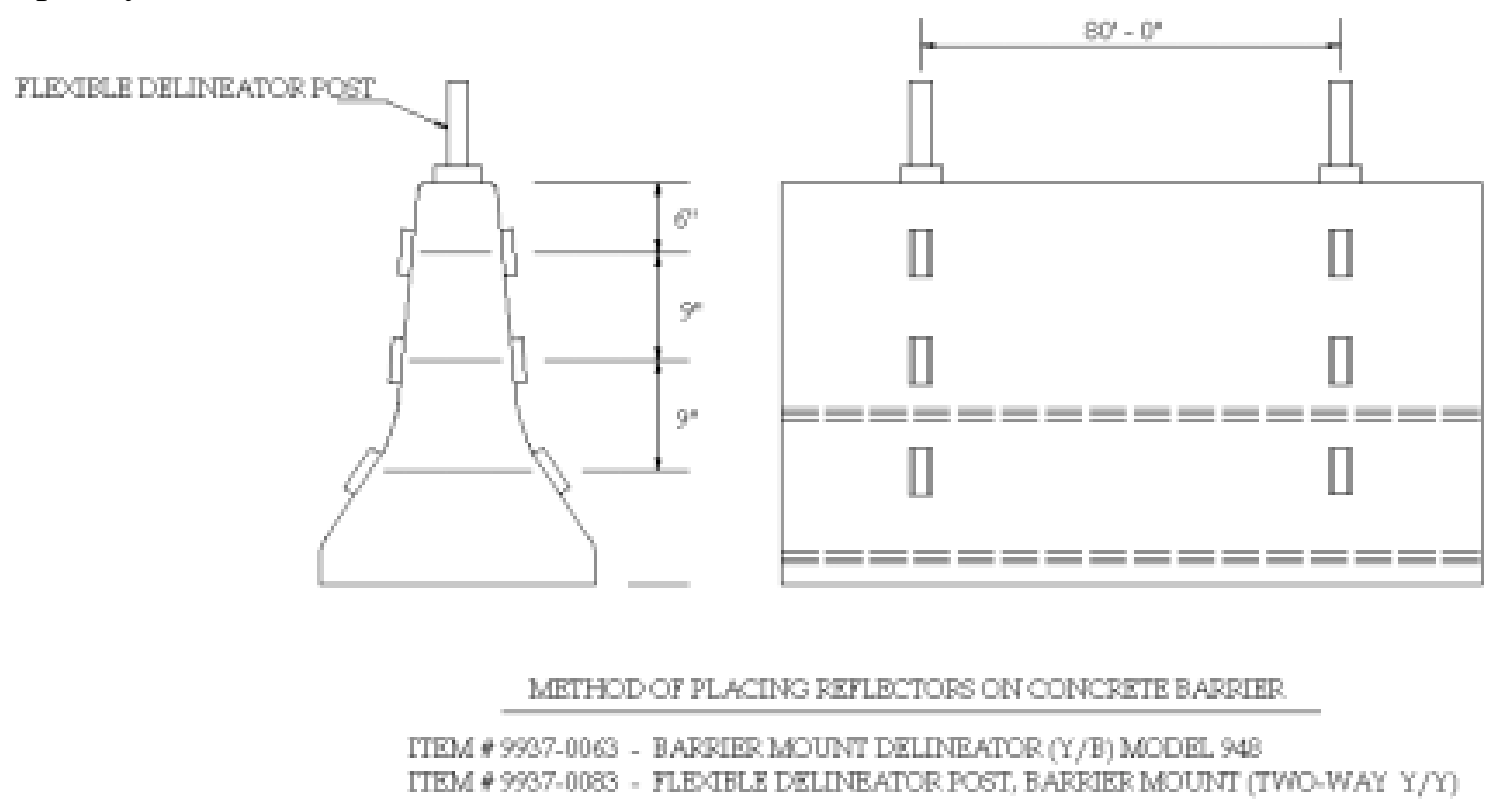

Figure VIII - Three Side Row Delineation Configuration 


\subsubsection{Delineator Standards from Other States}

A survey of other states was conducted to determine their standards and specifications for concrete median barrier delineation. The survey was conducted by telephone, as each state was asked to send their standards and specifications for these devices. Many states have these documents posted on a web site. In these cases, there was no need to contact them by phone.

Standards and/or specifications were reviewed for the following states. They are grouped by geographic area to demonstrate geographic coverage. See Appendix A for complete details.

$\underline{\text { Northeast }}$

Connecticut

Delaware (Specs Only)

Maryland

New Jersey

New York

Rhode Island

West Virginia

Vermont

$\underline{\text { South }}$

Alabama

Florida

Kentucky $\underline{\text { Midwest }}$

Indiana

Illinois

Michigan

Minnesota (specs only)

Missouri

North Dakota (specs only)

Ohio

South Dakota

$\underline{\text { West }}$

Alaska

Arizona

California 
Georgia

Oklahoma
Colorado

Montana

Nevada

Oregon

Utah

Standards for concrete median barrier delineation could not be found for the following states. In most cases, the standards for either delineation and/or concrete median barrier were located, but no mention was made, nor drawing shown, of delineation on concrete median barriers.

Alaska

Arizona

Georgia

Michigan

Oregon

Rhode Island

South Dakota

Idaho They will be developing a new standard for concrete median barrier delineators in the near future. Preliminarily, they are planning on specifying a device that connects to the pins in the median barrier.

Vermont It is believed that they do not use concrete median barrier in permanent situations. For temporary situations, the median barrier delineators are placed at a height of 
$21 "$ at 20 foot intervals. The delineators must have at least 9 in $^{2}$ of reflective surface, and they are placed on the sides only.

Alabama According to an Alabama DOT official, they do not have statewide standards for these devices. In general they are mounted at 40 foot spacing, with delineators similar to PENNDOT Type R on top and the previously used trapezoidal delineator on the side. The delineators are not mounted on the top and side, but instead either one or the other is used.

The review of the standards will follow a format whereby states having significant differences from the PENNDOT standards will be listed. The standards and specifications referenced in this review can be found in the Appendix. The states being compared are: Ohio, Connecticut, West Virginia, Nevada, California, Illinois, Utah, Kentucky, Oklahoma, Colorado, New York, Florida, Indiana, Montana, Maryland, New Jersey, and Missouri. In addition, the specifications were available for Delaware, Minnesota, and North Dakota. The specifications typically only provide reflective sheet and size information. Note that exclusion of a state from one of following lists does not necessarily imply anything, as in many cases the information could not be determined from the standards provided.

$\underline{\text { States that bolt delineators to the barrier in lieu of adhesive }}$

Missouri $\quad 1 / 4$ " by $11 / 4$ " hole drilled for an aluminum or galvanized fastener Utah attached with a "metal hit anchor" - detail shown in Appendix A 
Connecticut attached with $2-10 \mathrm{~mm}$ anchor bolts

New York attached with a $10 \mathrm{~mm}$ expansion bolt

Ohio connect delineation to bridge parapets with $2-3 / 8^{\prime \prime}$ x 3 " double wedge anchor bolts

$\underline{\text { States that do not have delineators on the side of the barrier (top only) }}$

New York

Connecticut

West Virginia

Nevada

California

Utah

Kentucky unless the two sides of the barrier are separated into two walls

Colorado

Oklahoma only if a glare screen is in place

Montana

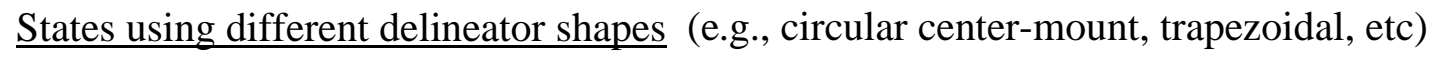

Missouri Similar to center-mount PENNDOT used in the past

Kentucky Trapezoidal delineator PENNDOT used in the past on the side 
Illinois Similar to center-mount PENNDOT used in the past (on top and sides)

New York Similar to center-mount PENNDOT used in the past (on top and sides)

Nevada Uses two center-mount reflectors aligned vertically

Indiana Similar to center-mount PENNDOT used in the past (on top)

Maryland Uses a different trapezoidal shaped delineator than PENNDOT used in the past

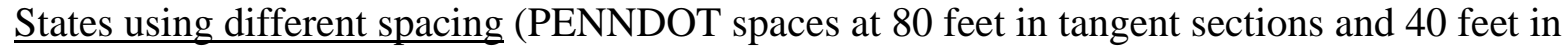
sharp curves)

Colorado Spaces at 200-ft

Missouri Spacing ranges from 100-ft in tangent and flat curves to 60-ft in sharp curves

Oklahoma Spacing ranges from $90-\mathrm{ft}$ to $50-\mathrm{ft}$

Kentucky Spacing ranges from $100-\mathrm{ft}$ to $50-\mathrm{ft}$

Utah Spacing ranges from $100-\mathrm{ft}$ to $20-\mathrm{ft}$

Illinois $\quad$ Spacing ranges from $400-\mathrm{ft}$ to $20-\mathrm{ft}$

California Maximum spacing is $50-\mathrm{ft}$

Nevada Spacing ranges from 50-ft to $20-\mathrm{ft}$

West Virginia Spacing ranges from 330-ft to $20-\mathrm{ft}$

Connecticut Spacing ranges from 200-ft to $20-\mathrm{ft}$

Ohio Spacing ranges from $100-\mathrm{ft}$ to $50-\mathrm{ft}$

Indiana Spacing in feet $=$ speed limit in $\mathrm{mph}$ with a minimum of $20-\mathrm{ft}$ 
Florida Spacing ranges from 80-ft to 40-ft depending on the distance from the barrier to the roadway

Montana Spaces at 30-ft

Maryland Spaces at $100-\mathrm{ft}$ to $50-\mathrm{ft}$

New Jersey Spaces at $80-\mathrm{ft}$

$\underline{\text { States that also use a flexible hinge/base for the top-mounted delineators }}$

West Virginia

California

States using different sized delineators on the top (PENNDOT uses 3"x12", 3" x 5", or 3" x 4")

Nevada minimum dimension is 6"

Oklahoma minimum dimension is 6"

Ohio $\quad$ uses $3 "$ × 6" (also specified a requirement of $7 \mathrm{in}^{2}$ minimum)

Connecticut uses 3" x up to 18" depending on the barrier height

West Virginia uses 4" x 4"

Nevada uses 3" x 3"

California uses 3" $\mathrm{x}$ up to $12 "$

Illinois uses $3 \frac{1}{2}$ " $\quad$ x 4 " or circular diameter of $23 / 4$ "

Utah uses 3" $\quad$ 4" 


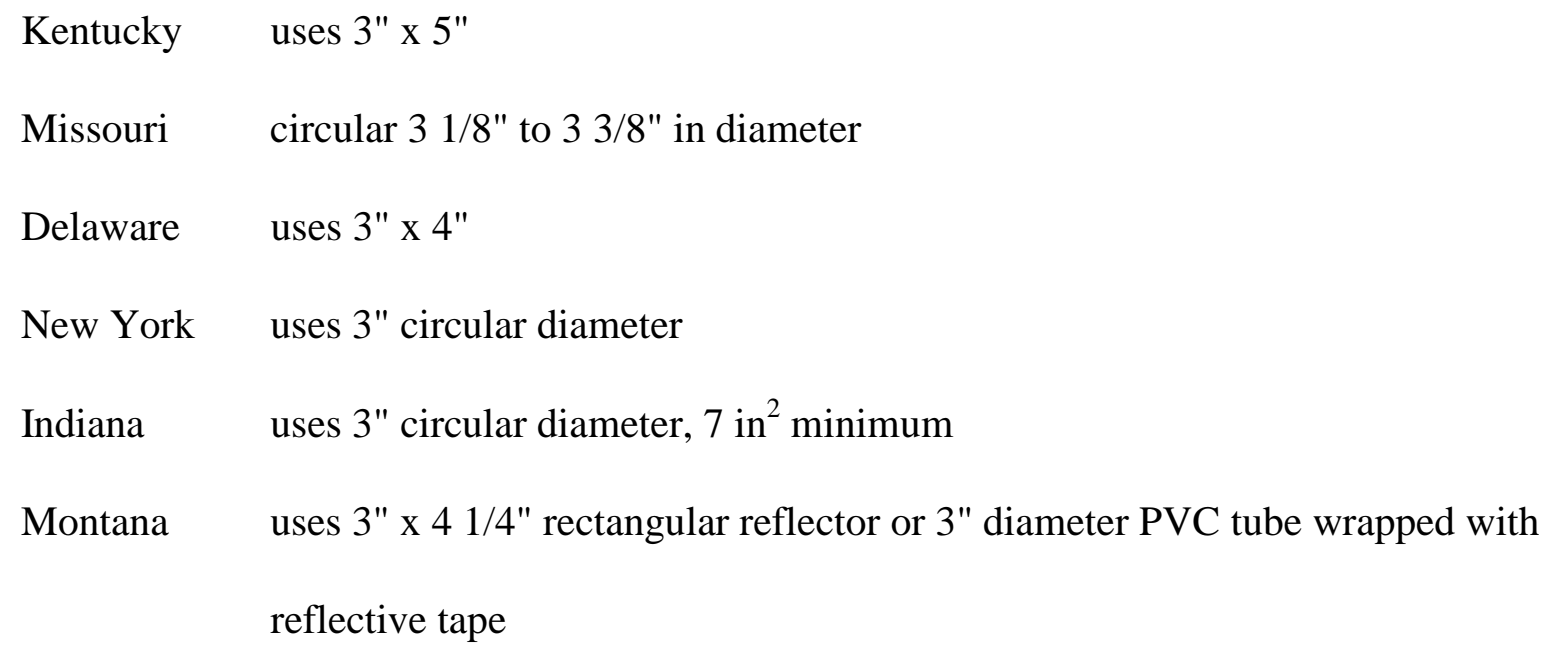




\section{$\underline{\text { Miscellaneous Findings }}$}

- None of the states surveyed puts more than one row of delineators on the side of the barrier.

- None of the states surveyed uses raised pavement markers or anything similar looking.

- Illinois glues delineators to the barrier, but specifies at least $7 \mathrm{in}^{2}$ of base for adhesion

- California only uses median barrier delineation when the barrier is closer than 8 foot; Ohio only uses it when the barrier is closer than 10 foot (when the reason for the barrier is based strictly on the distance to travel lane; they also have other warrants for installation), Maryland uses it for all barrier within 15 feet.

- Nevada and New York angle the top-mounted delineators towards traffic

- Ohio angles the delineators vertically to facilitate rain washing

- Florida spaces delineators strictly on the distance from the barrier to the roadway, not on horizontal curvature.

- Several states only use top-mounted delineators. Florida, New Jersey, and Maryland only use side-mounted delineators.

- Although it was not found in a standard, South Carolina used several rows of RPMs on the pavement adjacent to the base of the barrier, with reflective paint (like a lane line) on the barrier.

The key findings of this survey are as follows:

- Several states, including neighboring states Ohio and New York, bolt the delineators to the barrier. 
- In lieu of a flexible hinge, many states use sturdy metal brackets to counteract blows to the delineators.

- The 3" x 12" top-mounted delineator used by PENNDOT is among the largest of the states surveyed.

- The majority of states surveyed only use top-mounted delineation. Three only use sidemounted delineation. PENNDOT was one of the few states reviewed that used both. None used more than one delineator on the side.

- In general, spacing is in line with other states. However, at 80 feet, closer spacing is used by PENNDOT in tangent sections than most of the other states reviewed. It is also closer than that recommended by the MUTCD, which is 200 feet to 530 feet.

\subsubsection{Summary}

This review and survey has demonstrated the following general principles:

- Concrete median barrier delineation is an important traffic control device that primarily provides the driver with guidance information on roadway alignment. It also aids the driver in avoiding collisions with the barrier both during day and nighttime conditions. Finally, because the color of the delineator matches the appropriate pavement marking, it also provides regulatory information.

- Concrete median barrier delineation, because of its location in the near roadside area, is subject to many environmental forces, including vandalism, plowed snow, abrasion from 
blowing dust and anti-skid material, sunlight, etc. These forces can reduce or eliminate the effectiveness of the delineation in performing its desired intent.

- The effectiveness of concrete median barrier delineation is dependent on atmospheric conditions, and can be rendered completely or partially ineffective due to rain, snow, fog, or particulate matter under certain conditions.

- There is a wide variation in the application of concrete median barrier delineation between states and even within the state of Pennsylvania. Furthermore, there is no guidance on delineation strategies during poor atmospheric conditions.

Specific to PENNDOT's standard, this review suggests that the size of the 3 " x 12" (reflective area) delineator likely contributes to its vandalism problem because it is more conspicuous than other delineators. The benefits of the increased conspicuity are questionable because greater conspicuity likely has little value under normal nighttime driving conditions. Even under poor visibility conditions, the prior research is inconclusive about whether a larger reflective area contributes to greater visibility. Some research suggests that only an increase in light intensity contributes to increased visibility. Other states use more reflective material than the ASTM Type V sheeting recommended by the PENNDOT standard. Districts using RPMs in lieu of standard delineators are also using more reflectivity. Perhaps PENNDOT should consider a smaller delineator with greater reflectivity in lieu of the $3 " \mathrm{x} 12$ " variety. However, this is subject is beyond the scope of this research. For the purposes of this research, the 3" x 12" reflective area delineator will not be used in the field testing. 


\section{Chapter 3 Durability Testing}

\subsection{Introduction and Methodology}

Harsh environmental conditions present in the roadside environment where delineators are mounted can result in delineators falling off of the barrier with such frequency that it causes maintenance problems. This is particularly true during the winter months.

A durability test was conducted on S.R. 119, just north of Connellsville, Pennsylvania. Six test sections, each having approximately 17 delineators, were established at this location. Three test sections were adjacent to the northbound lanes, and the remaining three were on the opposite side of the barrier adjacent to the southbound lanes. Conditions in each of the test sections were very similar because they were set up over a short distance, had a uniform cross section, with similar traffic conditions, and identical winter maintenance treatment. This test section was chosen by the PENNDOT District 12-0 Traffic Engineer due to its uniformity with respect to both traffic and environmental conditions. Furthermore, all delineators were installed on the same day by a professional crew of PENNDOT maintenance personnel.

Three different adhesive types were tested: Liquid Nails, Tite Bond, and Peel-n-Stick (with butyl pad). Each adhesive was used to attach all of the delineators in two of the six sections. Each adhesive was used in one northbound and one southbound test section. All delineators were mounted on the side, approximately one foot from the pavement level, where environmental conditions should be harsher than the normal position, which is near the top of the barrier. 
In total, 101 delineators were mounted over the six test sections. The delineators were mounted during the first week in September 2001. The survival rate was closely monitored for one year, which was as long of a time period as feasible given the overall length of the research project. In addition, the application rates associated with each of the adhesive types were measured. The results of each are discussed below.

\subsection{Results}

\subsubsection{Application Rate}

The application rate associated with each adhesive type was determined by noting the total time to mount all of the delineators using the particular adhesive, and dividing it by the total number of delineators mounted using the particular adhesive. The results of this analysis are shown in Table 3-1 (See Appendix B for additional information). Note that not all of the delineators mounted for this test were included in the application rate determination. Some were not included if unusual circumstances arose, as per the judgment of the researchers.

Furthermore, delineators were also mounted on the top of the barrier as place markers at the same time they were mounted on the side in the southbound direction. Finally, note that the installation time includes measurement for the layout of the delineators and the removal of existing delineators in addition to the installation of the new delineators. The removal of existing delineators was found to be negligible, as it was less than five seconds. 
Table 3-1 - Application Rates Associated with Each Adhesive Type

\begin{tabular}{|l|l|l|l|}
\hline Delineator Type & Total Delineators & Total Time & Application Rate \\
(minutes) & (delineators/hour)
\end{tabular}

It was found that the application rate associated with the Peel-n-Stick delineators was the highest at 79 delineators per hour. This was expected, as there is no glue to apply to the delineator before attaching it to the barrier. It was nearly $20 \%$ faster than the Tite Bond attached delineators. However, there was not a great disparity between any of the rates. Tests of the statistical significance of the differences in rates revealed that there were no statistically significant differences in any of the rates.

\subsubsection{Survival Rate}

The 101 side-mounted delineators were distributed among the test sections as shown in Table 3-2. Note that the southbound sections were installed first, beginning in the north with Section 1. It was noted at the time that the barrier was slightly damp due to some morning dew. 
Table 3-2 - Arrangement of Delineators in the Durability Test Sections

\begin{tabular}{|l|l|}
\hline Southbound Sections & Northbound Sections \\
\hline Section 1 - 16 Attached Using Liquid Nails & Section 4 - 17 Attached Using Liquid Nails \\
\hline Section 2 - 16 Attached Using Tite Bond & Section 5 - 16 Attached Using Peel-n-Stick \\
\hline Section 3 - 18 Attached Using Peel-n-Stick & Section 6 - 18 Attached Using Tite Bond \\
\hline
\end{tabular}

The total sample size for each adhesive was as follows:

Liquid Nails -33

Tite Bond -34

Peel-n-Stick -34

The survival rate was closely monitored from the time the delineators were mounted in early September 2001 until September 2002. Over that time period, four of the 101 delineators had become detached. All four of the delineators were attached using Liquid Nails. One of these fell from the northbound Liquid Nails test section, and three fell from the southbound Liquid Nails test section. It was noted that one delineator became detached during each of the following four months October, December, March, and May. In short, the survival rates for each adhesive type for the one year period are as follows: Liquid Nails $-88 \%$, Tite Bond $-100 \%$, and Peel-n-Stick-100\%.

It must be noted that the winter that occurred during the test period was extremely mild compared to the normal conditions. Table 3-3 shows the normal and actual average temperatures 
for Pittsburgh, PA (as recorded by the National Weather Service) during the test period. The usual winter months of December and January were extremely mild. The period of February through May was slightly warmer than usual, with May actually being colder than normal. The last nighttime temperature in the 30's (Fahrenheit) occurred May 23, when the low temperature was 38 degrees

In addition, winter maintenance activities were significantly less frequent than usual. The first snowfall occurred on 11/20/02 when a trace of snow was recorded. There were only seven days all winter that had snowfalls greater than 1 inch. There were two each in December, January, and February, and one in March. The last snowfall occurred April 6 when again a trace was recorded.

Table 3-3 - Actual Mean Temperature vs. Normal Mean Temperature - 9/01 to 9/02, Pittsburgh, PA (Source: National Weather Service)

\begin{tabular}{|c|c|c|}
\hline Month & Actual Mean Temperature $(\mathrm{F})$ & Normal Mean Temperature $(\mathrm{F})$ \\
\hline $9 / 01$ & 62.1 & 63.9 \\
\hline $10 / 01$ & 54.1 & 52.3 \\
\hline $11 / 01$ & 48.2 & 42.3 \\
\hline $12 / 01$ & 37.4 & 31.4 \\
\hline $1 / 02$ & 35.4 & 27.5 \\
\hline $2 / 02$ & 35.0 & 30.5 \\
\hline $3 / 02$ & 40.9 & 39.8 \\
\hline $4 / 02$ & 52.7 & 49.9 \\
\hline $5 / 02$ & 56.7 & 60.0 \\
\hline $6 / 02$ & 70.6 & 68.4 \\
\hline $7 / 02$ & 76.0 & 72.6 \\
\hline $8 / 02$ & 74.1 & 70.8 \\
\hline
\end{tabular}




\subsubsection{Cost Analysis}

A cost analysis was performed using the results of the survival and application rate tests. The costs of the materials, installation, and replacement were the primary costs considered. The following assumptions were made in the cost analysis.

- First, it was assumed that the delineators could be replaced at the same unit cost that they were originally installed. This likely underestimates the cost since the fixed costs of installing the delineators are spread over a much smaller quantity when they are being replaced as opposed to the initial installation.

- The costs of traffic control are not included.

- The survival rate in all years of the delineator life cycle is equal to that experienced in the first year. The Liquid Nails adhesive, which had an $88 \%$ survival rate for one year, was projected to have a $41 \%$ survival rate at the end of five years.

- The life cycle of a delineator is five years. This was provided by the PENNDOT maintenance foreman, and was based on his estimate of the expected duration between total delineator replacement projects at a given location.

The results of the cost analysis are shown in Table 3-4 (See Appendix B for calculations). It was found that the Liquid Nails adhesive yielded the highest associated cost per delineator. This was mainly because of the replacement costs associated with the delineators expected to fall from the barrier. The adhesive with the lowest associated cost was Peel-n-Stick. The cost of the 
delineator alone was slightly higher than the others, however, once the cost of the adhesive was added to the Liquid Nails and Tite Bond attached delineators, they were all roughly the same cost. The timesavings associated with the Peel-n-Stick delineators then provided cost savings necessary to make it the least cost choice. Please note that had no delineators became detached during the durability test, the Peel-n-Stick delineators still would have been the least cost choice because of the cost savings associated with the decreased installation time.

Table 3-4 - Cost Analysis

\begin{tabular}{|c|c|c|c|c|}
\hline Delineator Type & $\begin{array}{l}\text { Material Cost } \\
\text { (\$/delineator) }\end{array}$ & $\begin{array}{l}\text { Installation } \\
\text { Cost } \\
\text { (\$/delineator) }\end{array}$ & $\begin{array}{l}\text { Replacement } \\
\text { Cost } \\
(\$ / \text { delineator })\end{array}$ & $\begin{array}{l}\text { Total Cost } \\
\text { (\$/delineator) }\end{array}$ \\
\hline Liquid Nails & 3.90 & 0.89 & 2.82 & 7.61 \\
\hline Tite Bond & 3.86 & 0.96 & 0 & 4.82 \\
\hline Peel-n-Stick & 3.88 & 0.81 & 0 & 4.69 \\
\hline
\end{tabular}

\subsection{Concluding Remarks}

The purpose of this study was to determine the best adhesive for use to minimize the cost of delineating concrete median barriers. Three adhesive types were tested, and the Peel-n-Stick delineators were identified as the least cost choice. They were the most expensive choice based on the cost of the delineator alone. However, when the cost of the adhesive is added in, they were all virtually the same cost. When the installation time savings offered by the Peel-n-Stick 
delineators are considered, they then become the least cost alternative. In addition, the survival rate of the Peel-n-Stick delineators during the one-year durability test was $100 \%$. The durability was also monitored during a six-month period, lasting from September, 2002 to March 2003. This time frame encompassed the winter months, which were harsher than those in the previous winter. It was found that an additional nine delineators became detached. However, Peel-n-Stick maintained a $100 \%$ survival rate. It should also be noted that in one of the Peel-n-Stick test sections, there were tire marks on the barrier, and in some cases the delineators were torn in half. Despite the damage done to the delineators, they still remained attached to the barrier. Lastly, although it was not considered, the delay costs for traveling public resulting from the traffic control required to install the delineators would also be the least for the Peel-n-Stick delineators. 


\section{Chapter 4 Visibility Testing}

\subsection{Introduction and Test Description}

In response to a perceived need for increased median barrier delineation in areas prone to poor visibility conditions, PENNDOT personnel have informally tried different delineation configurations than those shown on the typical drawings. Most of the variations included a sidemounted delineator near the base of the barrier, as it was felt that this identified the barrier roadway boundary better for the driver. Some of the variations also included three side-mounted delineators at a single location. One of the delineators was near the top in the location shown on the typical drawings, one was near the bottom as described previously, and a third was placed near the middle of the barrier. This configuration evolved from an unofficial configuration previously used by PENNDOT that utilized raised pavement markers instead of typical delineators. The raised pavement markers were preferred because they were thought to be more durable. However, they had less reflective surface per unit than the typical delineator, hence the need for additional units.

The visibility tests were conducted on US 40 just east of Uniontown, PA on what is locally known as "Summit Mountain." This area has a history of poor visibility conditions due to fog because it is several thousand feet higher in elevation than the Uniontown area just to the west.

Through the test site, U.S. 40 was two lanes in each direction separated by a typical safety-shaped concrete median barrier located 1 foot from the inside lane in both directions. Lane 
widths were 11 feet, and the outside shoulders were paved and were roughly 10 feet in width in the eastbound direction and 8 feet in the westbound direction. The test site was on a 7 to $8 \%$ grade, with the eastbound direction being upgrade. The overall site was divided into four subsections, each approximately 1800 feet in length. During the tests, each subsection was to contain a different delineator configuration than the subsection adjacent to it. Two of the subsections were in the eastbound direction and two were in the westbound direction. There was an approximately 2200-foot radius horizontal curve roughly in the middle of the overall site that formed the dividing point for the subsections.

In general, the visibility provided by competing delineators configurations was gauged by traveler speed. During poor visibility conditions, traveler speeds drop well below normal. The delineator configuration that resulted in the highest speed, i.e., most normal speed, was considered to be superior. In each subsection, automated traffic recorders that collected both volume and speed data were placed in both lanes approximately one third of the way into the subsection. In addition, there was a control station in each direction just over the summit where there was no concrete median barrier and hence no delineation or delineation changes from trial to trial. The purpose of these stations was to monitor for drastic changes in speeds from test to test.

Finally, although four test subsections were formed, only two competing delineator types were tested during each phase. Both the eastbound and westbound directions were setup identically. For example, a driver in the eastbound direction would encounter configuration A, followed by configuration B. The driver in the westbound direction would also encounter configuration A followed by B. Since the eastbound and westbound subsections were directly 
opposite of one another on the roadway cross-section, if configuration A was in the eastbound direction on one side of the barrier, configuration B would be on the opposite side of the barrier facing westbound traffic. See Figure X for the layout of the test sections.

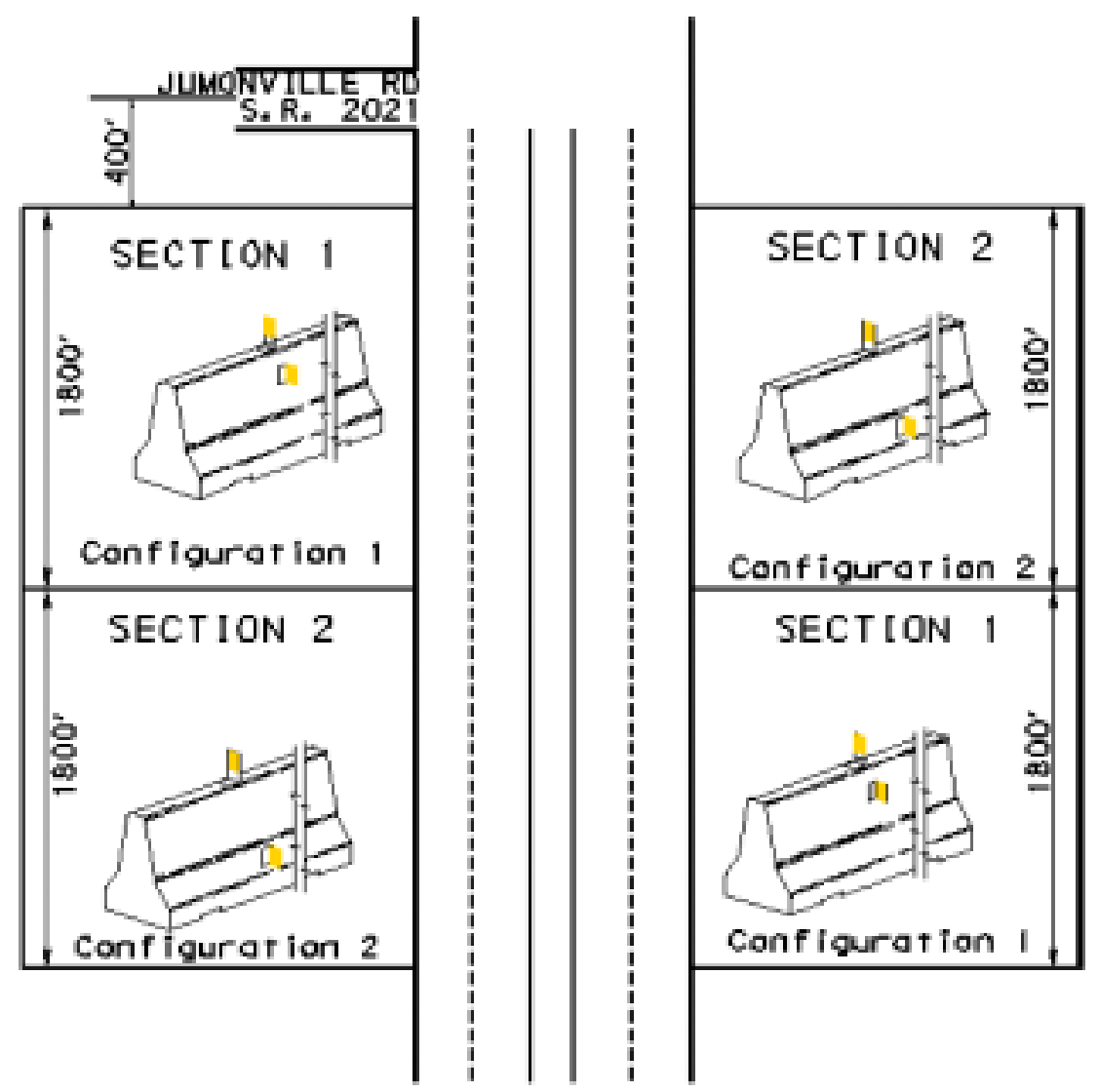

Figure X - Visibility Test Section Layout

The visibility test was conducted in four phases:

Phase I Traffic speeds and volumes were collected for the base condition, which was an assortment of past delineator installations. It was noted that many of the delineators were missing or old and ineffective. 
Phase II A test was conducted that compared two options of locating a single side-mounted delineator. One version had the single side-mounted delineator mounted near the top in conjunction with the typical top-mounted delineator. This is the current PENNDOT standard installation. The other version had the side-mounted delineator mounted near the bottom with the top-mounted delineator unchanged.

Phase III In the Phase II testing, the bottom side-mounted delineator outperformed the sidemounted delineator located near the top. Thus, this test compared a single sidemounted delineator with a configuration that used three side-mounted delineators (one near the top, one near the bottom, and one in middle. Both configurations had a single top-mounted delineator as per PENNDOT standards.

Phase IV In the Phase III testing, there was not a significant difference between the competing configurations. Therefore, the single side-mounted delineator near the bottom configuration was used to test the effectiveness of reducing the longitudinal spacing of the delineators. PENNDOT standards call for the delineators to be spaced at 80 feet in tangent sections and 40 feet in curves. Two of the subsections were setup at this spacing, and two were set up at halved spacing.

The details and results of each of the test phases are provided in the following sections 


\subsection{Phase I - Baseline Conditions}

Traffic volumes and speeds were collected in each of the test subsections and the two control locations on $6 / 11 / 01$ and $6 / 12 / 01$. No poor visibility conditions were present during the data collection. Nighttime data was queried from $9 \mathrm{pm}$ to $6 \mathrm{am}$, as sunrise was at 5:51 am and sunset occurred at 8:47 pm (National Weather Service - Pittsburgh). The pertinent traffic data are summarized in Table 4-1 (See Appendix C for complete data set). As can be seen, it is normal for speeds to be in the upper 40s or lower 50s through the test site. Furthermore, there is not a great differential between overall speeds and nighttime speeds. Finally, the combined control station speed was $50.6 \mathrm{mph}$ both over the entire time period and during the nighttime. 
Table 4-1 Summary of Baseline Conditions

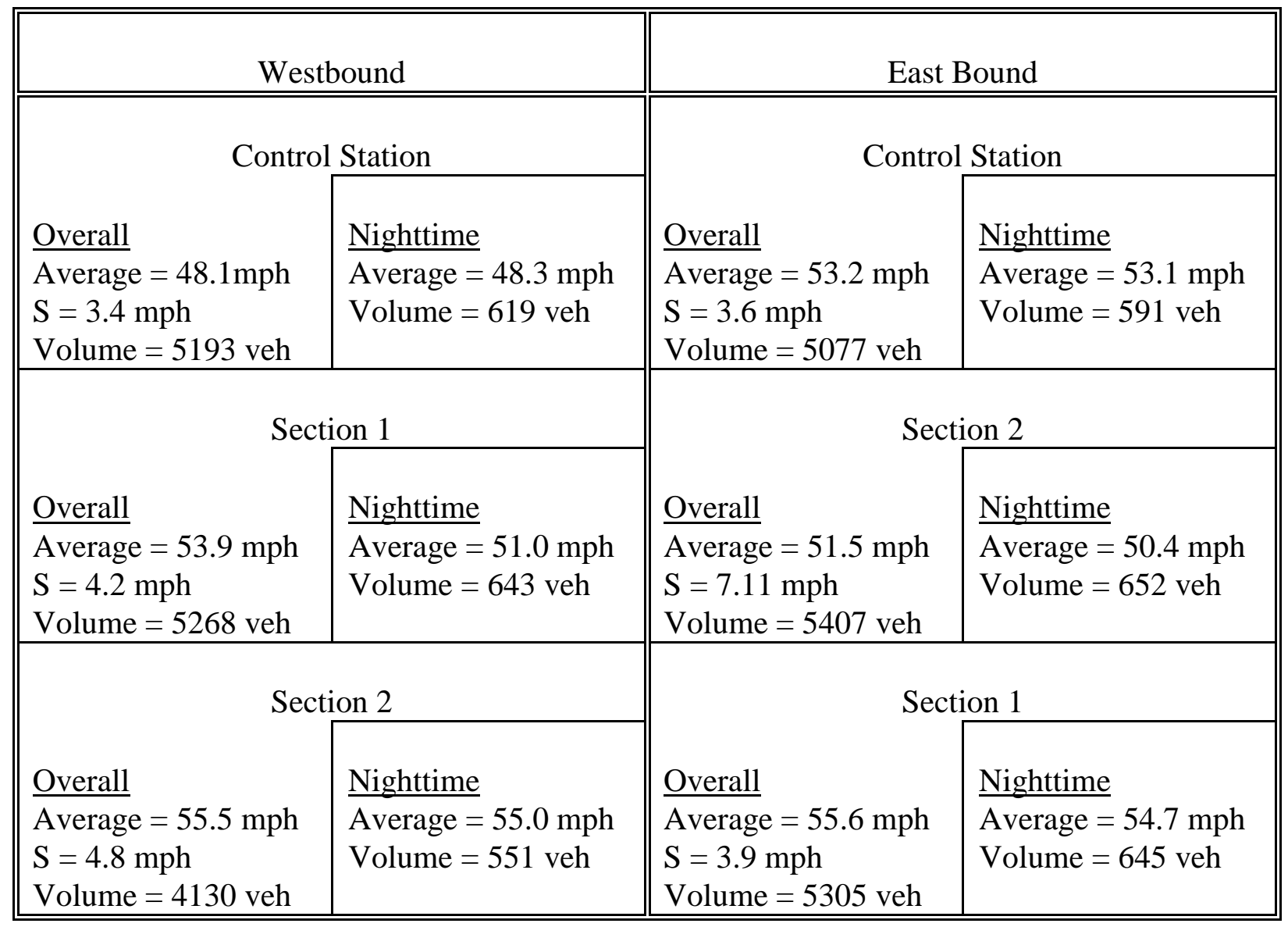

\subsection{Phase II - High vs Low Side-Mounted Delineators}

From 11/28/01 to 12/03/01, traffic data were recorded as part of Phase II. In this test, the differences between providing a single side-mounted delineator near the top of the barrier was compared with locating it near the bottom. A summary of general statistics from this test are provided in Table 4-2 (See Appendix D for complete data set). The period from 8 pm to 6 am was used as the nighttime hours. The sunrise during this time period was approximately 7:20am, 
and the sunset was approximately 5:00pm. However, the nighttime period was shortened so that commuter traffic and early evening traffic could be missed. During these periods of relatively high traffic, drivers can rely too heavily on the lights of other vehicles for guidance. The combined control station speed was $49.5 \mathrm{mph}$ overall and $50.4 \mathrm{mph}$ during the nighttime. Interestingly, none of the test sections had nighttime speed greater than the overall speed, whereas both the control stations did. The cause of this is unknown. See Figure XI for a detail of the configuration.
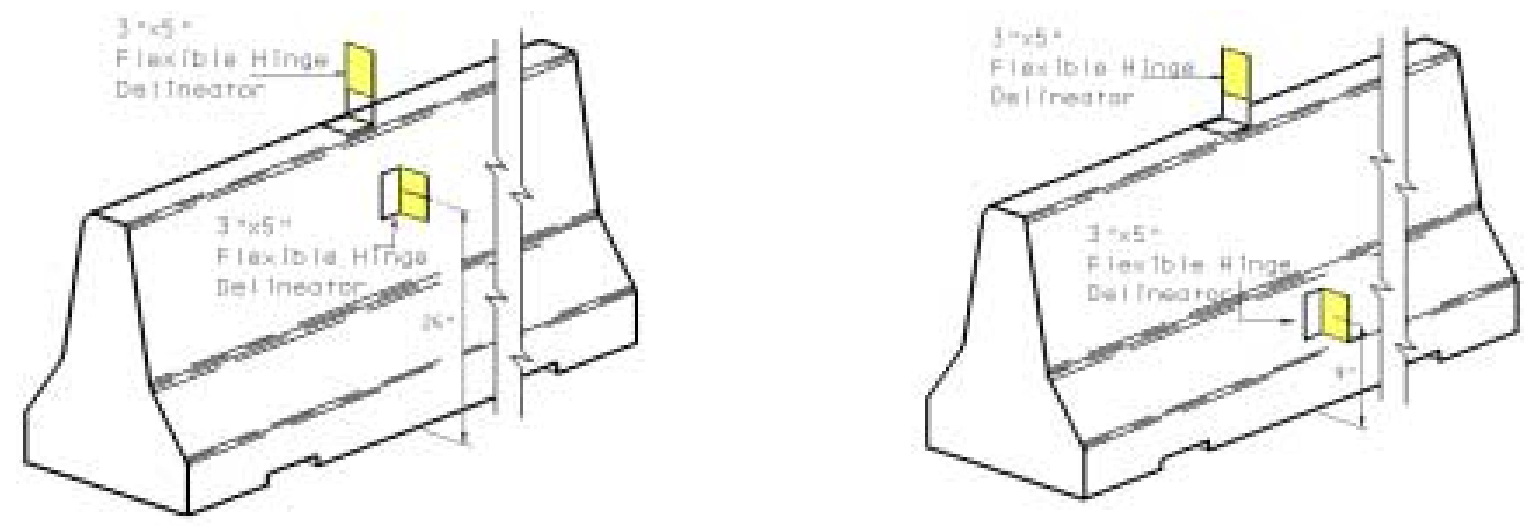

Figure XI - Phase II Configuration 
Table 4-2 Summary of Results for Phase II of the Visibility Testing

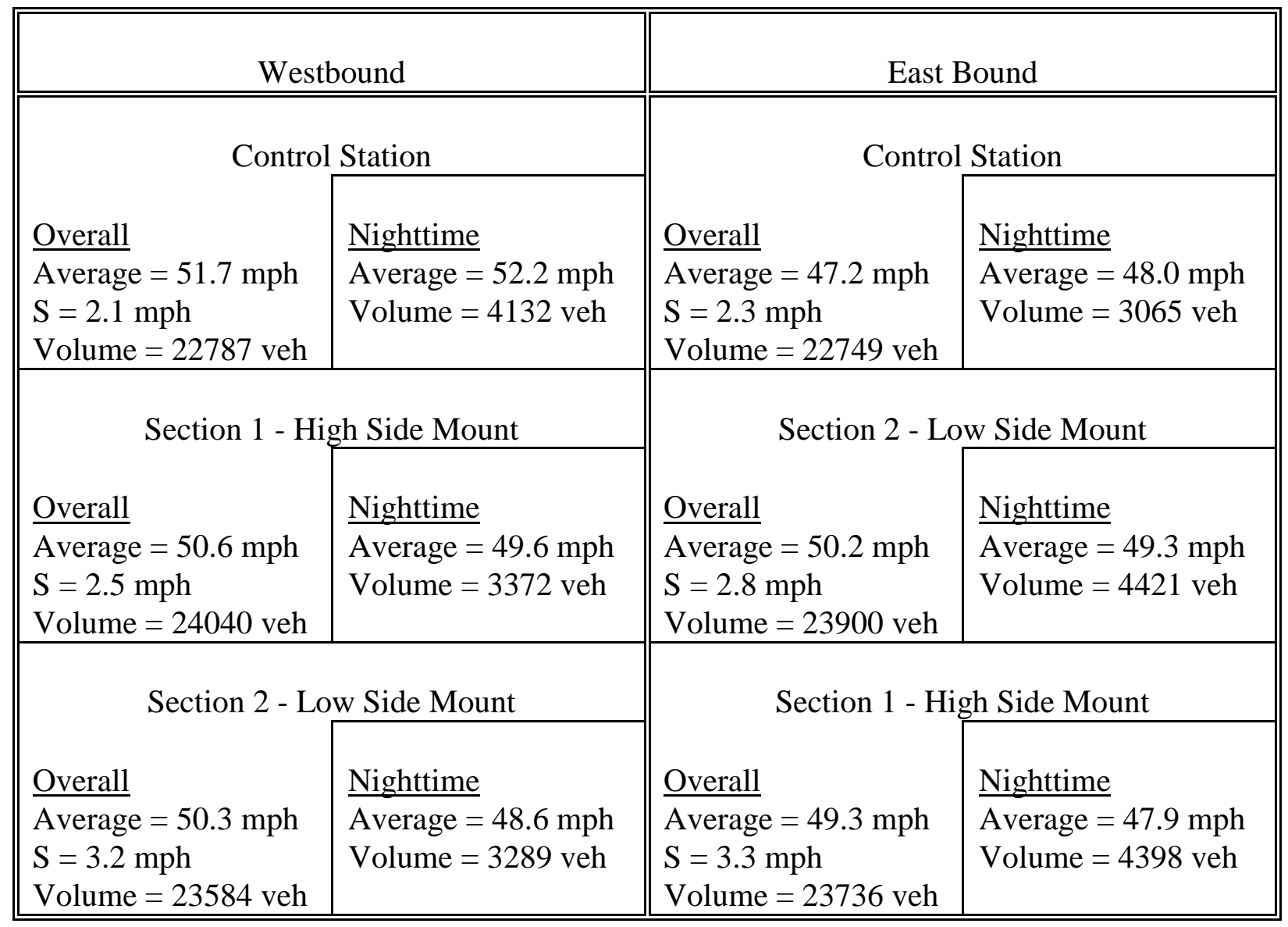

The individual hours during the test were examined to determine the times during which the slowest traffic occurred. The data during these times was aggregated and analyzed in a number of ways. First, the upper sections (Eastbound Section 2 and Westbound Section 1) were compared to each other. Next, the lower sections (Westbound Section 2 and Eastbound Section 1) were compared. Finally, the aggregation of sections with like delineator configuration was compared to one another. In other words, the data for the two Section 1s were aggregated and compared to the Section 2 s. In the analysis of the data for this phase and Phase III, it became apparent that the flashing beacon at the summit and the flashing warning sign located in 
Eastbound Section \#2 had an influence on driver speeds during the slow speed periods. While traffic speeds in other sections were depressed, the speeds in Eastbound Section \#2 remained relatively high. For that reason, the data comparisons involving this section were disregarded. In the end, only the data from the lower sections were used in the comparisons.

Table 4-3 shows a comparison of traffic speeds during the four slowest hours sampled. These were determined by ranking all of the hours sampled by the aggregate speed over the four subsections. There was a definitive breakpoint between these four hours and the fifth slowest hour, as there was a differential of $2.1 \mathrm{mph}$. In general, the procedure to determine the configuration yielding the highest speeds during the slowest period entailed comparing the difference in speeds between the two sections at that time against the difference experienced during the overall nighttime period. In this instance, during the normal nighttime hours, the WB section had speeds (48.6 $\mathrm{mph}$ ) that were $0.7 \mathrm{mph}$ higher than the EB section (47.9 $\mathrm{mph})$. During the four slowest hours, speeds in the WB section were a total of $4.5 \mathrm{mph}$ higher than the EB section. In four nighttime hours, it was expected that the differential should be $2.8 \mathrm{mph}(0.7 \mathrm{mph}$ times 4). Therefore, the delineators in the WB section outperformed those in the EB section by an even larger margin than was the case during the typical nighttime hours. However, it must be noted that the magnitude of the difference is small, and in two of the four hours, speeds in the EB direction were actually greater than those in the WB direction. 
Table 4-3 - Comparison of Speeds During the Low Speed Hours - Phase II

\begin{tabular}{|c|c|c|c|c|c|c|}
\hline $\begin{array}{c}\text { Hour } \\
\text { (Slowest } \\
\text { First) }\end{array}$ & $\begin{array}{c}\text { Overall } \\
\text { Speed (mph) }\end{array}$ & $\begin{array}{c}\text { WB } \\
\text { Section } \\
\text { Speed } \\
\text { (mph) }\end{array}$ & $\begin{array}{c}\text { EB Section } \\
\text { Speed } \\
(\mathrm{mph})\end{array}$ & $\begin{array}{l}\text { Difference } \\
\quad(\mathrm{mph})\end{array}$ & $\begin{array}{c}\text { Overall } \\
\text { Nighttime } \\
\text { Difference } \\
(\mathrm{mph}) \\
\end{array}$ & $\begin{array}{c}\text { Relative } \\
\text { Difference } \\
\text { (mph) }\end{array}$ \\
\hline 1 & 38.6 & 37.7 & 38.0 & -0.3 & 0.7 & -1.0 \\
\hline 2 & 40.1 & 38.6 & 36.8 & 1.8 & 0.7 & 1.1 \\
\hline 3 & 40.9 & 36.7 & 41.1 & -4.7 & 0.7 & -5.4 \\
\hline 4 & 41.0 & 43.1 & 35.4 & 7.7 & 0.7 & 7.0 \\
\hline \multicolumn{4}{|c|}{ AGGREGATE } & 4.5 & 2.8 & 1.7 \\
\hline
\end{tabular}

\subsection{Phase III - Low vs Three Side-Mounted Delineators}

From 5/31/02 to 6/07/02, traffic data were recorded as part of the third phase of the visibility testing, which was conducted to test for differences between providing a single sidemounted delineator near the bottom of the barrier and providing three side-mounted delineators. A summary of general statistics from this phase is provided in Table 4-4 (See Appendix E for complete data set). The period from $9 \mathrm{pm}$ to $5 \mathrm{am}$ was used as the nighttime hours. The sunrise during this time period was approximately 5:50am, and the sunset was approximately 8:40pm. The combined control station speed was $48.8 \mathrm{mph}$ overall and $48.9 \mathrm{mph}$ during the nighttime. 
These results are consistent with the control counts from the other phases. As in Phase II, the nighttime speed is slightly higher than the overall speed. See Figure XIII for the configuration for this phase.
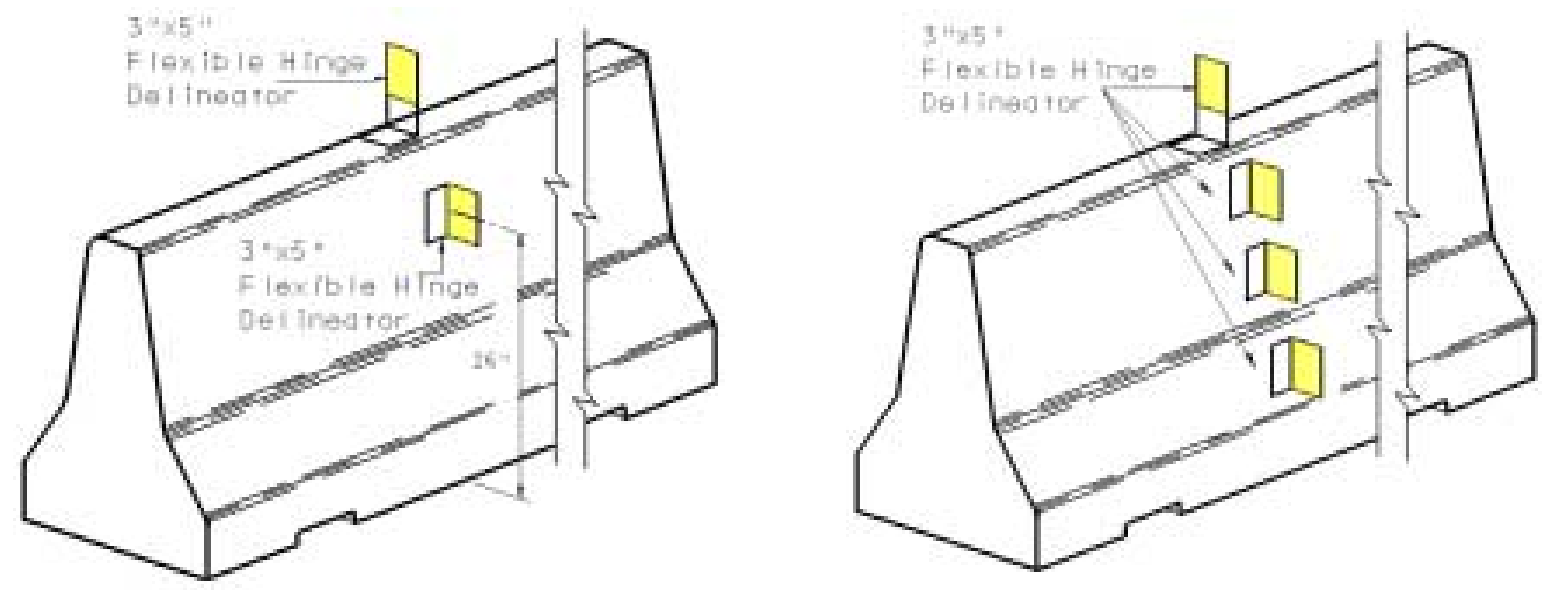

Figure XII - Phase III Configuration 
Table 4-4 Summary of Results for Phase III

\begin{tabular}{|c|c|c|c|}
\hline \multicolumn{2}{|c|}{ Westbound } & \multicolumn{2}{|c|}{ East Bound } \\
\hline \multicolumn{2}{|c|}{ Control Station } & \multicolumn{2}{|c|}{ Control Station } \\
\hline $\begin{array}{l}\frac{\text { Overall }}{\text { Average }=47.4 \mathrm{mph}} \\
\mathrm{S}=2.9 \mathrm{mph} \\
\text { Volume }=42353 \mathrm{veh}\end{array}$ & $\begin{array}{l}\frac{\text { Nighttime }}{\text { Average }=47.7 \mathrm{mph}} \\
\text { Volume }=4333 \mathrm{veh}\end{array}$ & $\begin{array}{l}\frac{\text { Overall }}{\text { Average }=50.1 \mathrm{mph}} \\
\mathrm{S}=4.7 \mathrm{mph} \\
\text { Volume }=43725 \mathrm{veh}\end{array}$ & $\begin{array}{l}\frac{\text { Nighttime }}{\text { Average }=50.1 \mathrm{mph}} \\
\text { Volume }=4288 \mathrm{veh}\end{array}$ \\
\hline \multicolumn{2}{|c|}{ Section 1 - Three Side Mounts } & \multicolumn{2}{|c|}{ Section 2 - Low Side Mount } \\
\hline $\begin{array}{l}\frac{\text { Overall }}{\text { Average }=48.4 \mathrm{mph}} \\
\mathrm{S}=3.2 \mathrm{mph} \\
\text { Volume }=40190 \mathrm{veh}\end{array}$ & $\begin{array}{l}\frac{\text { Nighttime }}{\text { Average }=46.2 \mathrm{mph}} \\
\text { Volume }=4498 \mathrm{veh}\end{array}$ & $\begin{array}{l}\text { Overall } \\
\text { Average }=57.9 \mathrm{mph} \\
\mathrm{S}=2.3 \mathrm{mph} \\
\text { Volume }=46991 \mathrm{veh}\end{array}$ & $\begin{array}{l}\frac{\text { Nighttime }}{\text { Average }=57.9 \mathrm{mph}} \\
\text { Volume }=5402 \mathrm{veh}\end{array}$ \\
\hline \multicolumn{2}{|c|}{ Section 2 - Low Side Mount } & \multicolumn{2}{|c|}{ Section 1 - Three Side Mounts } \\
\hline $\begin{array}{l}\frac{\text { Overall }}{\text { Average }=54.3 \mathrm{mph}} \\
\mathrm{S}=2.2 \mathrm{mph} \\
\text { Volume }=44017 \mathrm{veh}\end{array}$ & $\begin{array}{l}\frac{\text { Nighttime }}{\text { Average }=52.4 \mathrm{mph}} \\
\text { Volume }=4594 \mathrm{veh}\end{array}$ & $\begin{array}{l}\text { Overall } \\
\text { Average }=48.4 \mathrm{mph} \\
\mathrm{S}=2.2 \mathrm{mph} \\
\text { Volume }=45168 \mathrm{veh}\end{array}$ & $\begin{array}{l}\frac{\text { Nighttime }}{\text { Average }=46.9 \mathrm{mph}} \\
\text { Volume }=4516 \mathrm{veh}\end{array}$ \\
\hline
\end{tabular}

As was done with the data from Phase II, the hours were ranked by overall speed and the slowest hours were selected for further analysis. Table 4-5 shows a comparison of traffic speeds during the five slowest hours sampled as part of Phase III. When the analytical procedures used for Phase II were used with these data, it revealed that WB section had the higher overall speeds at nighttime, and that margin grew even larger during the low speed times. Therefore, it was not expected that there was any benefit to the three delineator configuration over the single sidemounted delineator near the bottom. 
Table 4-5 - Comparison of Speeds During the Low Speed Hours - Phase III

\begin{tabular}{||c||c|c|c|c|c|c||}
\hline $\begin{array}{c}\text { Hour } \\
\text { (Slowest } \\
\text { First) }\end{array}$ & $\begin{array}{c}\text { Overall } \\
\text { Speed (mph) }\end{array}$ & $\begin{array}{c}\text { WB } \\
\text { Section } \\
\text { Speed } \\
(\mathrm{mph})\end{array}$ & $\begin{array}{c}\text { EB Section } \\
\text { Speed } \\
(\mathrm{mph})\end{array}$ & $\begin{array}{c}\text { Difference } \\
(\mathrm{mph})\end{array}$ & $\begin{array}{c}\text { Overall } \\
\text { Nighttime } \\
\text { Difference } \\
(\mathrm{mph})\end{array}$ & $\begin{array}{c}\text { Relative } \\
\text { Difference } \\
(\mathrm{mph})\end{array}$ \\
\hline \hline \multirow{2}{*}{1} & 45.1 & 50.5 & 41.6 & 8.9 & 5.5 & 3.4 \\
\hline 2 & 46.2 & 48.4 & 43.7 & 4.6 & 5.5 & -0.9 \\
\hline 3 & 46.4 & 51.5 & 40.6 & 10.9 & 5.5 & 5.4 \\
\hline 4 & 46.6 & 50.2 & 43.0 & 7.2 & 5.5 & 1.8 \\
\hline 5 & 47.6 & 51.5 & 43.4 & 8.1 & 5.5 & 2.6 \\
\hline \hline \multicolumn{1}{|c|}{ AGGREGATE } & & 39.7 & 27.5 & 12.2 \\
\hline
\end{tabular}

\subsection{Phase IV - Halved Spacing}

From $8 / 29 / 02$ to $9 / 04 / 02$, traffic data were recorded for the final testing phase, which was conducted to test for differences between normal PENNDOT spacing and halved spacing. The configuration used in this phase was the single side-mounted delineator near the bottom in combination with a top mounted delineator. A summary of general statistics from this phase is provided in Table 4-6 (See Appendix F for complete data set). The period from $8 \mathrm{pm}$ to 6 am was used as the nighttime hours. The sunrise during this time period was approximately 6:50 am, and the sunset was approximately 7:50 pm. The combined control station speed was 47.6 mph overall and $48.3 \mathrm{mph}$ during the nighttime. These results are consistent with the control 
counts from the other phases. As with the other testing phases, the nighttime speed is slightly higher than the overall speed.

Table 4-6 - Summary of Results for Phase IV

\begin{tabular}{|c|c|c|c|}
\hline \multicolumn{2}{|c|}{ Westbound } & \multicolumn{2}{|c|}{ East Bound } \\
\hline \multicolumn{2}{|c|}{ Control Station } & \multicolumn{2}{|c|}{ Control Station } \\
\hline $\begin{array}{l}\frac{\text { Overall }}{\text { Average }=48.3 \mathrm{mph}} \\
\mathrm{S}=2.35 \mathrm{mph} \\
\text { Volume }=49530 \mathrm{veh}\end{array}$ & $\begin{array}{l}\frac{\text { Nighttime }}{\text { Average }=49.5 \mathrm{mph}} \\
\text { Volume }=7393 \mathrm{veh}\end{array}$ & $\begin{array}{l}\frac{\text { Overall }}{\text { Average }=46.8 \mathrm{mph}} \\
\mathrm{S}=1.12 \mathrm{mph} \\
\text { Volume }=49309 \mathrm{veh}\end{array}$ & $\begin{array}{l}\frac{\text { Nighttime }}{\text { Average }=46.9 \mathrm{mph}} \\
\text { Volume }=6545 \mathrm{veh}\end{array}$ \\
\hline \multicolumn{2}{|c|}{ Section 1 - Halved Spacing } & \multicolumn{2}{|c|}{ Section 2 - Regular Spacing } \\
\hline $\begin{array}{l}\frac{\text { Overall }}{\text { Average }}=50.9 \mathrm{mph} \\
\mathrm{S}=3.36 \mathrm{mph} \\
\text { Volume }=48738 \mathrm{veh}\end{array}$ & $\begin{array}{l}\frac{\text { Nighttime }}{\text { Average }=49.2 \mathrm{mph}} \\
\text { Volume }=7631 \mathrm{veh}\end{array}$ & $\begin{array}{l}\frac{\text { Overall }}{\text { Average }=51.1 \mathrm{mph}} \\
\mathrm{S}=1.98 \mathrm{mph} \\
\text { Volume }=48257 \mathrm{veh}\end{array}$ & $\begin{array}{l}\frac{\text { Nighttime }}{\text { Average }=50.0 \mathrm{mph}} \\
\text { Volume }=6599 \mathrm{veh}\end{array}$ \\
\hline \multicolumn{2}{|c|}{ Section 2 - Regular Spacing } & \multicolumn{2}{|c|}{ Section 1 - Halved Spacing } \\
\hline $\begin{array}{l}\frac{\text { Overall }}{\text { Average }=54.8 \mathrm{mph}} \\
\mathrm{S}=8.36 \mathrm{mph} \\
\text { Volume }=30512 \mathrm{veh}\end{array}$ & $\begin{array}{l}\frac{\text { Nighttime }}{\text { Average }=52.9 \mathrm{mph}} \\
\text { Volume }=4849 \mathrm{veh}\end{array}$ & $\begin{array}{l}\frac{\text { Overall }}{\text { Average }=50.5 \mathrm{mph}} \\
\mathrm{S}=2.00 \mathrm{mph} \\
\text { Volume }=19524 \mathrm{veh}\end{array}$ & $\begin{array}{l}\frac{\text { Nighttime }}{\text { Average }=49.0 \mathrm{mph}} \\
\text { Volume }=3008 \mathrm{veh}\end{array}$ \\
\hline
\end{tabular}

As with the other phases, the hours were ranked by overall speed and the slowest hours were selected for further analysis. Table 4-7 shows a comparison of traffic speeds during the three slowest hours sampled as part of Phase IV. The same analytical procedures as described under Phase II were used. This analysis revealed that while the WB section had the higher 
overall speeds at nighttime, the EB section generally had the higher speeds during the slowest periods. This is the section that had the spacing halved. Therefore, it is expected that the halved spacing was beneficial to the drivers during the slowest periods.

Table 4-7 - Comparison of Speeds During the Low Speed Hours - Phase IV

\begin{tabular}{|c|c|c|c|c|c|c|}
\hline $\begin{array}{l}\text { Hour } \\
\text { (Slowest } \\
\text { First) }\end{array}$ & $\begin{array}{c}\text { Overall } \\
\text { Speed (mph) }\end{array}$ & $\begin{array}{c}\text { WB } \\
\text { Section } \\
\text { Speed } \\
\text { (mph) }\end{array}$ & $\begin{array}{c}\text { EB Section } \\
\text { Speed } \\
(\mathrm{mph})\end{array}$ & $\begin{array}{l}\text { Difference } \\
\quad(\mathrm{mph})\end{array}$ & $\begin{array}{c}\text { Overall } \\
\text { Nighttime } \\
\text { Difference } \\
(\mathrm{mph})\end{array}$ & $\begin{array}{c}\text { Relative } \\
\text { Difference } \\
\text { (mph) }\end{array}$ \\
\hline 1 & 42.7 & 45.2 & 39.4 & -5.8 & 3.9 & -9.7 \\
\hline 2 & 45.7 & 48.8 & 44.6 & -4.2 & 3.9 & -8.1 \\
\hline 3 & 47.4 & 47.2 & 48.8 & 1.6 & 3.9 & -2.3 \\
\hline \multicolumn{4}{|c|}{ AGGREGATE } & -8.4 & 11.7 & -20.1 \\
\hline
\end{tabular}

\subsection{Conclusions}

In conclusion, from the visibility tests that were conducted, the following recommendations can be made:

In poor visibility conditions, the single side-mounted delineator at the bottom provides better guidance to the driver than the single side-mounted delineator at the top. Note that this assumes a top-mounted delineator will be provided. It is speculated that during poor visibility conditions, more drivers use their low headlight beams, and that this may have contributed to the 
results of the test. Also note that these were newly mounted delineators, and that delineators mounted lower to the road are more subject to abrasion and abuse that would cause them to fall off, and materials that can coat the delineator and cause it to lose its reflectivity. Finally, note that of the three tests conducted, the results of this test were the weakest.

There was no difference in speeds found between providing the single bottom sidemounted delineator and three side-mounted delineators. Although the three side-mounted delineator configuration creates a redundancy issue it guards against having no side-mounted delineation for $80^{\prime}$ to $160^{\prime}$ in the case where the delineator would become detached from the barrier.

The halved spacing provided drivers with better guidance information during poor visibility conditions. Of the three tests conducted, the results of this test were the strongest. As a result of the visibility testing outcome, PENNDOT has developed a preliminary standard which specifies mounting delineators on the top or on the side near the top and on the side near the bottom. The configuration is shown in Figure XIII. This configuration will be implemented in upcoming construction projects, and monitored to test the effectiveness of the preliminary configuration. 


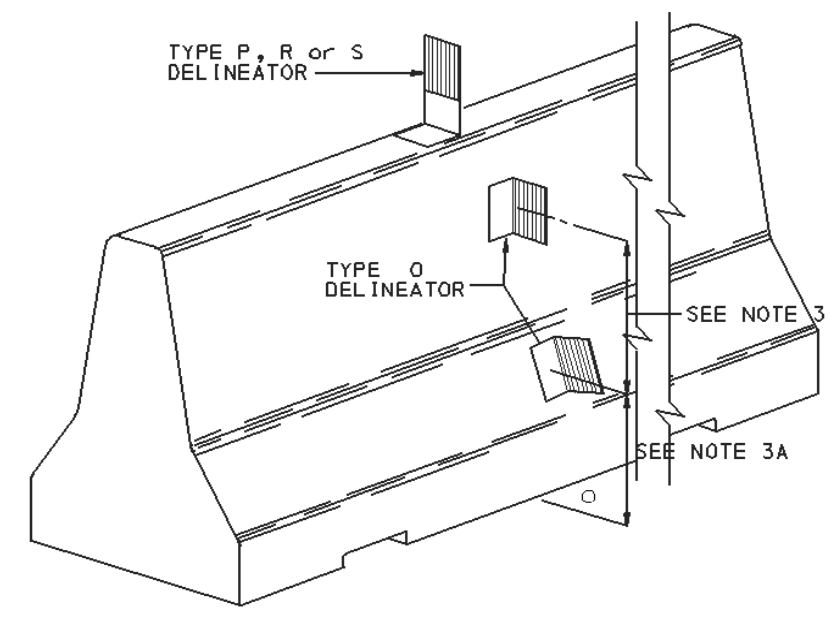

Figure XIII - Preliminary Configuration for PENNDOT Standard 


\section{Chapter 5 Summary of Conclusions}

\subsection{Summary of Conclusions}

This research was comprised of three main research efforts:

1. Literature Review and State of the Practice Survey

2. Durability Test

3. Visibility Test

The conclusions from each are summarized below

\subsection{Literature Review and State of the Practice Survey}

This review and survey demonstrated the following general principles:

Concrete median barrier delineation is an important traffic control device that primarily provides the driver with guidance information on roadway alignment. It also aids the driver in avoiding collisions with the barrier both during day and nighttime conditions. Finally, because the color of the delineator matches the appropriate pavement marking, it also provides regulatory information. 
Concrete median barrier delineation, because of its location in the near roadside area, is subject to many environmental forces, including vandalism, plowed snow, abrasion from blowing dust and anti-skid material, sunlight, etc. These forces can reduce or eliminate the effectiveness of the delineation in performing its desired intent.

The effectiveness of concrete median barrier delineation is dependent on atmospheric conditions, and can be rendered completely or partially ineffective due to rain, snow, fog, or particulate matter under certain conditions.

There is a wide variation in the application of concrete median barrier delineation between states and even within the state of Pennsylvania. Furthermore, there is no guidance on delineation strategies during poor atmospheric conditions.

Specific to PENNDOT's standard, this review suggests that the size of the 3" x 12" (reflective area) delineator likely contributes to its vandalism problem because it is more conspicuous than other delineators. The benefits of the increased conspicuity are questionable because greater conspicuity likely has little value under normal nighttime driving conditions. Even under poor visibility conditions, the prior research is inconclusive about whether a larger reflective area contributes to greater visibility. Some research suggests that only an increase in light intensity contributes to increased visibility. Other states use more reflective material than the ASTM Type V sheeting recommended by the PENNDOT standard. Districts using RPMs in lieu of standard delineators are also using more reflectivity. Perhaps PENNDOT should consider a smaller delineator with greater reflectivity in lieu of the $3 "$ x 12 " variety. However, this subject is beyond the scope of this research. 
Several states, including neighboring states Ohio and New York, bolt the delineators to the barrier. In lieu of a flexible hinge, many states use sturdy metal brackets to counteract blows to the delineators.

The 3" x 12" top-mounted delineator used by PENNDOT is among the largest of the states surveyed.

The majority of states surveyed only use top-mounted delineation. Three only use side-mounted delineation. PENNDOT was one of the few states reviewed that used both. None used more than one delineator on the side.

In general, spacing is in line with other states. However, at 80 feet, closer spacing is used by PENNDOT in tangent sections than most of the other states reviewed. It is also closer than that recommended by the MUTCD, which is 200 feet to 530 feet.

\subsection{Durability Test}

The purpose of this study was to determine the best adhesive for use to minimize the cost of delineating concrete median barriers. Three adhesive types were tested, and the Peel-n-Stick delineators were identified as the least cost choice. They were the most expensive choice based on the cost of the delineator alone. However, when the cost of the adhesive was added in, they were all virtually the same cost. When the installation time savings offered by the Peel-n-Stick delineators were considered, they then become the least cost alternative. In addition, the survival rate of the Peel-n-Stick delineators during the one-year durability test was 100\%. Lastly, 
although it was not considered, the delay costs for traveling public resulting from the traffic control required to install the delineators would also be the least for the Peel-n-Stick delineators.

\subsection{Visibility Test}

In conclusion, from the visibility tests that were conducted, the following recommendations can be made:

In poor visibility conditions, the single side-mounted delineator at the bottom provides better guidance to the driver than the single side-mounted delineator at the top. Note that this assumes a top-mounted delineator will be provided. It is speculated that during poor visibility conditions, more drivers use their low headlight beams, and that this may have contributed to the results of the test. Also note that these were newly mounted delineators, and that delineators mounted lower to the road are more subject to abrasion, abuse that would cause them to fall off, and materials that can coat the delineator and cause it to lose its reflectivity. Finally, note that of the three tests conducted, the results of this test were the weakest.

There was no difference found between providing the single bottom side-mounted delineator and three side-mounted delineators.

The halved spacing provided drivers with better guidance information during poor visibility conditions. Of the three tests conducted, the results of this test were the strongest. 


\subsection{Recommendations}

It is recommended that in areas prone to poor visibility conditions, that consideration be given to decreasing the longitudinal spacing, and providing delineation lower on the barrier than shown in the standards. Site specific conditions and engineering judgment can dictate how much closer the spacing should be, as well as how low on the barrier to mount a delineator. It must be noted that due to time restrictions, this research was not able to address whether delineators remain effective when exposed to conditions near the pavement surface over a long period of time. This should be monitored in the appropriate instances. With respect to durability, in instances where the peel-and-stick delineators (such as those currently offered by Sun Labs) are comparable in price to obtaining the delineators and adhesive separately, that special consideration should be given to the peel-and-stick delineators. Their installation time was found to be less, and their durability was perfect over the one-year period monitored and again during the six-month update. They should also be given special consideration in instances where user delay due to the traffic control set up to install the delineators is critical. Finally, the literature review revealed the ultimate solution to delineation under poor visibility conditions is lightemitting delineation. Consideration should remain open to such solutions. 


\section{References}

Alexander, Gerson J. and Harold Lunenfield, "Positive Guidance in Traffic Control", U.S. Department of Transportation, Washington, D.C., 1975.

Allen, T.M., H. Lunenfield, and G.J. Alexander, "Driver Information Needs", Highway Research Record 366, 1971.

A Policy on the Geometric Design of Highways and Streets, American Association of State Highway and Transportation Officials (AASHTO), Washington D.C., 2001.

Blaauw, G. J. and Padmos, P., "Nighttime Visibility of Various Types of Road Markings; A Study on Durability, Including Conditions of Rain, Fog and Dew" In Society of Automotive Engineers (SAE) Technical Paper Series. Paper No. 820412. Warrendale, PA. 1982.

Blackledge, J.M. and B.E. Burritt, "A Review of Arizona Dust Storm Signing on Interstates 8 and 10," Symposium on Driver Visibility Under Varying Adverse Weather Conditions, August 1977, Portland, Oregon.

Burnham, A.C., Chapter 8 of the Traffic Engineering Handbook, 4th Edition, Institute of Transportation Engineers, Prentice Hall, Englewood Cliffs, NJ, 1992.

Heiss W.H., "Highway Fog - Visibility Measures and Guidance Systems," National Cooperative Highway Research Program Report 171, Transportation Research Board, 1976.

Hoffman, A.G., and B.W. Firth, State of the Practice Retroreflective Measurement Devices for Pavement Markings, Report No. FHWA-TS-84-222, Federal Highway Administration, Washington, D.C., December 1985.

Institute of Transportation and Traffic Engineering, "Fog Accident Prevention Study: Visibility of Colored Luminous Areas in Fog,” Berkeley, California, April 1969.

Krammes, R. A. and Tyer, K. D., "Post Mounted Delineators and RPMs: Their Effect on Vehicle Operations at Horizontal Curves on Two-Lane Rural Highways", Transportation Research Record No. 1324, 1991.

Manual of Traffic Signs, http://members.aol.com/rcmoeur/signman.html, Richard Moeur, 1999.

Manual on Uniform Traffic Control Devices for Streets and Highways, U.S. Department of Transportation, Federal Highway Administration, Washington DC., 1988. 
Manual on Uniform Traffic Control Devices for Streets and Highways, Millenium Edition, www.mutcd.fhwa.gov, U.S. Department of Transportation, Federal Highway Administration, Washington, DC., 2001.

Migletz, J., J.K. Fish, and J.L. Graham, Roadway Delineation Practices Handbook, Report No. FHWA/SA-93/001, Federal Highway Administration, Washington, DC., 1994.

Parker, M.R., Synthesis of Safety Research: Adverse Environmental Conditions, FHWA-TS-89046, Federal Highway Adminstration, Washington, DC, 1990.

Post, Theodore J. Gerson J. Alexander, and Harold Lunenfield, A Users' Guide to Postive Guidance (2nd Edition), FHWA-TO-81-1, Federal Highway Administration, Washington, DC, December 1981.

Wright, Paul, Highway Engineering, John Wiley \& Sons, Inc., US, 1996.

McGee, H.W., and D.L. Mace, Retroreflectivity of Roadway Signs for Adequate Visibility: A Guide, Report No. FHWA-DF-88-001, Federal Highway Administration, Washington, D.C., November 1987. 


\section{Appendix A}

Standards and Specifications from Other States 
Upon completion of the work under this Section any damage to the pavement or other facilities caused by the operation or the Contractor's equipment, shall be repaired by the Contractor as directed without additional cost to the State.

705.04 Method of Measurement.

Pavement Markers installed as directed and accepted will be measured by counting separately the number of various class and types of markers provided by the plans or proposal.

\subsection{Basis of Payment.}

(a) UNIT PRICE COVERAGE.

The number of Pavement Markers measured as noted above will be paid for at the respective contract unit price bid for each class and type specified by the plans or proposal. Said contract unit prices bid shall be full compensation for furnishing and installing the pavement markers, removing temporary pavement markers (if required), and for all materials, equipment, labor and incidentals necessary to complete the work.

(b) PAYMENT WILL BE MADE UNDER ITEM NO.: 705-A Pavement Markers, Class , Type - per each

\section{SECTION 707 DELINEATORS AND HAZARD MARKERS}

707.01 Description.

This Section shall cover the work of furnishing delineators and hazard markers and the installation of such at the locations designated on the plans or directed, in conformity with the plans and these specifications.

Delineators will be classified by the "type" installation in accordance with plan details, which set forth details of various types of delineator installation. All delineators will be mounted on posts.

Hazard Markers will be classified according to the type of installation, in accordance with plan details. Hazard markers may be composed of sign panel and/or reflectors with backing panel, mounted on posts or highway structures.

707.02 Materials.

Materials furnished for use shall be new, complying with the appropriate sections of Division 800 , Materials. Special reference is made to Section 881.

707.03 Construction Requirements.

(a) DELINEATOR INSTALLATIONS.

1. ERECTING POSTS.

The posts for the delineators shall be set at the locations shown on the plans and as directed by the Engineer. Posts shall be erected to a true vertical position. Any post damaged or otherwise unsuitable for the work shall be removed and replaced by the Contractor at his expense. Posts shall be inserted into the ground to a depth of not less than 24 inches $\{600 \mathrm{~mm}\}$.

Posts may be driven where this can be done without damage to the posts or galvanization. Otherwise, at the Contractor's election, posts shall be set in a 6 inch $\{150 \mathrm{~mm}\}$ diameter drilled hole and backfilled with sand and thoroughly flooded with water to insure compaction. This backfill shall extend up to the existing ground elevation, or the Contractor may use poured concrete in lieu of sand. If solid rock is encountered, holes shall be drilled and backfilled with concrete to the top of the rock or as directed.

Concrete for setting posts shall be Class A, Type 2 complying with applicable portions of Section 501, with the following modifications:

The concrete may be dry batched at a central mixing plant and delivered to the project. Before the concrete is placed water shall be added. This may be done in small amounts as needed and mixed on a mixing board or in a mortar box. After water is added, the mix shall be used within sixty (60) minutes. Posts shall be held in proper position until the concrete hardens. The concrete shall have cured for 72 hours before any strain is placed on the post.

Test cylinders for the concrete will not be required. 
Where posts are required to be set in concrete medians, holes approximately 6 inches $\{150 \mathrm{~mm}\}$ in diameter may be drilled or square holes approximately 6 inches by 6 inches $[150 \mathrm{~mm}$ by $150 \mathrm{~mm}\}$ may be cut or formed during placing of the concrete median. The posts shall be set by driving or other approved means, to a depth of not less than 24 inches $\{600 \mathrm{~mm}\}$ below top of the median and to such greater depth as may be required to erect the delineator at the required elevation, above the pavement. After the post has been set, the hole up to the bottom of the pavement shall be backfilled and compacted; the hole for the depth of the median pavement shall then be filled with one of the appropriate bituminous plant mixes provided in the Specifications.

2. ATTACHING DELINEATORS.

After erection of the delineator posts as noted, the delineators shall be affixed to the post in the manner shown on the plans.

(b) HAZARD MARKERS INSTALLATIONS.

1. ERECTING POSTS.

Posts, when required, shall be installed in the same manner prescribed in Subarticle (a) for delineator posts modified to cover embedment depth of posts shown by plan details.

\section{ATTACHMENT OF MARKERS AND PANELS.}

After erection of posts, when required, markers and panels shall be affixed to posts or structures as required in accordance with the details shown on the plans.

(c) PUBLIC CONVENIENCE AND FINAL CLEANUP.

The road may be fully open to the public travel during the progress of work under this section. Hence, when work is to be performed under traffic, the Contractor shall operate his equipment as well as store materials and supplies in such a manner as to cause a minimum of inconvenience to the traveling public. Special attention is directed to Article 107.07.

Upon completion of the work under this Section, the Contractor shall remove all surplus and waste material caused by this work and shall restore the area to at least the same condition as was existing prior to commencing of the work. Any damage to slopes, pavement, etc. caused by the operation of the Contractor's equipment shall be repaired as directed without additional cost to the Department.

\subsection{Method of Measurement.}

Delineator Installations installed as directed and accepted will be measured by counting separately the number of a particular type or types of delineator installations provided by the plans or proposal.

Hazard Marker Installations installed as directed and accepted will be measured by counting separately the number of a particular type or types of hazard marker installations provided by the plans or the proposal.

\subsection{Basis of Payment.}

(a) UNIT PRICE COVERAGE.

The number of the particular type of Delineator Installations ordered and accepted, measured as noted above, will be paid for at the respective unit prices bid for each type installation, Said unit price bid shall be full compensation for furnishing and installation of the delineators complete in place, including posts, hardware, brackets, braces and all materials, equipment, tools, labor and incidentals necessary to complete the work.

The number of the particular type of Hazard Marker Installations ordered and accepted, measured as noted above, will be paid for at the respective unit prices bid for each type installation. Said unit price bid shall be full compensation for furnishing and installing the Hazard Marker Installation complete in place, including post or anchors as required by plan details, hardware, brackets, braces and all materials, equipment, tools, labor and incidentals necessary to complete the work.

(b) PAYMENT WILL BE MADE UNDER ITEM NO.:

707-A Type __ Color Delineator Installation - per each

707-B Type __ Hazard Marker Installation - per each 


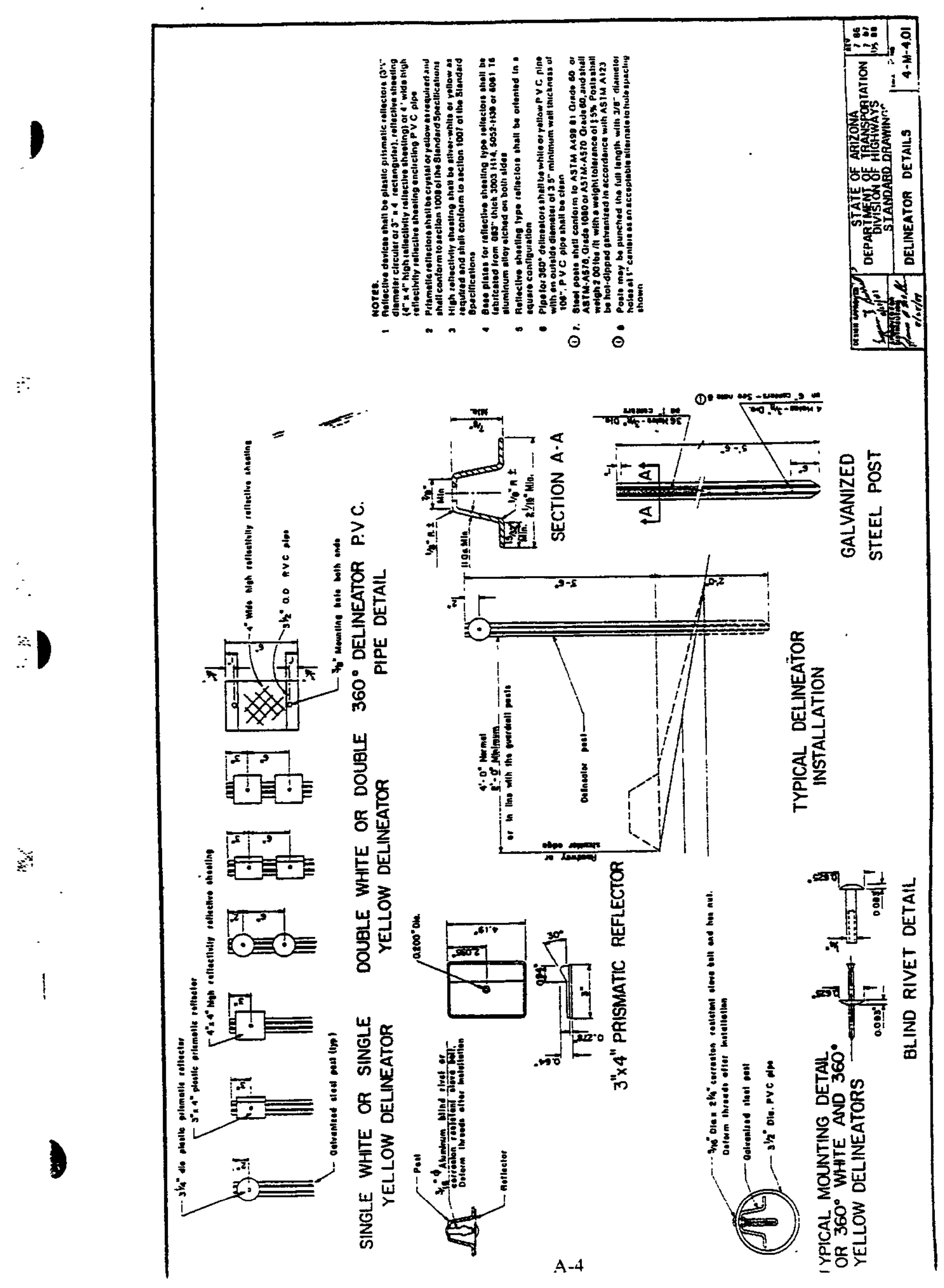




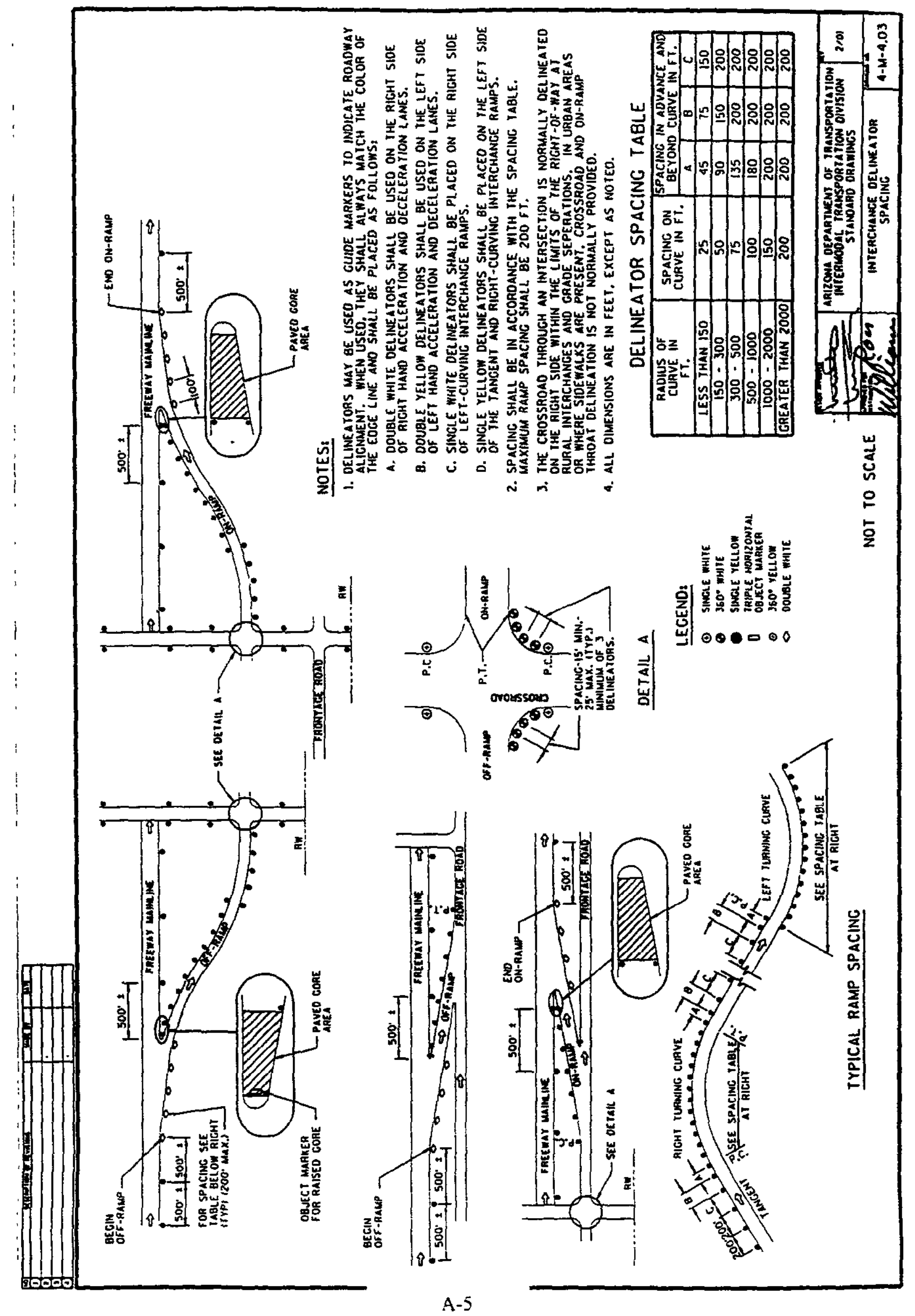




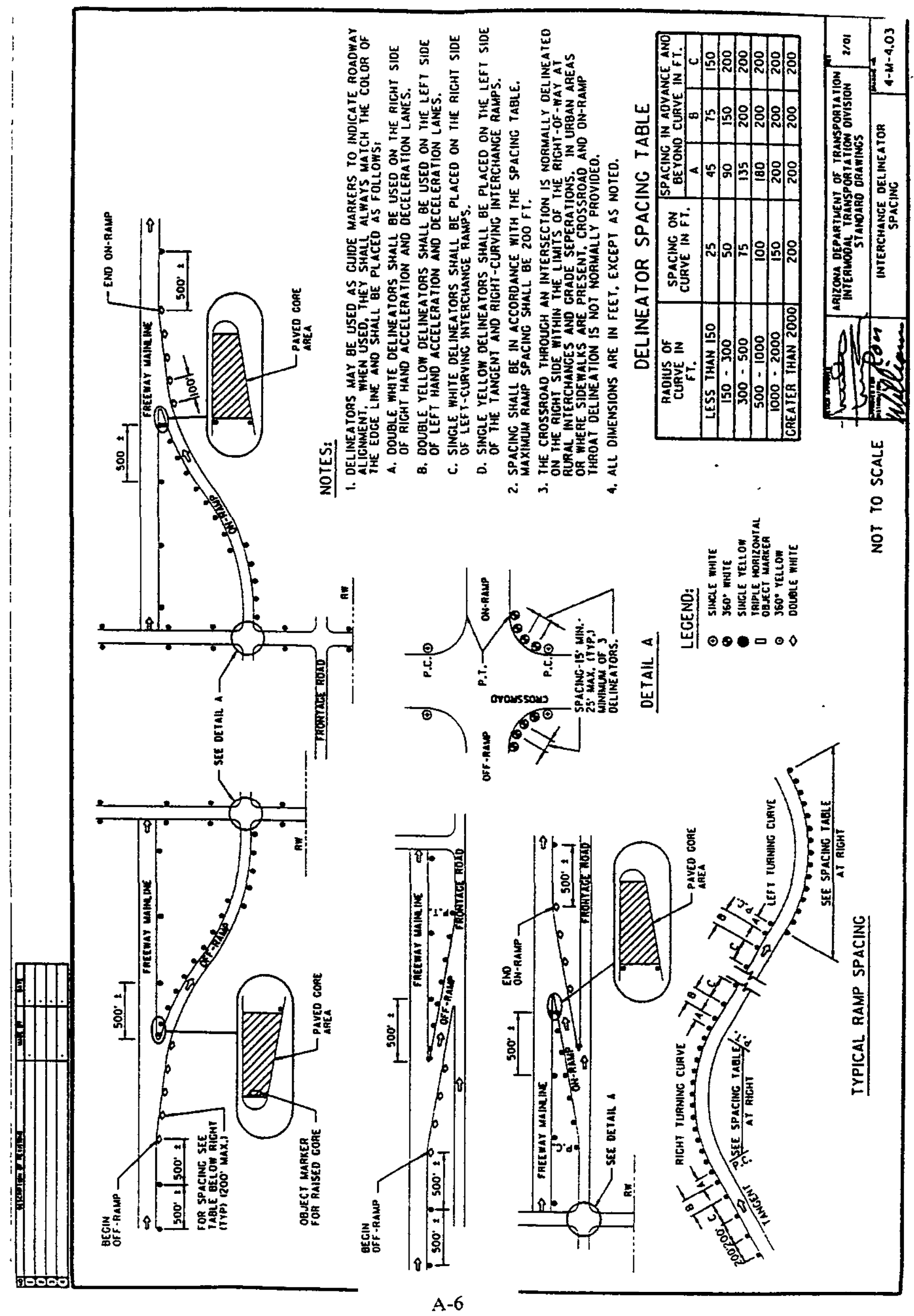




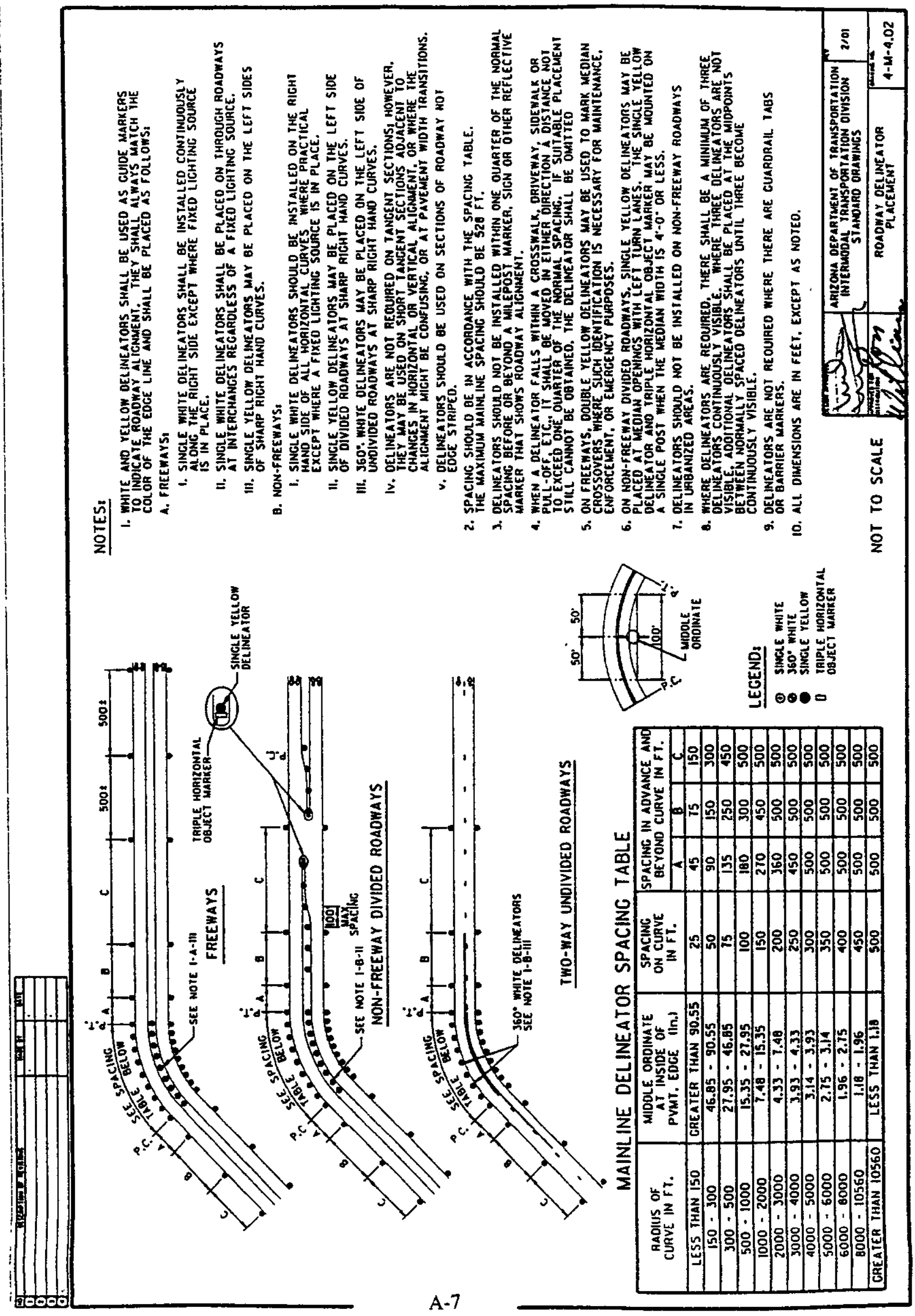


From: <Gonzalo_Gomez@dot.ca.gov>

To: <Jim.Frenchiii@mail.wvu.edu>

Date: $\quad 3 / 30 / 016: 40 \mathrm{PM}$

Subject: Median Barrier Delineation

Caltrans does have a standard for median barrier marking. It can be accessed through the interNet at:

http:/issc.dot.ca.gov/trafops/offsigns/delineat/trafman.htm

(This may not be accessible to the public)

Also, here is a copy of the text:

\section{6-04.9 Median Barrier Delineation}

Median barriers should be delineated when the clearance between the barrier and the edge of traveled way is less than

$2.44 \mathrm{~m}$.

In general, when delineated, it should be with an approved median barrier marker, the same color as the left edgeline.

They should be placed on top of the barrier at $14.64 \mathrm{~m}$ centers.

Markers placed on the sides of barriers, near the splash zone, should be avoided because of the tendency to collect dirt

which reduces their effectiveness. See Figure 6-50, TYPICAL MEDIAN BARRIER DELINEATION AND CHANNELIZERS.

(figure is attached as a jpeg file)

I hope this helps.

Gonzalo Gomez

Maintenance Program

Califomia Dept of Trans

(See attached file: TrafMan6-50.jpg) 


\section{TYPICAL MIEDIAN BARRIER DELINEATION AND CHANNELIZERS}

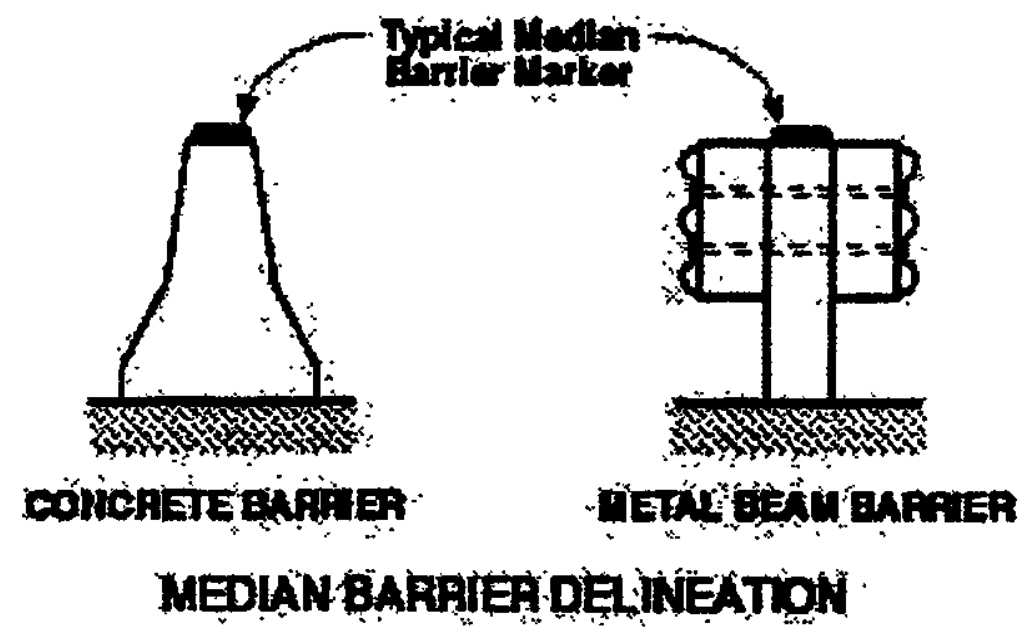

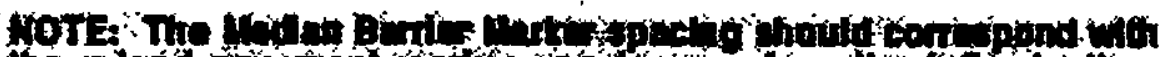

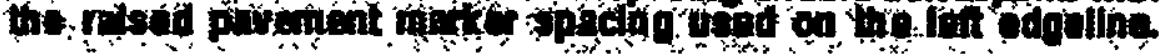

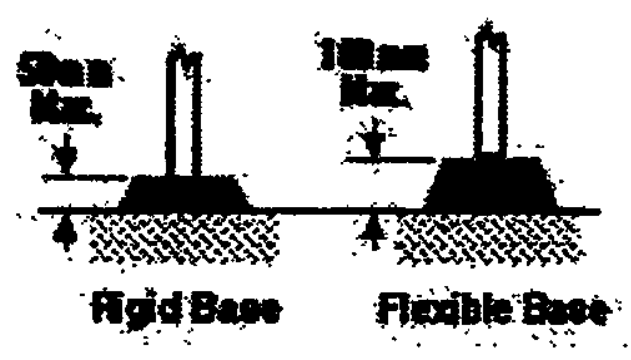

oupricenopite?

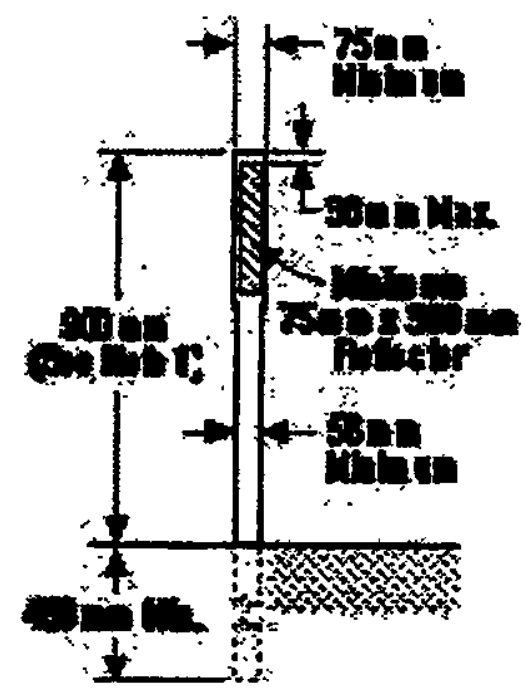

Eephrofice AHOHOA

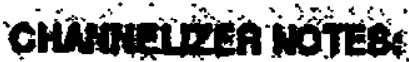

CHNMALAPS:

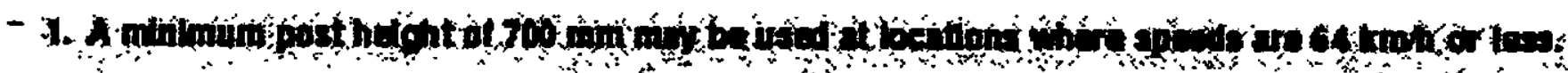

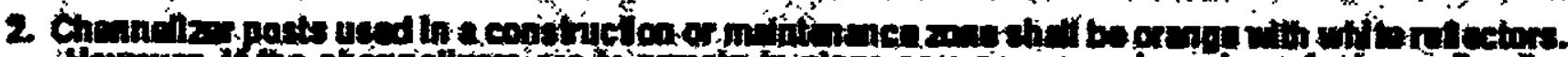

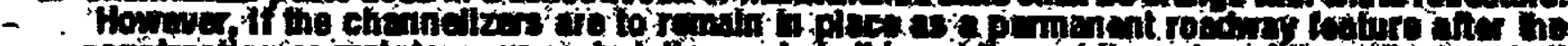

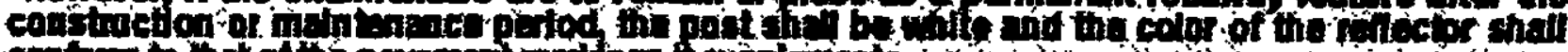

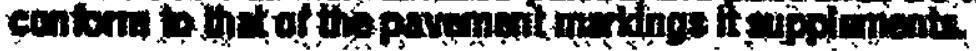




\section{Delineators 6.04}

\section{6-04.7 Introduction}

Delineators are retroreflective devices mounted at the side of the roadway, in series, to indicate the roadway alignment. Delineators are effective aids for night driving and under other conditions of reduced visibility. They are devices to guide rather than warn. Delineators may be used on long continuous sections of highway or through short stretches where there are changes in horizontal alignment, particularly where the alignment might be confusing, or at pavement width transitions. An important advantage of delineators is that they remain visible when the roadway is wet or snow covered.

Delineators are normally placed in the ground outside of the edge of pavement. Where delineation is required within a paved area, surface mounted channelizers may be used. See Section 6.06, CHANNELIZERS.

Installations should be inspected at night to ensure that there are no confusing or misleading delineators.

\section{6-04.2 Delineator Design}

Delineators shall consist of retroreflector units capable of clearly reflecting light under normal atmospheric conditions from a distance of $300 \mathrm{~m}$ when illuminated by the upper beam of standard automobile lights. The size of retroreflector units shall be a minimum of $75 \mathrm{~mm} \times 300 \mathrm{~mm}$ for the front, and when applicable, $75 \mathrm{~mm} \times 75 \mathrm{~mm}$ for the back.

There are two classes of delineator posts and several types of retroreflectorization as shown in Figure 6-45, TYPICAL DELINEATORS.

\section{6-04.3 Delineator Application}

Delineation is intended to be a clear and simple guide to the motorist regarding alignment of the highway.

The color of the delineator retroreflectors shall conform to the color of edgelines except for the use of yellow on the right at narrow bridges and red at truck escape ramps.

Examples of the use of delineators are shown in Figure 6-45. TYPICAL DELINEATORS. Color exceptions, are shown in Figure 6-48, NARROW BRIDGE SIGNING AND MARKINGS and Figure 6-49, TYPICAL RUNAWAY TRUCKRAMP SIGNING AND MARKINGS.

\section{TYPICAL DELINEATORS AND USES:}

- Type E - White Retroreflector (2 Sided). For use on the left or right of 2-lane 2-way streets and highways when it is desirable to have a reflector on the front, and one on the back of the delineator facing the opposite direction of traffic.

- Type F - White Retroreflector (1 Sided). For use on the right of freeways and expressways. They may also be used on 2 lane 2-way streets and highways when the Type $\mathrm{E}$ is not needed.

- Type G - Yellow Retroreflector (1 Sided). For use on the left of divided highways and 2-lane highway intersections as shown in Figure 6-46, TYPICAL EXAMPLES OF DELINEATOR PLACEMENT WHEN USED AT INTERSECTIONS, ISLANDS, RAMPS AND CONNECTORS. 
- Type I - Yellow Retroreflector (2 Sided). For use at approaches to narrow bridges as shown in Figure 6-48, NARROW BRIDGE SIGNING AND MARKINGS.

- Type J - Red Retroreflector (1 Sided). For placement on both sides of Truck Escape Ramps as shown in Figure 6-49, TYPICAL RUNAWAY TRUCK RAMP SIGNING AND MARKINGS.

Delineators with the appropriate retroreflector color are used to indicate the narrowing of the pavement where either an outside or inside lane merges into an adjacent lane. The delineators should be used adjacent to the lane affected for the full length of the convergence and should be so placed and spaced to show the width reduction as shown in Figure 6.15, TYPICAL LANE REDUCTION TRANSITION.

\subsubsection{Delineator Placement and Spacing}

Delineators, when used, shall be mounted so that the top of the retroreflector is about $1.2 \mathrm{~m}$ above the edge of traveled way. They shall be placed 0.61 to $1.83 \mathrm{~m}$ outside the outer edge of the shoulder, or if appropriate, in the line with the guardrail post.

Delineators should be placed at a constant distance from the edge of the roadway except that, where a guardrail or other obstruction intrudes into the space between the pavement edge and the extension of the line of delineators, the delineators should be in line with or taper to inside the innermost edge of the obstruction. See Figure 6-45, TYPICAL DELINEATORS.

Unless local conditions justify otherwise, delineators shall be placed on all State highways and should be provided on all city and county roads as follows: a. On the outsides of highway curves of 914 $m$ radius or less (including medians in divided highways). freeway exit and entrance ramps and connectors. Exception to this, is where a median barrier is delineated as shown in the Median Barrier Delineation Detail in Figure 6-50, TYPICAI MEDIAN BARRIER DELINEATION ANDCHANNELIZERS. Delineator spacing on curves is shown in Figure 6-47, DELINEATORSPACINGONCURVES.

b. On the right of tangent sections of freeway entrance and exit ramps, collector roads, freeway connectors and lane reduction transition sections at $60 \mathrm{~m}$ spacing.

c. On embankments higher than $3.0 \mathrm{~m}$ and with side slopes steeper than 1:4. Delineator spacing is approximately $160 \mathrm{~m}$.

d. On approaches to narrow bridges as shown in Figure 6-48. NARROW BRIDGE SIGNING AND MARKINGS.

e. On tangent sections of rural State highways where there are no reflective pavement markers, such as in snow areas. Delineator spacing is approximately $160 \mathrm{~m}$.

f. On all new guardrail or bridgerail installations, or when maintenance is required on existing guardrail or bridgerail, within $3.66 \mathrm{~m}$ of the edge of traveled way and curves of $900 \mathrm{~m}$ radius or less. The spacing on tangent sections is approximately $160 \mathrm{~m}$. For spacing on curves, see Figure 6-47, DELINEATOR SPACING ON CURVES. 
Delineators may also be placed as follows:

a. At intersections, road approaches, and median openings, as shown in Figure 6-46, TYPICAL EXAMPLES OF DELINEA. TOR PLACEMENT WHEN USED AT INTERSECTIONS, ISLANDS, RAMPS AND CONNECTORS.

b. On sections of highway with non-standard shoulder width.
Where normal uniform spacing is interrupted by driveways, intersections, etc., delineators may be moved a distance not exceeding $1 / 4$ of the normal spacing. If they still fall within such areas, the delineator should be eliminated.

Delineator spacing should be adjusted on approaches to and throughout horizontal curves so that several are always visible to the motorist. On short radius curves, it may be necessary to adjust the delineator several degrees toward the roadway so that it is perpendicular to the line of oncoming traffic. 


\section{Miscellaneous Delineators}

\section{6-04.5 Culvert Markers}

Culvert markers may be placed on both sides of the highway at those culverts where they are necessary. They should be so placed as not to interfere with a line of delineators and shall not be reflectorized, or contain kilometer post marker information. Further information on culvert markers is shown in the Caltrans Maintenance Manual chapter on TRAFFIC SAFETY DEVICES.

\section{6-04.6 Kilometer Post Markers}

Procedures and responsibilities for establishing postmile values and placing markers on State highways are described in Chapter 3, ACCIDENT AND ROADWAY RECORDS, Kilometer Post Markers, of this Manual.

\section{6-04.7 Emergency Passageway Marker}

Where freeway median passageways are provided for emergency vehicles, delineation for the crossover should be as follows:

a. At a point, $320 \mathrm{~m}$ in advance of the crossover, one Class 1 Delineator, with a yellow post and two $75 \mathrm{~mm} \times 300 \mathrm{~mm}$ white retroreflectors stacked vertically (600 mm of white retroreflectance), should be placed on the left side of the through roadway facing approaching traffic.

b. At a point, $160 \mathrm{~m}$ in advance of the crossover, one Class 1 Delineator, with a yellow post and two $75 \mathrm{~mm} \times 300 \mathrm{~mm}$ yellow retroreflectors stacked vertically. should be placed on the left side as in (a). c. At the far side of the crossover, one Class 1 Delineator, with a yellow post and one 75 $\mathrm{mm} \times 300 \mathrm{~mm}$ white retroreflector over one $75 \mathrm{~mm} \times 300 \mathrm{~mm}$ yellow retroreflector stacked vertically. should be placed on the left side as in (a).

The need and location of emergency markers may be coordinated between the emergency agency and the Department. See Chapter 7, TRAFFIC SAFETY SYSTEMS of this manual, for a discussion of emergency passageways.

\section{6-04.8 Narrow Bridge Signing and Marking}

The placement of warning signs, object markers. delineators, and edgelines at narrow bridges is dependent upon the width of the bridge and approach roadway. Narrow bridge signing and marking shall conform to the details shown in Figure 6-48,NARROW BRIDGESIGNING AND MARKINGS.

\section{6-04.9 Median Barrier Delineation}

Median bariers should be delineated when the clearance between the barrier and the edge of traveled way is less than $2.44 \mathrm{~m}$.

In general, when delineated, it should be with an approved median barrier marker, the same color as the left edgeline. They should be placed on top of the barrier at $14.64 \mathrm{~m}$ centers.

Markers placed on the sides of barriers, near the splash zone, should be avoided because of the tendency to collect dirt which reduces their effectiveness. See Figure 6-50, TYPICAL MEDIAN BARRIER DELINEATION AND CHANNELIZERS. 

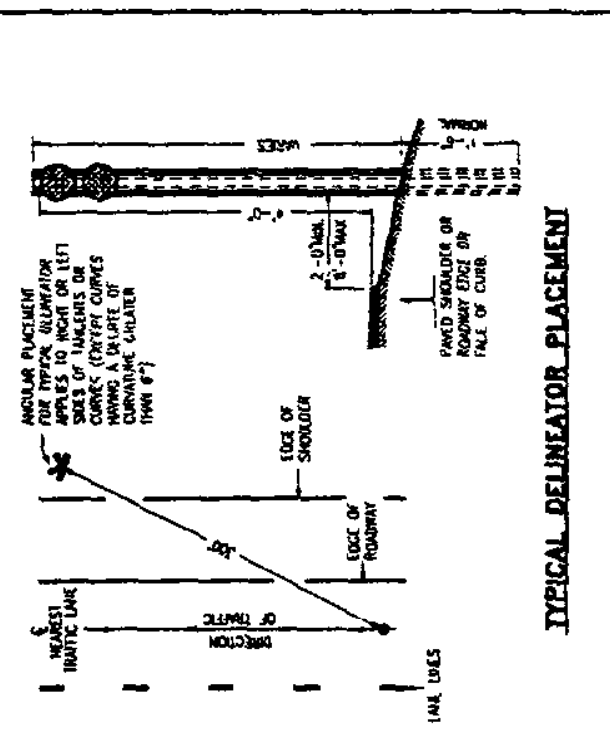

Ill

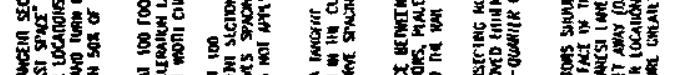

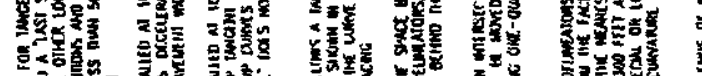

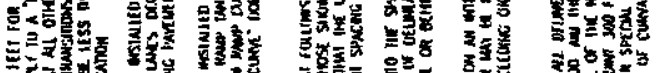

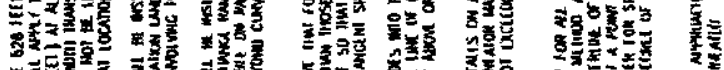

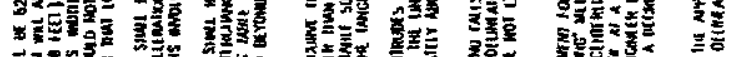

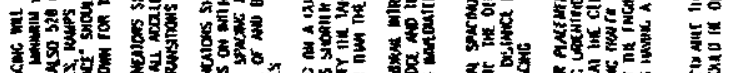

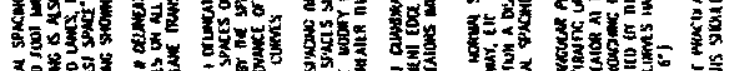

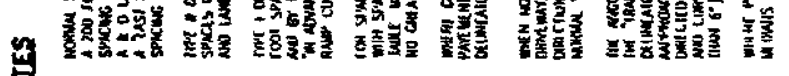

궇

$=\geq \geq=2=$

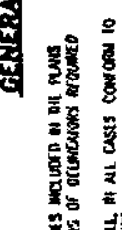

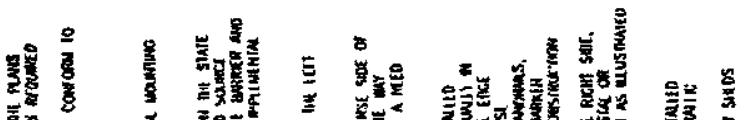

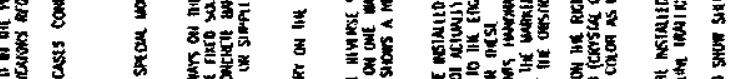

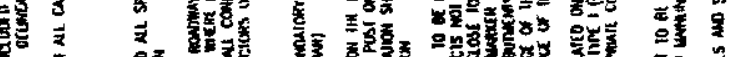

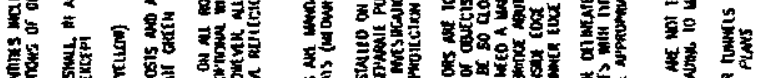

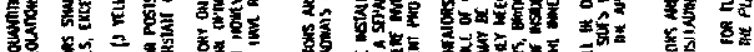

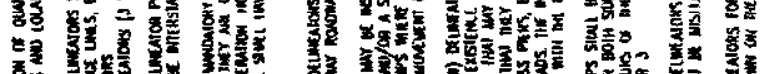

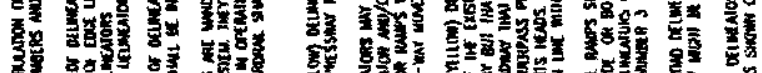

重家

政
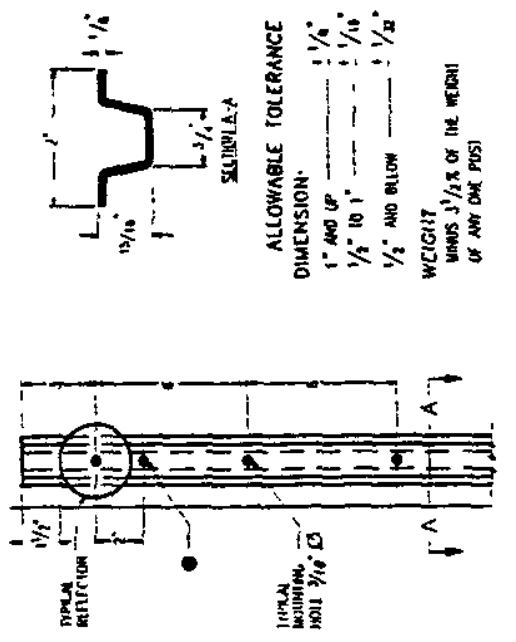

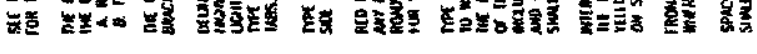

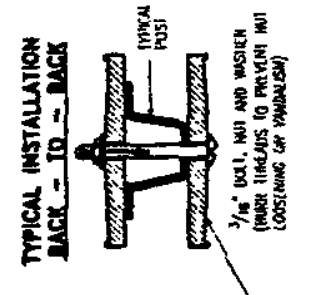

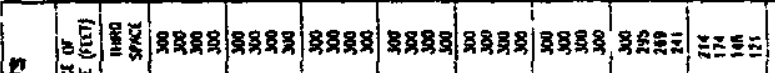

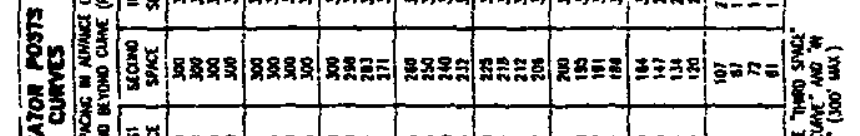

势

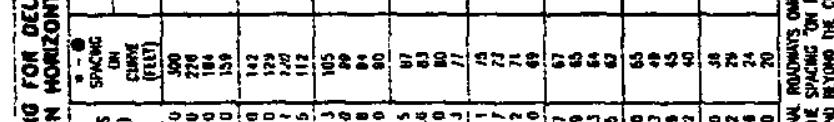

(2)
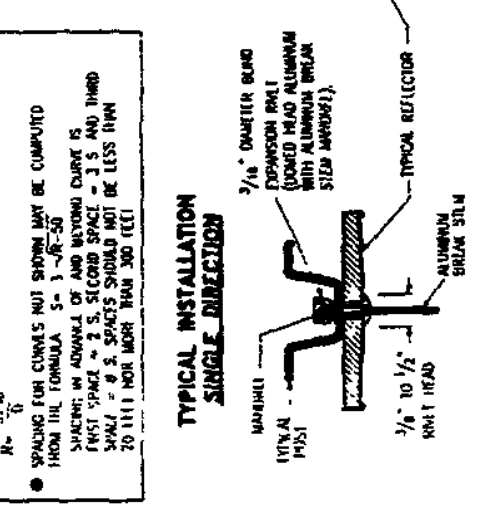

봄

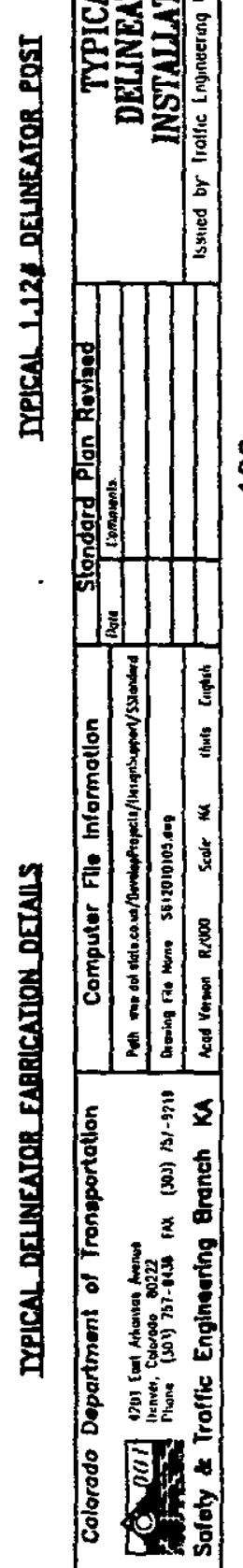

$\stackrel{1}{\frac{1}{8}}$
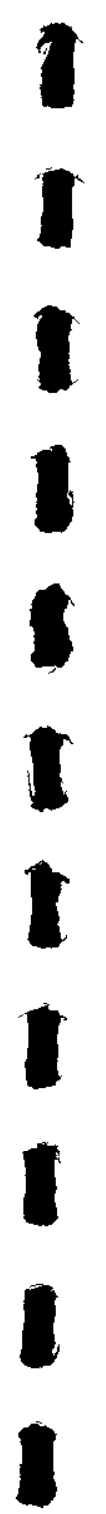


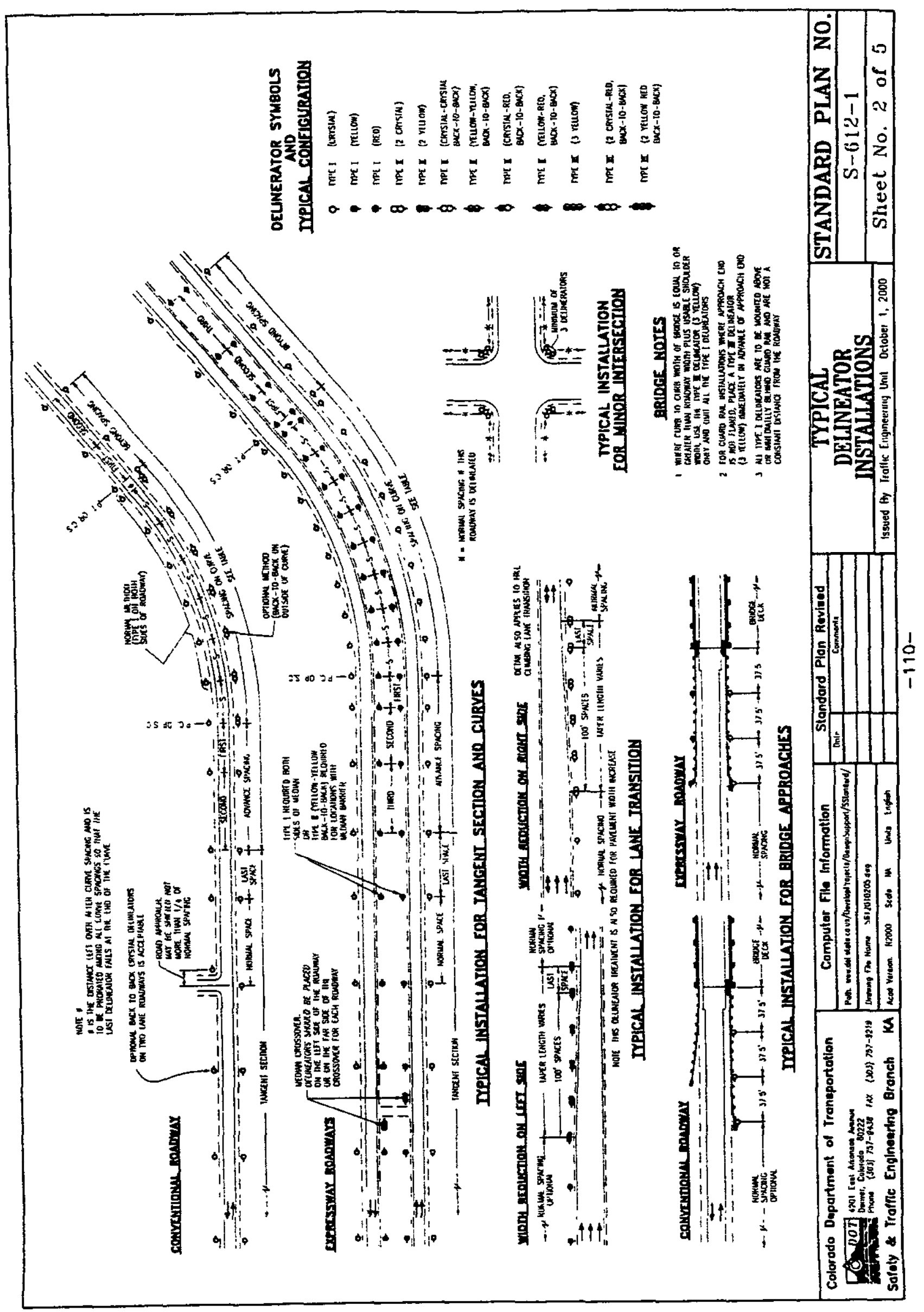




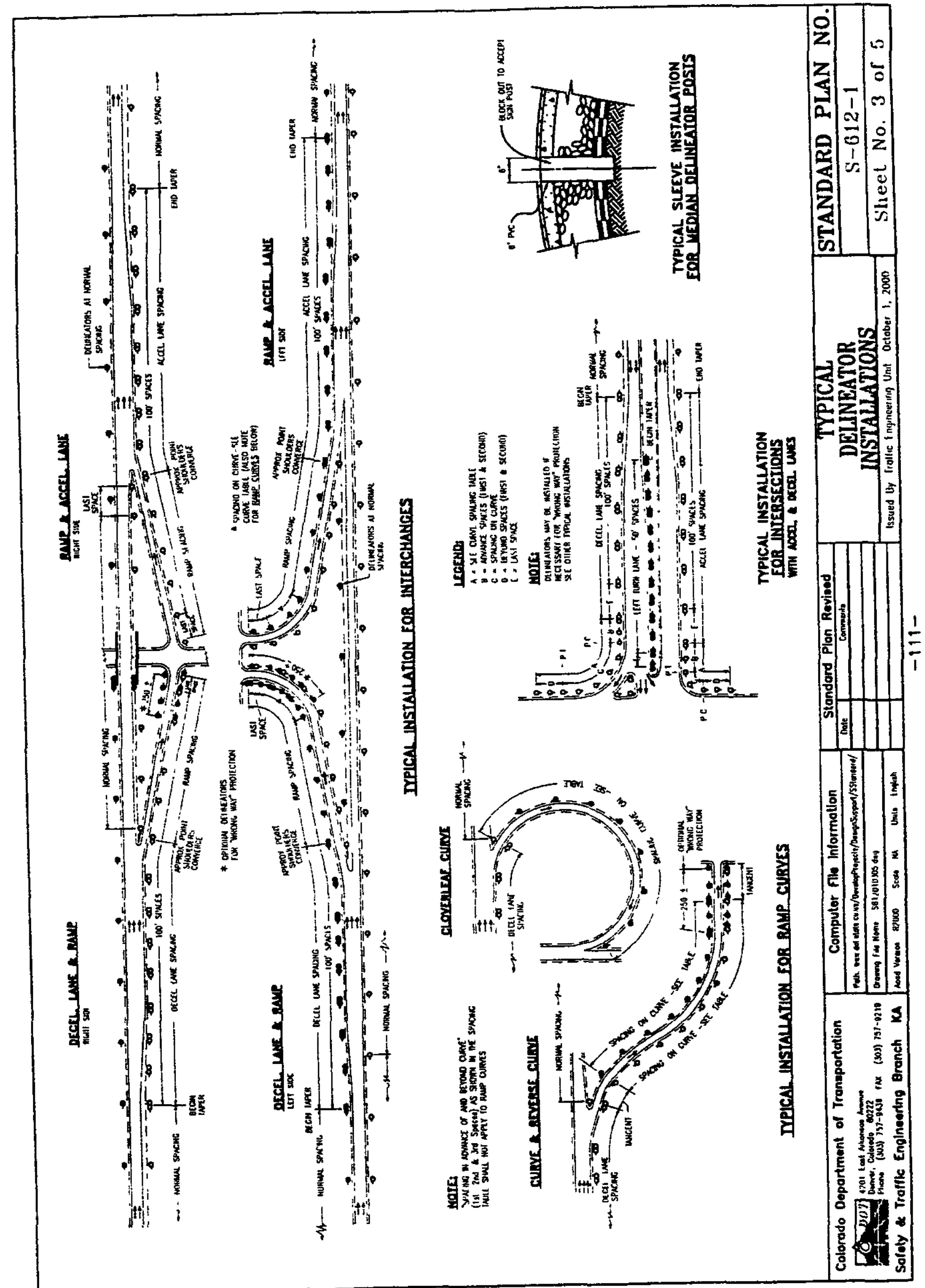




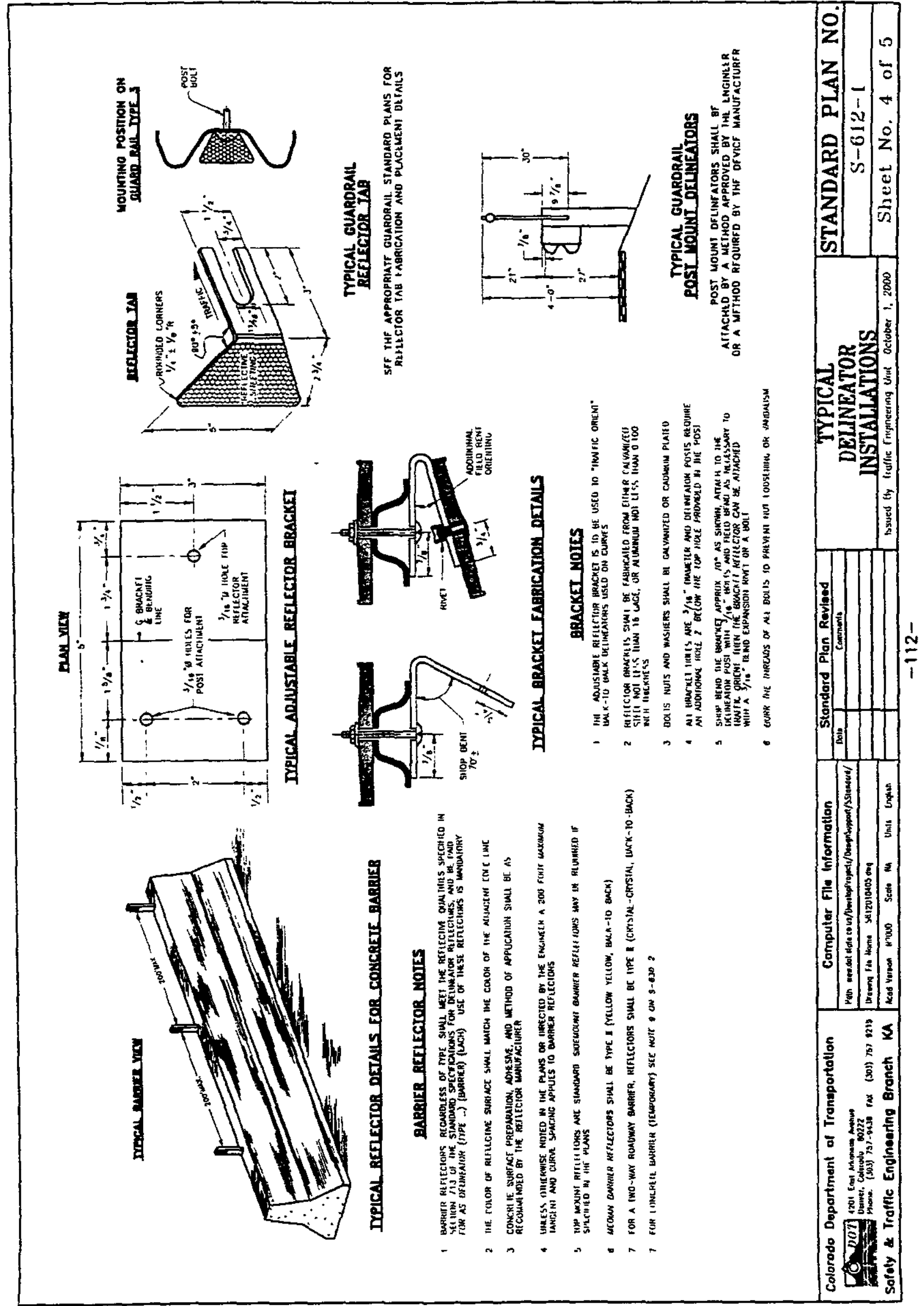



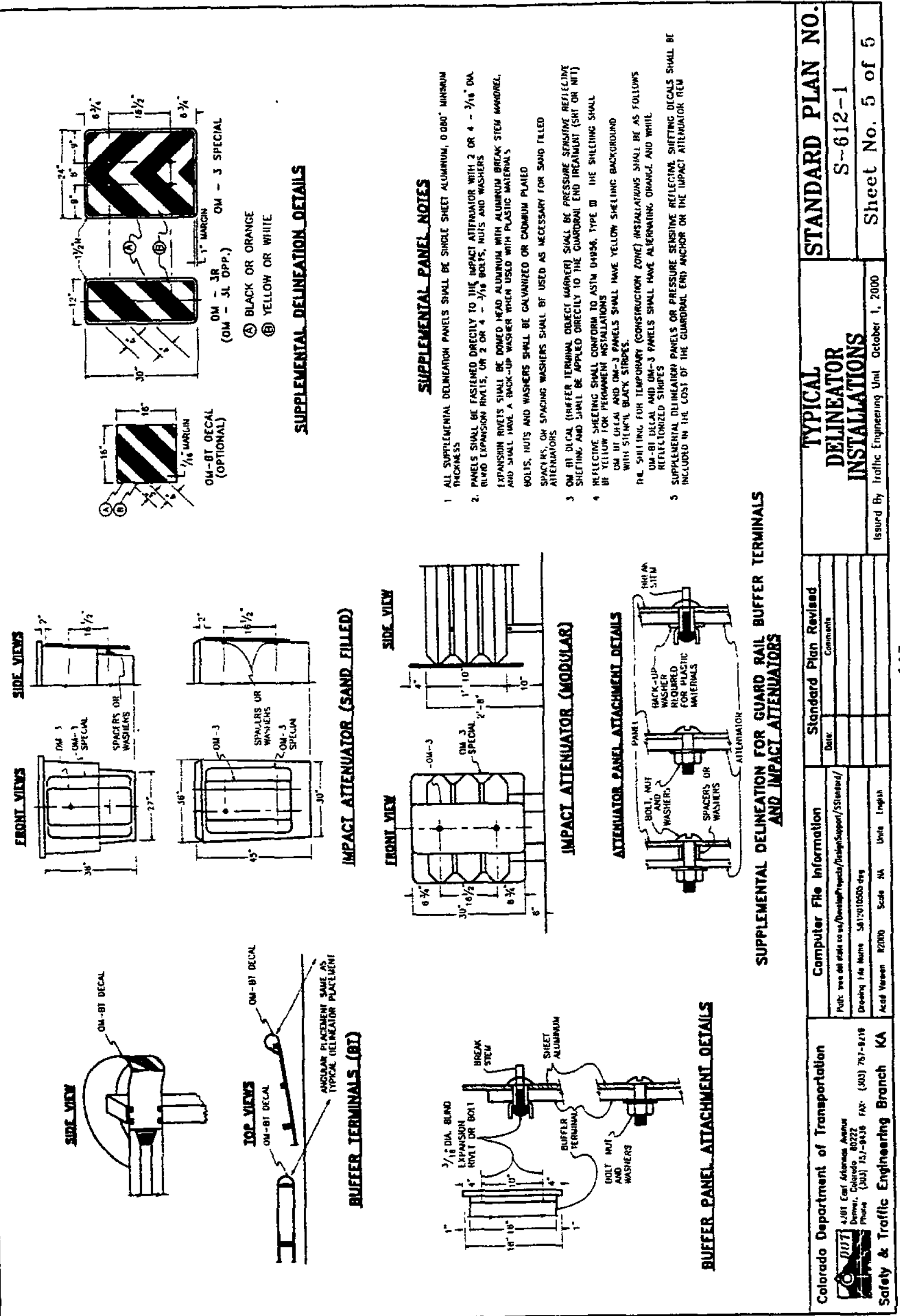


\section{DELINEATORS AND REFLECTORS}

Delineation is intended to be a guide to the vehicle operator as to the alignment of the highway; whatever is needed to provide that guidance in a clear and simple way should be installed. An important advantage of delineators is that they remain visible when the roadway is wet or snow covered.

\section{2,00 INSPECTION - DELINEATORS AND REFLECTORS}

\section{BEFORE WORK STARTS:}

1. Inspect posts and reflectors for damage

2. Check that location of delineator is correct.

\section{DURING WORK:}

3. Inspect for specified height and lateral clearance from roadway.

4. Verify that spacing between delineators complies with the table shown on the Standard.

5. Delineator posts must be plumb.

6. Number and color of reflectors must be correct.

7. Check for painting of posts when required. 


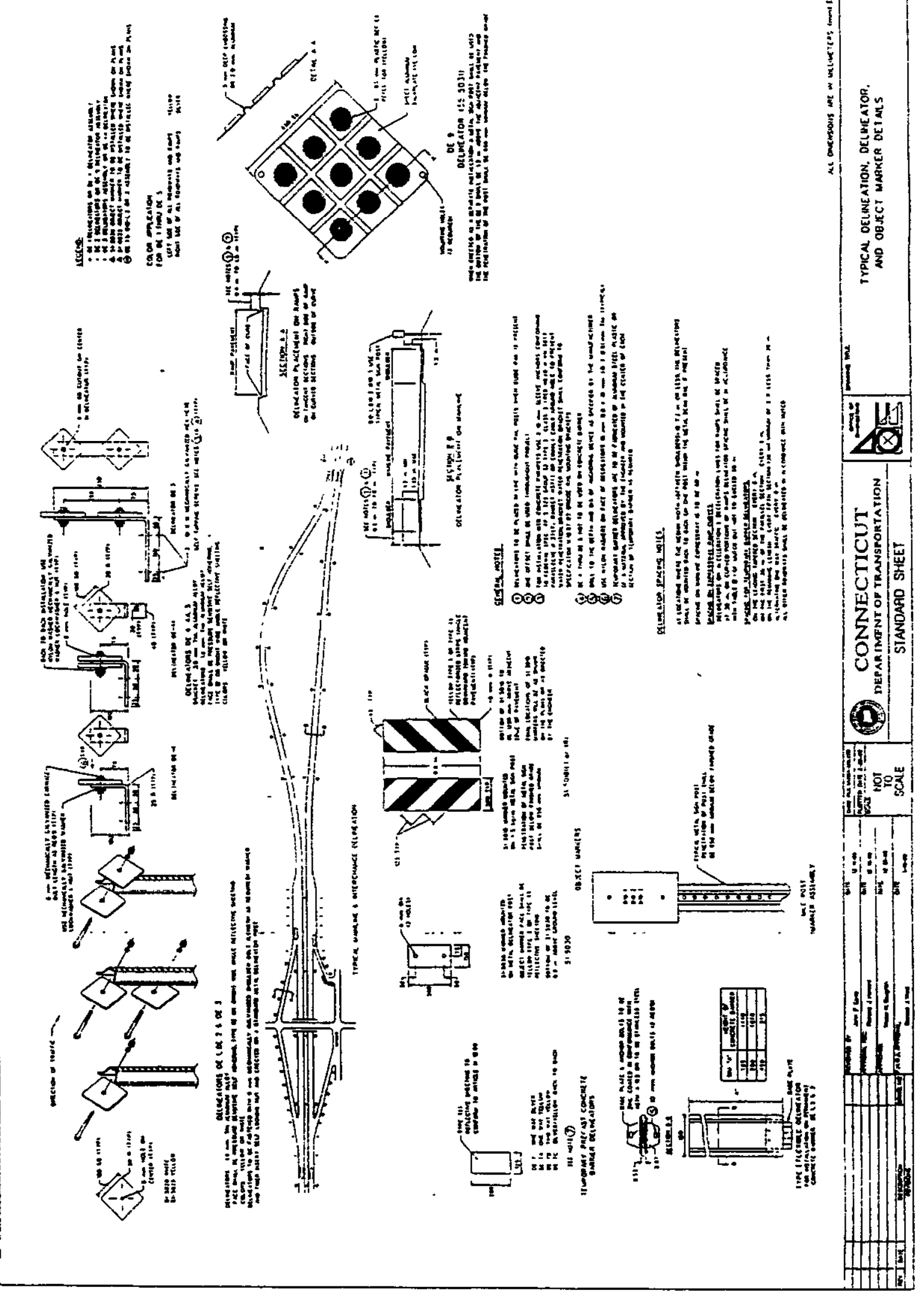




\author{
720536 - REFLECTORs, DOUBLE HHITE, CONCRETr \\ 720537 - RHTLCTORS, DOUBLE Yruton, CONCEETs

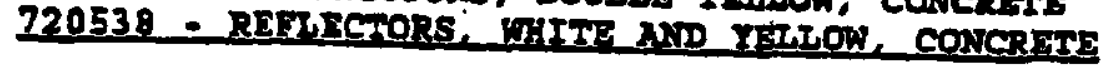

\title{
Derextiptlog:
}

This work consiste of furinishting and installing reflectore with double white faced, or double yellow Eaced or white and yellow faced, on P.C.C. Safery Barrier or on concrete surfaces in accordance with the designated locations on Plans and/or as directed by the Engineer.

\section{Materth 23 and Coretruction Kerhode;}

The reflector shalI be ASTRO OPTICS NO. JD-1, manufactured by ASTRo OPTICS or Flex 2020 Barrier Delineacor 100 nam $x 75 \mathrm{~nm}$, menufactured by DURA FIEX or approved equal.

The reflector urlt ghall be inetalled to the P.C.C. Safety Barrier or to any other required concrete objects in accordance with the Manufacturer's recommendations and/or notes on the Plans.

\section{Kethod of Meanuremene:}

The quantity of reflectors will be measured as the actual number of reflectors installed on concrete surfaces and accepted.

\section{Basie of Payment:}

The quantity and refloctore will be paid for at the contract unit price bid per each. Price and payment will constitute full compensarion for furrighing the reflector, inscalling, labor,
equipment, tools, and incidentais recessary to complese ihe work.

$$
N-7 / 12 / 99
$$




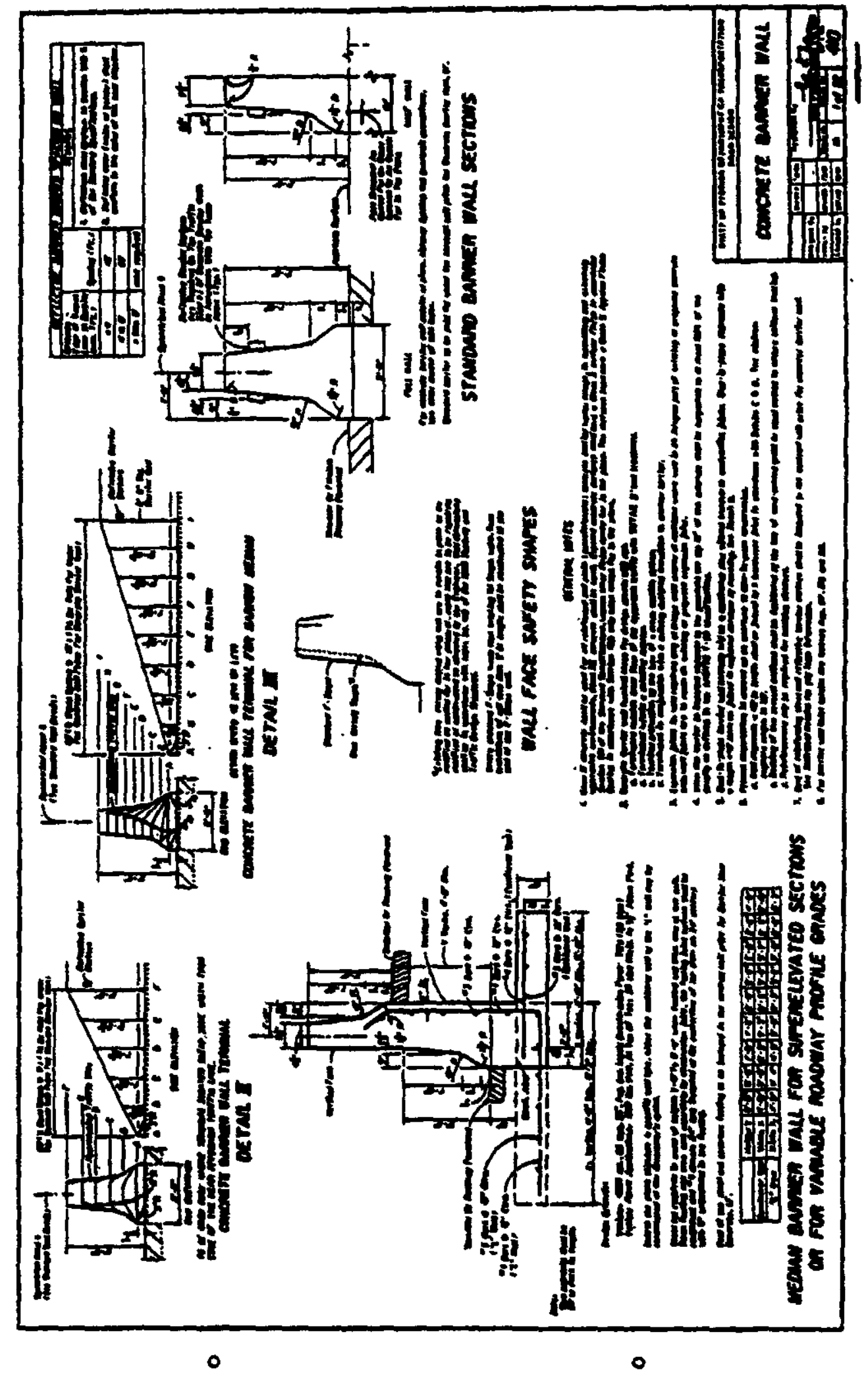




\section{SECTION 705 HIGHWAY DELNEATORS}

\section{5-1 Description.}

Furnish and install object markers and highway delineators, with supporting posts, of the types and at the locations called for in the plans. Highway delineators consist of a reflector, or reflective sheeting permanently adhered to sheet ahumimum, mounted to delineator post. Use only delineator posts, reflectors and reflective sheeting listed on the Qualified Products List.

\section{5-2 Materials.}

705-2.1 Delineator Assembly: Meet the requirements of Sections 993 and 994.

705-2.2 Object Markers: Mect the arrangement and design requirements of Section 3C of the MUTCD, with the following additions:

(1) Use 0.080 inch [2.0 mm] aluminum sheets and plates and conform to ASTM B 209 [ASTM B 209M], Alumimum Association Alloy 6061-T6 or 5052-H38, or Fiberglass Reinforced Plastic Sign Panels conforming to 700-2.2.

(2) Obtain the Engineer's approval of the object marker bracket and attachment.

705-2.3 Metal Delineator Posts: Meet the requirements of Section 993.

705-2.4 Flexible Delinentor Posts: Meet the requirements of Section 972.

705-2.5 Reflective Sheeting for Delineator Posts: Use Types III-A, III-B, III-C, or III-D reflective sheeting meeting the requirements of Section 994.

\section{5-3 Installation Requirements.}

Install the posts and mount the delineator assemblies or object markers to the top of the posts in accordance with the manufacturer's instructions. Install surface mounted posts to a height of 36 inches [1 $m$ ] from the existing surface to the top of the posts. Install ground mounted posts to a height of 48 inches [1.2 m] from the existing ground to the top of the posts.

Where reflective sheeting is a part of the delineator assembly, provide an assembly having a minimum of 4 by 8 inches [ 100 by $200 \mathrm{~mm}$ ] of reflective sheeting, free of physical damage prior to and after installation Mount the reflective sheeting using pressure sensitive adhesive in accordance with sheeting mamufacturer's requiremerts, to prevent disbonding of the sheeting during the life of the post.

\section{5-4 Method of Mensurement.} and accepted.

The quantity to be paid for will be the number of delineators or object markers furnished, installed

\section{5-5 Basis of Payment.}

Prices and payments will be full compensation for work specified in this Section, including the cost of labor, materials, and incidental items required to complete the work.

Payment will be made under:

Item No. 705- 1-

Item No. 2705- 1 -

Item No. 705- 2-

Delineator, Single Unit - each.

Item No. 2705- 2 -

Delineator, Single Unit - each.

Item No. 705- 3 -

Detineator, Double Unit - each.

Item No. 2705-3-

Item No. 705-10-

Delineator, Double Unit - each.

Delineator, Triple Unit - each.

Item No. 2705- 10-

Delineator, Triple Unit - each.

ltem No. 705-71.

Object Marker - each.

Object Marker - each.

Tubular Delineator (Flexible) - each. 


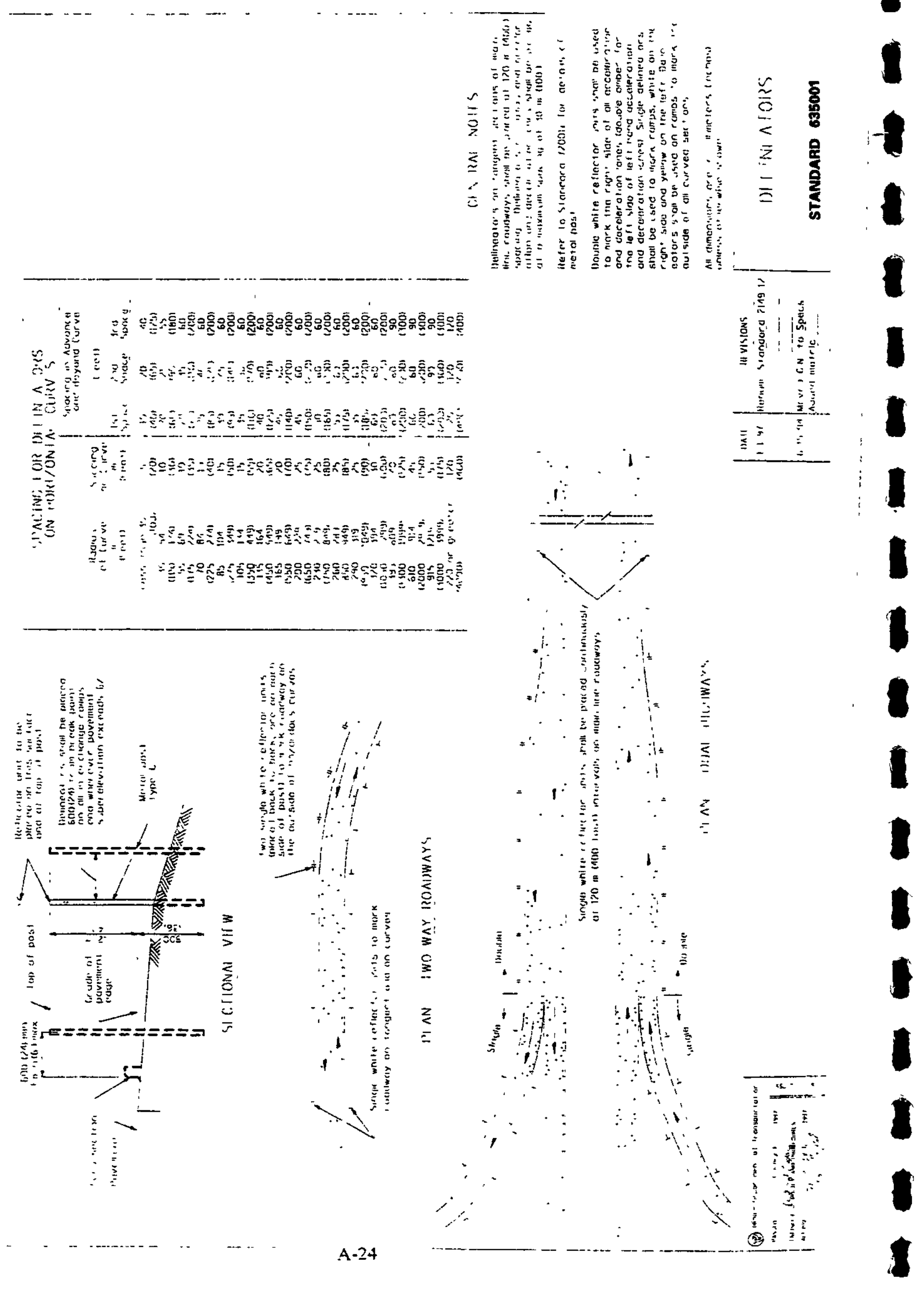




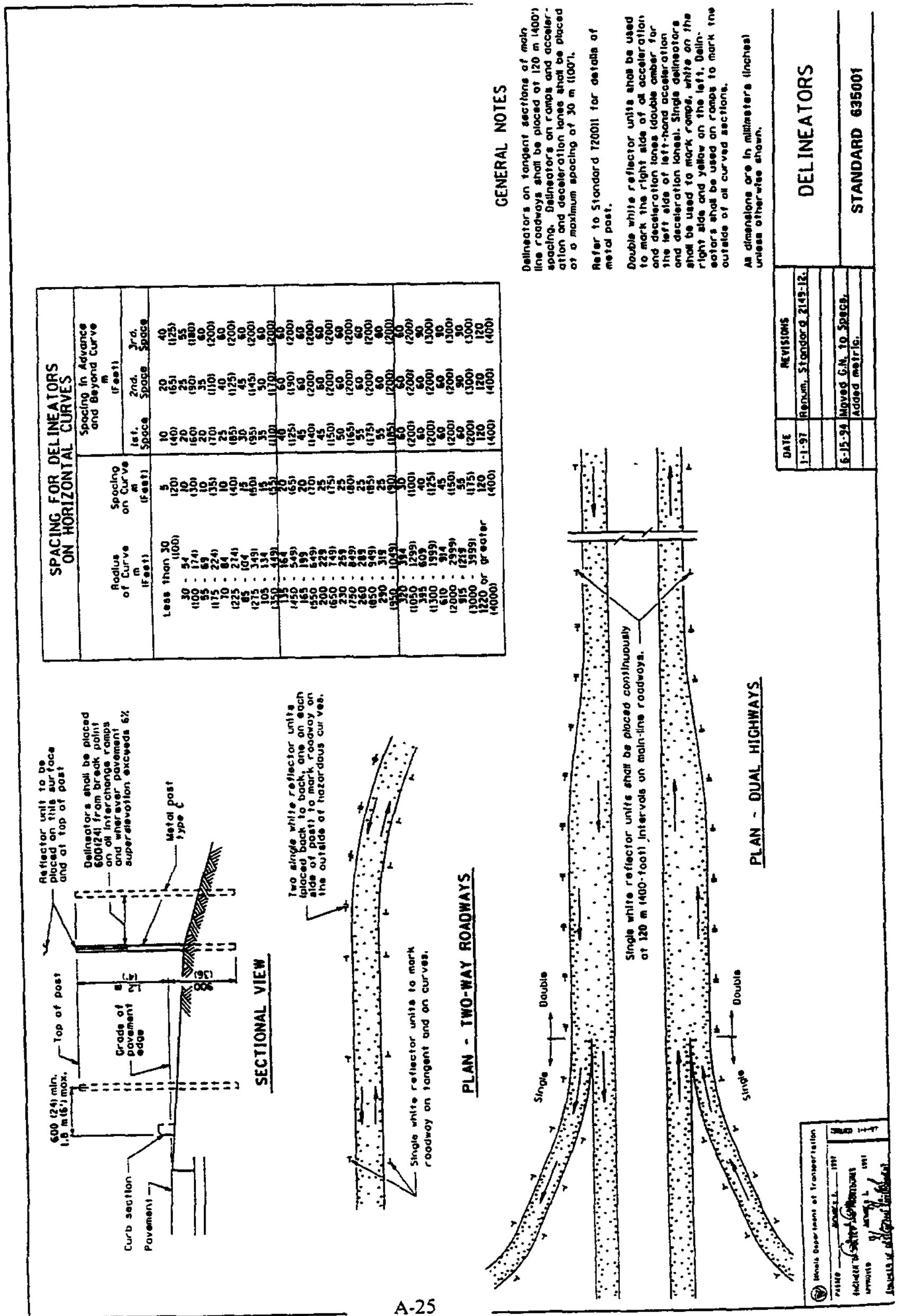




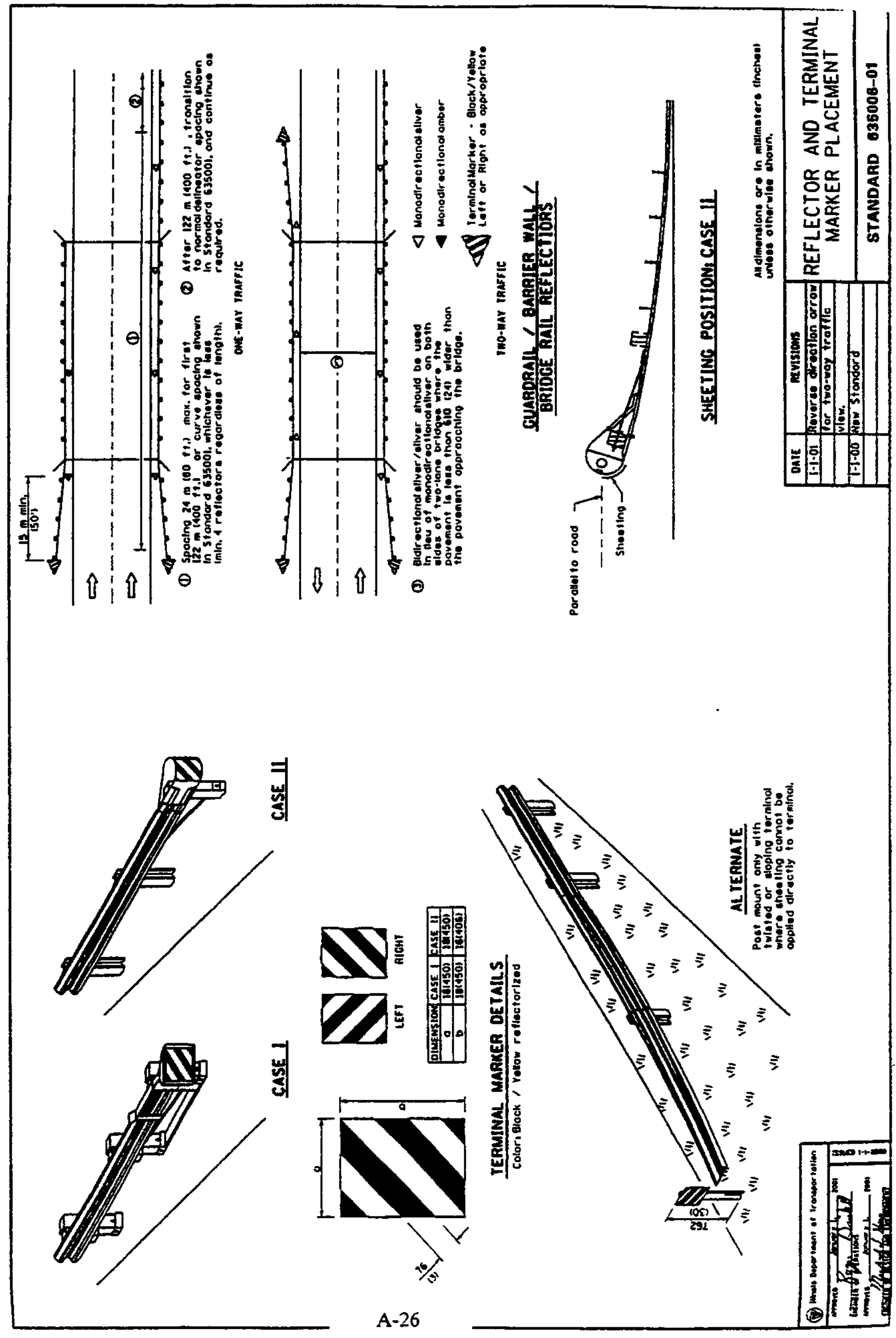




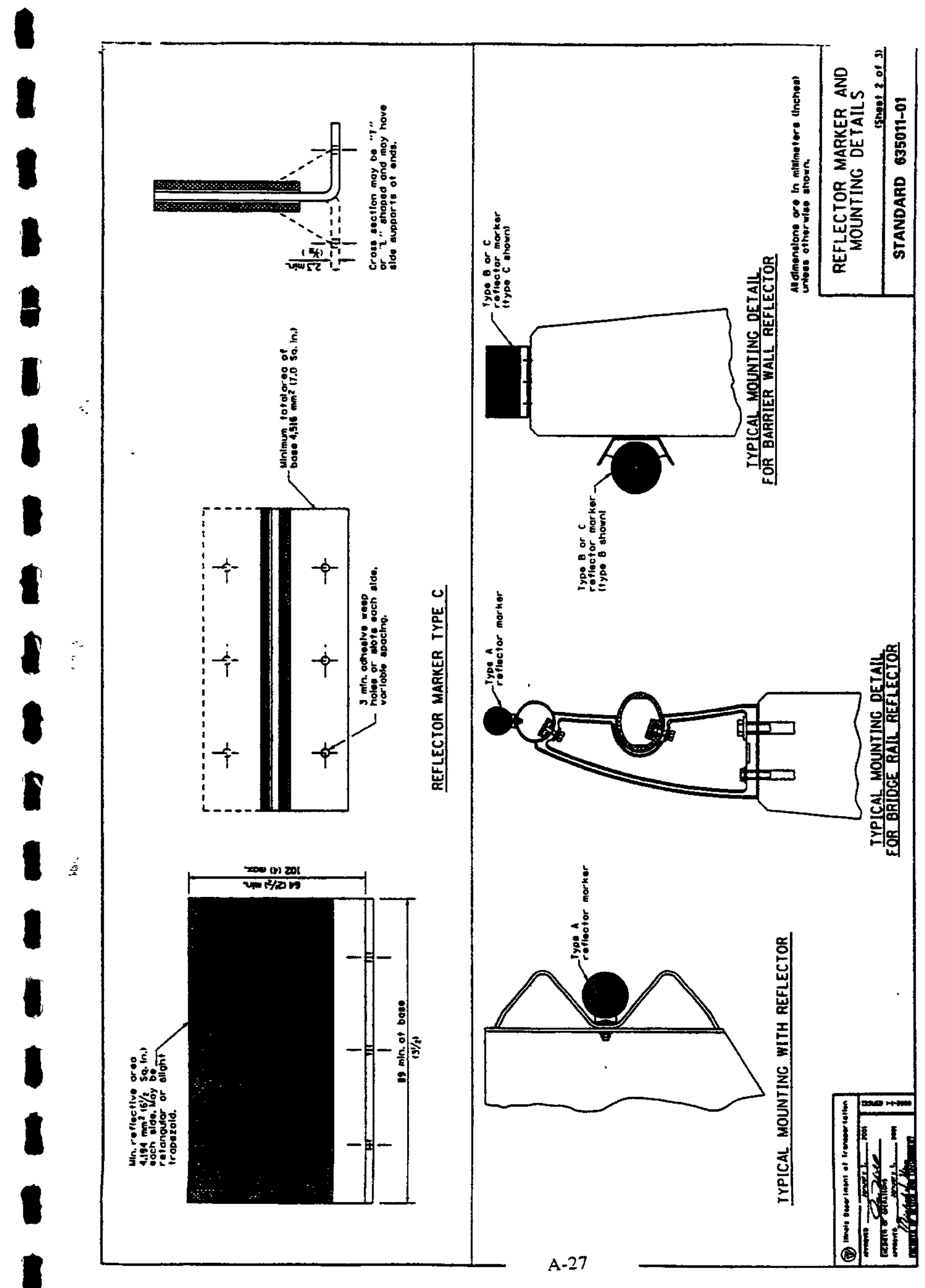




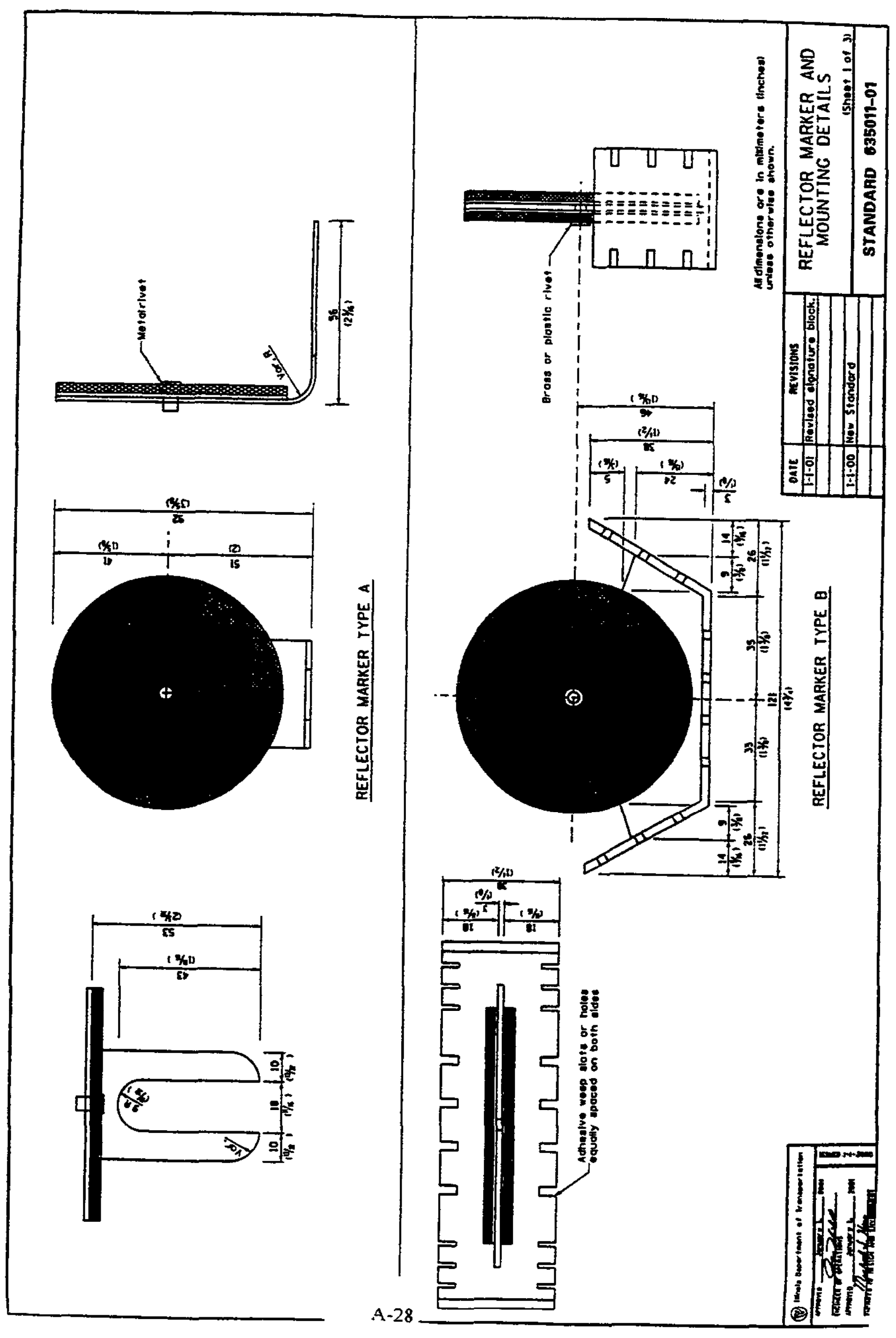




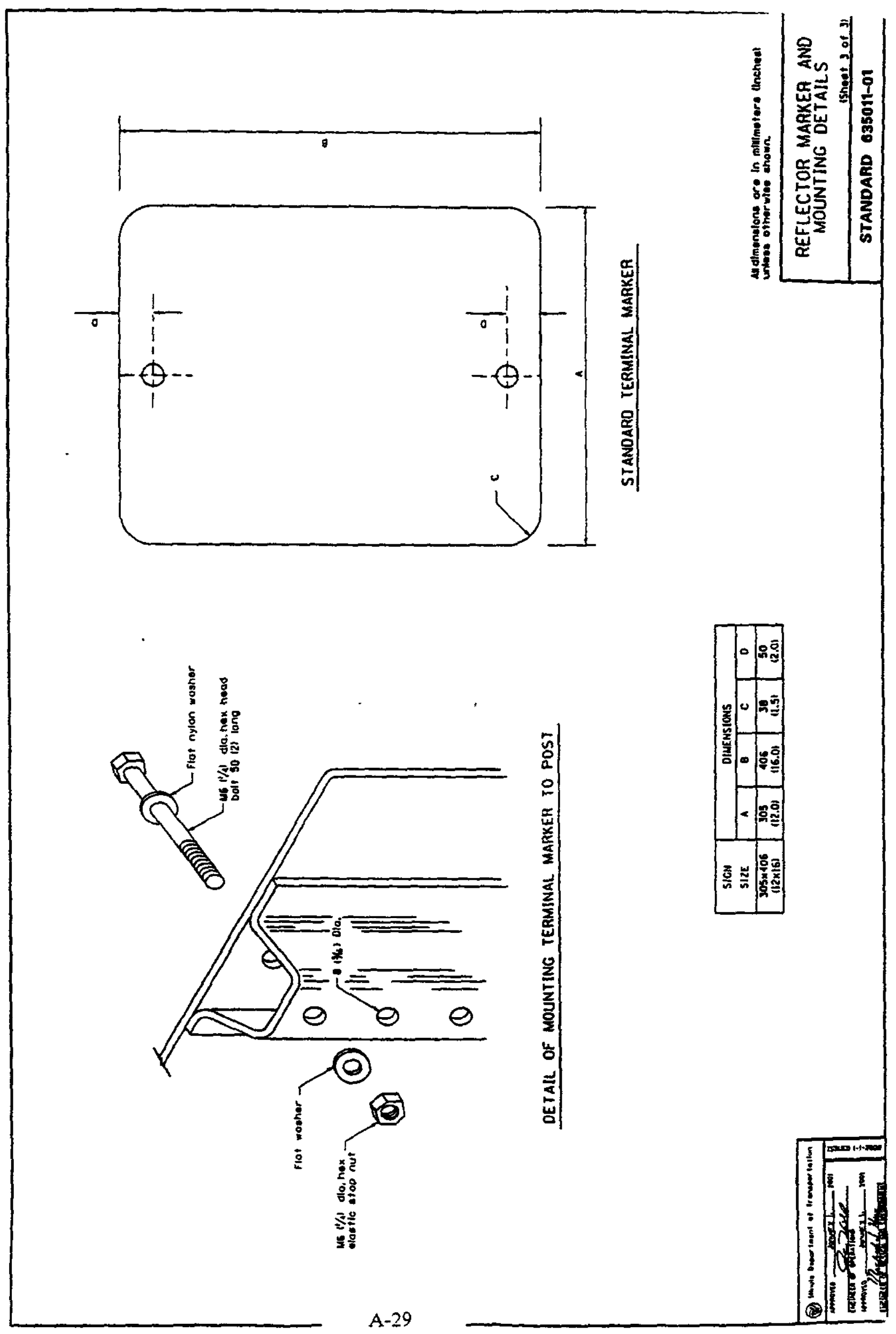




\author{
State of llitinols \\ Department of Transportation \\ SPECIAL PROVISION \\ FOR \\ GUARDRAIL AND BARRIER WALL DELINEATION \\ Effectrve December 15, 1993 \\ Revised January 4.1997
}

Descrnption This work shall consist of fumıshing and installing reflectorized guardrail markers, bridge rail markers, or bamer wall markers complete with reflectors or reflective faces as specified, and terminal marker post. when specried

Matenals. Matenals shall be according to the following

(a) Terminal Marker Post. The posts shall be according to Article 1006.29 of the Standard Specificatons for Type $C$ galvanized posts.

Hardware for attaching sign panels to posts shall be stainless steel and be according to Article 1006.29(d) of the Standard Spectications.

(b) Terminal Markers.

(1) Direct Applied Reflectonzed Teminal Marker Direct applied refiectonzed termunal markers shall be fabncated using Type A or Type AP reflectorized sheeting. All matenals used shall be according to Section 1090 and 1091 of the Standard Spectications.

The sheeting shall be uniform in color throughout and be according to the latest approprate standard color tolerance chart issued by the US. Department of Transportation. Federal Highway Administration of through instrumental color testing, the diffuse day color of the reflective matenal shall be according to Table 1.

TABLE 1

Color Spectication Limits (Daytime)

Type AP

Color

Yellow

\begin{tabular}{ll}
\multicolumn{2}{c}{1} \\
\hline 0498 & $Y$ \\
0.412 \\
0.303 & 0.287
\end{tabular}

\begin{tabular}{ll}
\multicolumn{2}{c}{2} \\
\hline$X$ & $Y$ \\
0557 & 0.442 \\
0.368 & 0.353
\end{tabular}

\begin{tabular}{ll}
\multicolumn{2}{c}{3} \\
\hline$X$ & $Y$ \\
0479 & 0.520 \\
0.340 & 0.380
\end{tabular}

\begin{tabular}{ll}
\multicolumn{2}{c}{4} \\
\hline$X$ & $Y$ \\
0.438 & 0.472 \\
0.274 & 0316
\end{tabular}

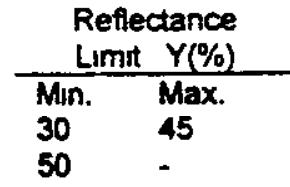

The 4 pairs of chromatiaty coordinates determine the acceptable color in terms of the CIE 1391 standard colorimetre system measured with standard illuminant D 65 .

Type AP sheeting shall have the minimum values shown in Table 1091-1 for the type and coler of matenal specified.

Type AP sheeting surface shall exhibit an 85 degree gloss-meter rating of not less than 50 when tested according to ASTM D 523.

The thickness of Type AP sheetng without protective liner shall not be more than $0.64 \mathrm{~mm}$ (0.025inches)

(2) Post Mounted Reflectorized Terminal Marker. Post mounted reflectonzed markers shall be fabncated using a Type I Sign Panel complete with reffectonzed sheeting The reflectonzed matenal shall be Type A or Type AP Sheeting All matenals used shall be according to Sections 1090 and 1091 of the Standard Specfications. 


\section{CHECK SHEET \#38}

(c) Guardrail and Bamer Wall Markers.

(1) Type A Reflector Makker. The reflectors shall conform to the requirements of Section 1097 of the Standard Specifications.

The steel mountung bracket utlized for attaching reflectors to guardrall shall be fabricated from 12 gauge (minimum) steel, and galvanized according to AASHTO M 111.

The steel banding utlized for attaching reflectors to bndge rall shall be $19 \mathrm{~mm}$ (344 inch) stainless steel banding.

(2) Type B Reflector Marker. The reffectors shall be according to Section 1097 of the Standard Specifications.

The lexan mounting bracket shall be made of high impact lexan approved by the Department The bracket shal be whte or brown in color. Brown brackets shall be specified for use with weathenng M 222 (M $222 \mathrm{M}$ ) steel guardrail applications. and whte brackets shall be specified for all other applications.

(3) Type C Refiector Marker. Molded reflectrve surfaces, when used, shall be according to Section 1090 of the Standard Specrications, except subparagraph (d).

Flexible rellective sheeting faces, when used, shall be fabncated of ether a weather resistant sealed micropnsmatic sheetng or a high-performance reflectuve sheeting meetong the minimum reflective values for ineadence angles of -4 and +30 degrees for Type A sheeting as set forth in Table 1091-1 of the Standard Spectications or the requirements for Type AP sheeting contained herein. The sheeting shall be manufactured by ether $3 \mathrm{M}$. Sumsonsite. Reftexte, or an approved equivalent. The Contractor shall fumish written documentation from the sheeting manufacturer that the sheetung is approved as being compatible for use as a permanent reflector face. The sheeting shall adhere securety to the bracket at temperatures of -34 ${ }^{\circ} \mathrm{C}$ to $+71^{\circ} \mathrm{C}\left(-30^{\circ} \mathrm{F}\right.$ to $\left.+160^{\circ} \mathrm{F}\right)$ and shall not crack when struck at $-23^{\circ} \mathrm{C}\left(-10^{\circ} \mathrm{F}\right)$.

The base material shall be fabricated from high impact themoplastic, lexan, nylon, or other approved matenal which shall not shatter or crack under impact at temperatures of $-34^{\circ} \mathrm{C}\left(-30^{\circ} \mathrm{F}\right)$.

\section{CONSTRUCTION REQUIREMENTS}

(a) Terminal Marker Posts The posts shall be drven by hand or mechanical means to a minimum depth of 900 mm ( $3 \mathrm{nt}$ ) and installed according to the detals shown on the plans or as directed by the Engineer. The top of the post shall be $760 \mathrm{~mm}$ ( 30 inches) above ground. The post shall be protected by a suitable driving cap and if required by the Engineer, the matenal around the post shall be compacted aner driving. The posts shall be vertical and onented so the face of the terminal marker shall be at 90 degrees to the center tine of the adjacent pavernent.

Scratching, chipping, or other damage to the post shall be avoided during handling and installation. Chips and scratches may be recoated in the field by a method meeting the coating manufacturer's recommendation except chips and scratches totaling more than 5 percent of the surface area of any one post andlor more than 5 percent of the surface area in $305 \mathrm{~mm}$ ( $1 \mathrm{~h}$.) segment of any one post shall be cause for rejection of the post.

(b) Terminal Markers.

(1) Direct Applied Refiectorzed Teminal Marker. The direct applied reflectonzed guardrail terminal markers shall be unstalled directly on the guardrail nose. The marker shall be installed as shown on the plans and directly to the guardrail terminal end. The surface of the guardrail terminal end shall be cleanod of all contaminants pnor to the installation of the terminal marker. The surface shall be cleaned using a 5.8 percent phosphonc acid solubon and tinsed with clean water or as recommended by the manufacturer of the direct appled terminal marker sheeting and as approved by the Engineer.

(2) Post Mounted Reflectonzed Terminal Marker Post mounted reflectorzed terminal markers shall be installed on terminal marker posts. A minimum of 2 bolts per post shall be required for reflectonzed teminal marker panel attactment.

(c) Guardrall and Barner Wall Markers. 
(1) Type A Reflector Marker Type A reflector marker shall be installed on guardrall or bridgerall as shown on the plans When installed on guardrail, bolts for fastening will be required The bolt-on guardrall marker shall consist of 1 or 2 round pnsmatic reflectors as specified attached to a steel mounting bracket. The reflector(s) shall be securely fastened to the bracket wnth an aluminum rvet When used with "W" section guardrail, it shall be attached by loosening a guardral bolt, then slipping the slotted bracket under the head of the both and retrghtening the bolt

Type A Reflective Markers stall be used on oval or carcular bridge rals. The marker shall be attached to the bndge rail using stanless steel banding

The face of the marker shall be vertical and onented so the reflector face shall be at 90 degrees to the centerine of the guardrail web, or to the centerline of the bndge rail.

(2) Type B Reflector Marker. Type B reflector marker shall be installed on the concrete bamer wall or guardrail, as shown on the plans, using an adhesive The direct applied marker shall consist of 1 or 2 round pnsmatic reflectors as specified attached to a lexan mounting bracket The locations for mounting the markers on bamer walls shall be as directed by the Engineer

The surface of the guardrail or the barrier/bndge parapet wall to which the marker is to be applied shall be free of foreign matter and any matenal which would adversely affect the bond of the adhesive Cleaning of the surfaces shall be to the satısfaction of the Engineer

An adhesive meeting the reflector unit manufacturer's spectications shall be placed erther on the surface or the botton of the marker in sufficient quantity to ensure complete coverage of the contact area with no voids present and with a slight excess after the marker is pressed firmly in place.

The face of the marker shall be vertical and onented so the reflector face shall be at 90 degrees to the centertine of the guardrail web, or to the surface of the barrier.

(3) Type C Reflector Marker Type C reflector marker shall be installed on concrete barrier wall as shown on the plans. The direct applied bamer wail marker shall consist of 1 or 2 reflective surfaces as specified applied to a base fabricated of suitable matenal.

Basis of Payment This work will be paid for at the contract unit pnce each for TERMINAL MARKER. DIRECT APPLIED, TERMINAL MARKER-POST MOUNTED, TERMINAL MARKER POSTS, and GUARDRAIL MARKERS and BARRIER WALL MARKERS of the types and lens color specified.

The cost of work and material involved to perform any necessary alterations to the embedment length of the terminal marker post shall be included in the contract unit pnce bid for Termunal Marker Posts. 


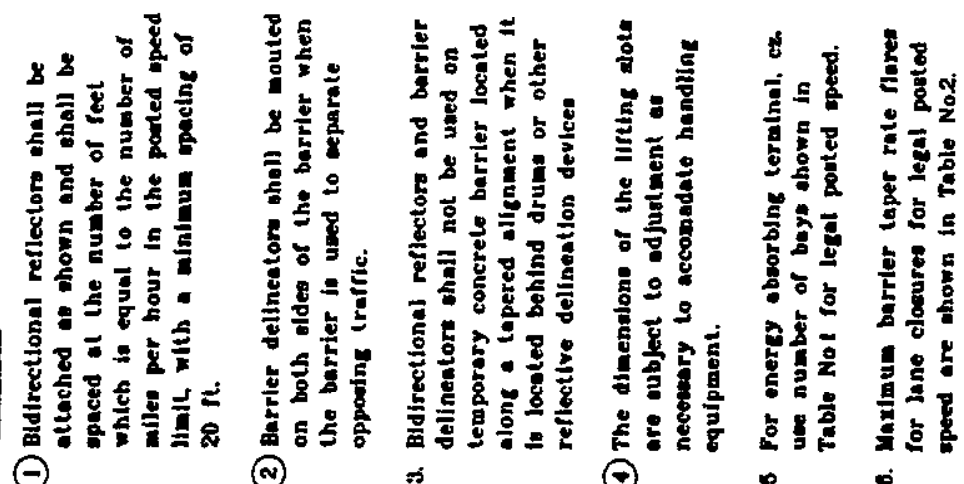

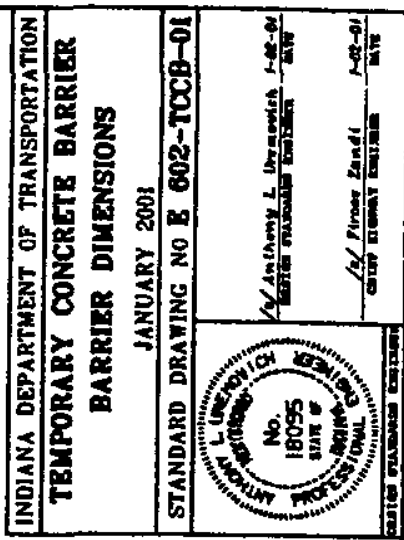

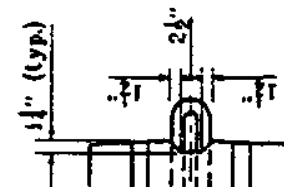

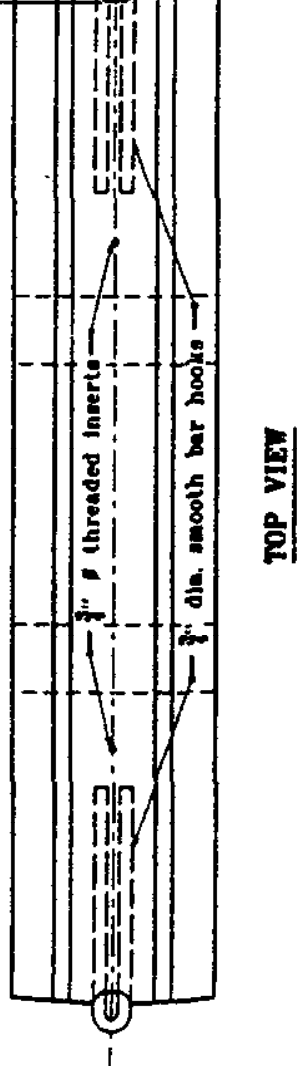

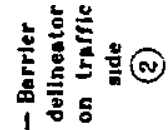
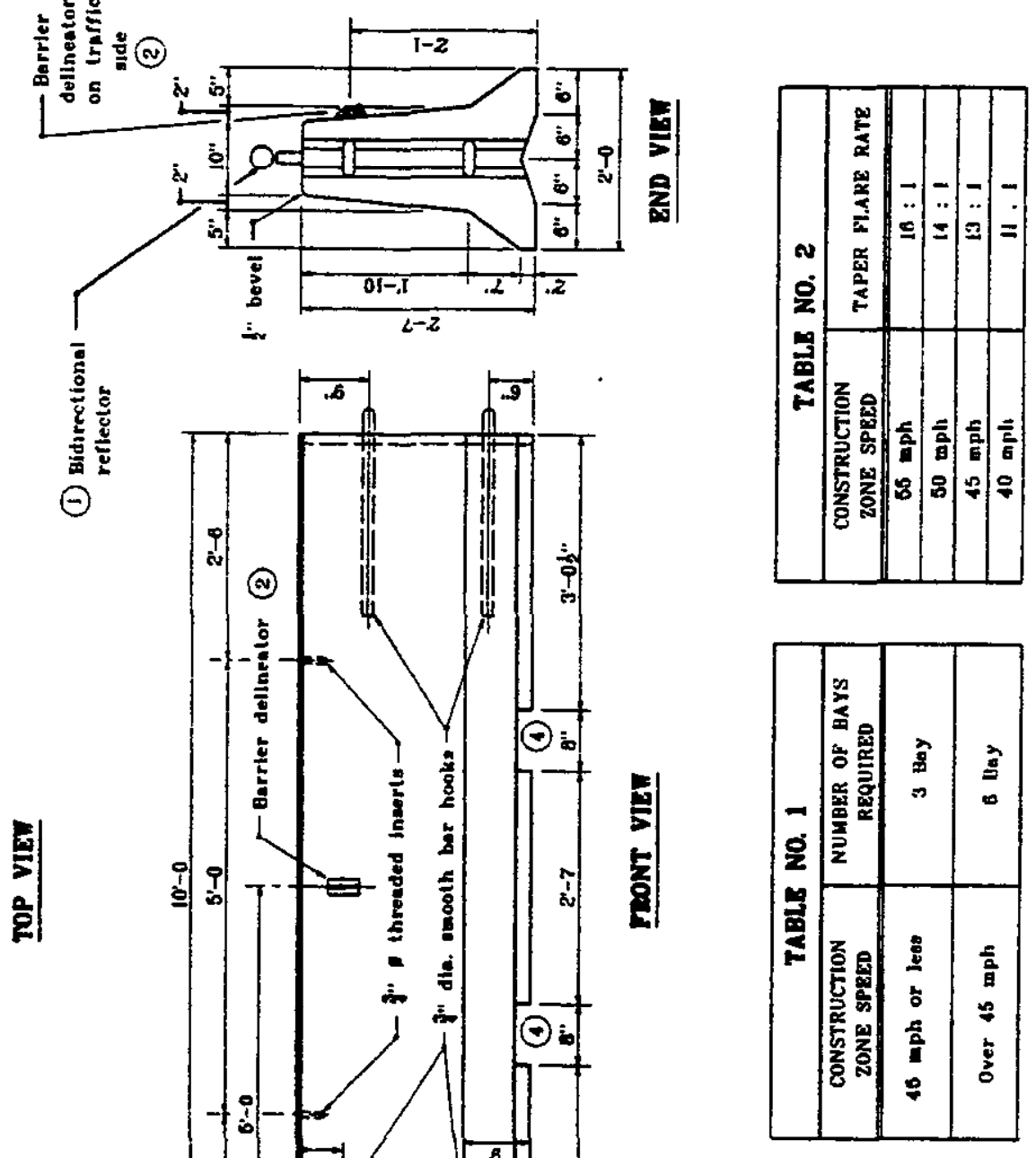
All welders and welding operators shall be previously qualified by tests in accordance with Part B. Section IX, of the ASME Boiler and Pressure Vessel Code. Evidence of previous qualification of the welders and welding operators to be employed may be accepted. The same process and type of equipment that is required for execution of the contract work shall be used in qualifying welders and welding operators.

\section{SECTION 804 -- DELINEATORS}

804.01 Description. This work shall consist of furnishing and erecting delineators in accordance with 105.03 and 107.12. Delineators shall be installed as required unfess approval is obtained from the District Traffic Engineer to make modifications.

\section{MATERIALS}

804.02 Materials. Materials shall be in accordance with the following:

Delineator Posts

Flexible Delineator Posts

Delineators

The types of delineators shall be:

(a) D1 - single;

20

(b) D2 - double;

(c) D3 - triple.

Hardware for mounting delineators on posts shall be aluminum alloy in accordance with $913.10(\mathrm{e}) 2$; stainless steel or galvanized steel in accordance with 913.10(e)1; or aluminum pull-through blind rivets. Bolts and lock- nuts or rivets shall be $4.8 \mathrm{~mm}(3 / 16$ in.) diameter.

\section{CONSTRUCTION REQUIREMENTS}

804.03 Delineator Visibility. Delineator reflector units shall be positioned so as to be visible for a distance of $300 \mathrm{~m}$ (1000 ft) on tangent sections or at maximum visibility distances on curves. These locations shall be established under normal weather and atmospheric conditions when illuminated by the upper beam of standard automobile headlights.

804.04 Posts. Posts shall be installed in accordance with 802.07.

804.05 Flexible Delineator Posts. These posts shall be installed according to the manufacturer's recommendations and shall be set so that the top is no more than $13 \mathrm{~mm}$ (1/2 in.) from any vertical plane through the bottom. 
804.06 Method of Measurement. Delineators with posts, delineator posts, and flexible delineator posts will be measured by the number of units of the type specified.

804.07 Basis of Payment. The accepted quantities of delineators, delineators with post, delineator post, and flexible delineator post, if set out as a separate pay item, will be paid for at the contract unit price per each for the type specified, complete in place.

Payment will be made under:

Pay Item

Pay Unit Symbol

Delineator EACH

Delineator Post EACH

Delineator Post, Flexible. EACH

Delineator with Post. EACH

Where new delineator posts are installed to replace existing delineator posts, the cost of the removal of the existing post shall be included in the cost of the new post.

\section{SECTION 805 .- TRAFFIC SIGNALS}

805.01 Description. This work shall consist of furnishing miscellaneous materials, not furnished by the Department, and installing traffic signals in accordance with these specifications and in reasonably close conformance with the lines, grades, and locations shown on the plans or as directed.

\section{MATERIALS}

805.02 Materials. Materials shall be in accordance with the following:

Aggregate, Class A, B, C, D, or E size No. 8 904.02

Castings for Handhole

Concrete, Class A, B, or C

Reinforced Concrete Pipe

Traffic Signal Materials and Equipment

Treated Lumber 911.02

The proposed work shall be examined in order to determine what materials not furnished by the Department are required to complete the contract. The Department will furnish only the materials specified on the Department Furnished Materials special provision. If materials to be furnished by the Contractor are listed, the list is only a guide for estimating purposes. All additional materials required to complete an operating installation as specified shall be furnished. 
The color of the post and the reflective sheeting shall match the color of the adjacent edgeline.

When installed, the flexible post shall withstand, without damage, five vehicle impacts at ambient air temperatures of $0^{\circ} \mathrm{C}\left(32^{\circ} \mathrm{F}\right)$ and at $30^{\circ} \mathrm{C}\left(85^{\circ} \mathrm{F}\right)$ each. The vehicle impacts shall include both bumper and tire impacts It shall be able to bend to an angle of 85 degrees from vertical and right itself to within 10 degrees of the vertical immediately and stand erect within $\mathbf{4 h}$ within the same ambient air temperature range.

Only flexible delineator posts from the Department's list of approved Flexible Delineator Posts shall be used. Flexible delineator posts will be placed and maintined on the Department's approved list in accordance with ITM 806, procedure G.

913.07.1 Tubular Marker. The vertically placed portion of this device shall consist of high density polyethylene plastic in accordance with ASTM D 5203. The base material shall be butyl rubber in accordance with ASTM D 5900 or high impact polystyrene in accordance with ASTM D 4549. Epoxy material used to attach the base to the roadway surface shall be in accordance with the manufacturer's recommendations. The tubular portion shall be covered with high intensity reflective sheeting in accordance with $913.10(\mathrm{~b})$.

\subsection{Delineators.}

(a) Acrylic Plastic Delineators. Acrylic plastic delineators shall consist of a hermetically sealed optical system with a circular plastic face and prismatic molded rear surface. The optical system shall have a minimum diameter of $75 \mathrm{~mm}(3 \mathrm{in}$.) with a minimum area of approximately $4520 \mathrm{~mm}^{2}\left(7 \mathrm{in}\right.$. ${ }^{2}$. The trademark of the manufacturer shall be molded legibly into the face of the lens. Color shall be clear, red, or yellow in daylight as well as when viewed by reflected light at night. Photometric or optical requirements shall equal or exceed the following minimum values:

\begin{tabular}{|c|c|c|c|c|}
\hline \multirow{2}{*}{$\begin{array}{l}\text { Observation Angle } \\
\text { Degrees }\end{array}$} & \multirow{2}{*}{$\begin{array}{l}\text { Entrance Angle } \\
\text { Degrees }\end{array}$} & \multicolumn{3}{|c|}{$\begin{array}{c}\text { Specific Intensity } \\
\text { Candelas/ux (candle power/footcandle) }\end{array}$} \\
\hline & & Clear & Yellow & Red \\
\hline 0.1 & 0 & $11.1(119)$ & $7.3(79)$ & $2.6(28)$ \\
\hline 0.1 & 20 & $4.4(47)$ & $2.6(28)$ & $1.0(11)$ \\
\hline
\end{tabular}

Note: The observation angle is the angle at reflector between the observer's line of sight and firection of light incadent on reflector. The entrance angle ts the angle $a$ the refiector between the direction of ligh lacident on it and the direction of refector axis. The spectic thensity is the condepower returned a the chosen observation angle by a reflector or refleative surface for each lux (footande) of Dunination at the reiector.

The opaque backing shall be made from aluminum sheet having a minimum thickness of $0.50 \mathrm{~mm}(0.02 \mathrm{in}$.). The backing shall form an integral part of the delineator and shall retain the optical system securely. A single aluminum grommeted hole in the center of the reflector shall be provided for mounting. The inside diameter of the grommet hole shall be $5 \mathrm{~mm}$ ( $3 / 16 \mathrm{in}$.). 
Only acrylic plastic delineator models and colors from the Department's list of approved Delineators shall be used. Acrylic plastic delineators will be placed and maintained on the Department's approved list in accordance with ITM 806, procedure G.

(b) Reflective Sheeting Delineators. Reflective sheeting delineators shall consist of reflective sheeting affixed to an aluminum backing material. The white delineator shall be $75 \mathrm{~mm}$ by $200 \mathrm{~mm}$ ( 3 in. by $8 \mathrm{in}$.) $\pm 3 \mathrm{~mm}( \pm 1 / 8 \mathrm{in}$.). The yellow delineator shall be $125 \mathrm{~mm}$ by $125 \mathrm{~mm}$ ( 5 in. by $5 \mathrm{in}$.) $\pm 3 \mathrm{~mm}( \pm 1 / 8 \mathrm{in}$.). The backing material shall be in accordance with 913.10 (a) except the minimum thickness shall be $1.6 \mathrm{~mm}(0.064 \mathrm{in}$.). Reflective sheeting shall be in accordance with $913.10(\mathrm{~b})$.

There shall be two mounting holes, $5 \mathrm{~mm}(3 / 16 \mathrm{in}$.) in diameter, with one at the top and one at the bottom. The holes shall be $150 \mathrm{~mm}(6 \mathrm{in}.) \pm 2 \mathrm{~mm}(1 / 16 \mathrm{in}$.) center to center for the rectangular shape. Holes shall be $125 \mathrm{~mm}(5 \mathrm{in}) \pm 2 \mathrm{~mm}(1 / 16$ in.) center to center and in the corners of the square units. Completed delineators shall be dip coated with a high gloss clear finish coat as specified and supplied by the sheeting manufacturer. The finished units shall be clean cut, sharp, and have essentially a plane surface.

Material furnished under this specification shall be covered by a type $C$ certification in accordance with 916 .

(c) Barrier Delineators. The delineators shall consist of a transparent acrylic plastic face, herein referred to as the lens, and an opaque back fused to the lens under heat and pressure around the entire perimeter to form a unit permanently sealed against dust, water, and water vapor. The reflector lens shall be colorless.

The lens shall consist of a smooth front surface free from projection or indentations other than for purposes of identification or orientation of the reflector. The rear surface shall have a prismatic configuration such that it will effect total internal reflection of light. The manufacturer's trademark shall be molded legibly into the face of the lens.

The reflector lens, having a minimum effective reflex area of $4194 \mathrm{~mm}^{2}$ (6.5 in.). shall be methyl methacrylate in accordance with Federal Specification LP.380C, type 1, Class 3. Photometric or optical requirements shall equal or exceed the minimum values in $913.08(a)$.

Only barrier delineator models and colors from the Department's list of approved Delineators shall be used. Barrier delineators will be placed and maintained on the Department's approved list in accondance with ITM 806, procedure G.

913.09 Glass Beads. Glass beads shall be in accordance with AASHTO M 247. Type I except sampling shall be in accordance with the frequency manual. The beads shall have a moisture resistant coating. 
STANDARD SPECIFICATIONS

FOR

ROAD AND BRIDGE CONSTRUCTION

EDITION OF 2000

Approved for January 1,2000

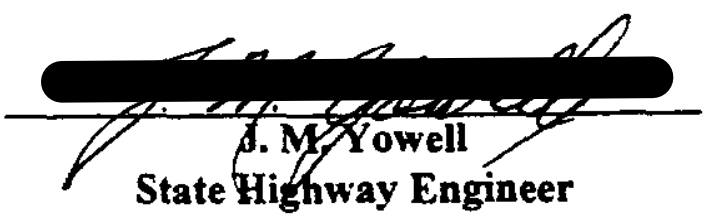

Copies of this publication may be obtained from:

Transportation Cabinet Department of Administrative Services

Division of Management Services

State Office Building

Frankfort, Kentucky 40622

(502) 564-6927 


\section{$k=1-1 \mathrm{Ck}\}$ \\ SECTION 508 - PERMANENT CONCRETE MEDIAN BARRIERS}

998.01 DESCRIPTION. Prepare the foundation for the median bartier; furnish, place, consolidate, finish, and cure the barrier; construct all transverse joints; construct other incidentals necessary to complete the work; and attach delineators and other appurtenances when specified in the Contract.

508.02 MATERIALS AND EQUIPMENT.

508.02.01 Concrete. Conform to Subsection 601.02 and 601.03 .

508.02.02 Steel Reinforcement. Conform to Section 811 .

508.92.03 Joint Material. Conform to Section 807, preformed fillers.

508.02.04 Dowel Bars. Conform to Section 811 .

508.02.05 Tie Bars for Precast Sections. Conform to Section 811 .

508.02.06 Mortar Sand. Conform to Section 804.

508.02.07 Cement. Confom to Section 801 .

508.02.08 Water. Conform to Section 803 .

508.02.09 Masonry Coating. Conform to Section 828.

508.02.10 Delineators for Barriers. Lise Sumsonite Marker 962, AKT Corporation Marker No 181 , or a Department approved equal.

508.02.11 Forms. Conform to Subsection 601.02. In addstion to the requirements for slip forms, use a slip form or extrusion machine that is equipped with automatic guidance controls capable of sensing grade and alignment from an outside reference consistung of a taut line or wire

508.03 CONSTRUCTION. Construct concrete median barriers of each type to the lines, grades, cross section, and detalls specified in the Plans and Standard Drawings. Use Class A concrete according to Subsection 601.03. When it is necessary to transition the concrete median bartier into a section different from the uniform section specified in the Plans, such as at a bridge pier, sign pedestal, or bridge end wall, do so in a smooth, uniform manner as shown on the Standard Drawings. Provide concrete median bamer that are precast, cast-in-place using fixed forms, or slip formed according to Subsection 601.03.12.

Bevel the upper longitudinal edge of the barier $7 / 8$ inch, or construct it to a radius satisfactory to the Engineer.

When required, construct items such as delineators and conduit according to the Contract. Secure conduit to prevent movement.

Cure cast-in-place concrete median bartiers according to Subsection 501.03.15. Use the same method of curing on each contunuous section of the barier. Cure precast concrete median barners according to Subsection 605.03.05.

508.03.01 Fixed Form Construction. Construct 12-inch transverse expansion joints throughout the entire eross section at unifom intervals of no less than 15 feet or greater than 25 feet For construction in conjunction with PCC pavements, locate transverse expanston joints so that a joint occurs at the same stations as that of the ngid pavement transverse joints. Construct additional transverse contraction joints in the bamer 

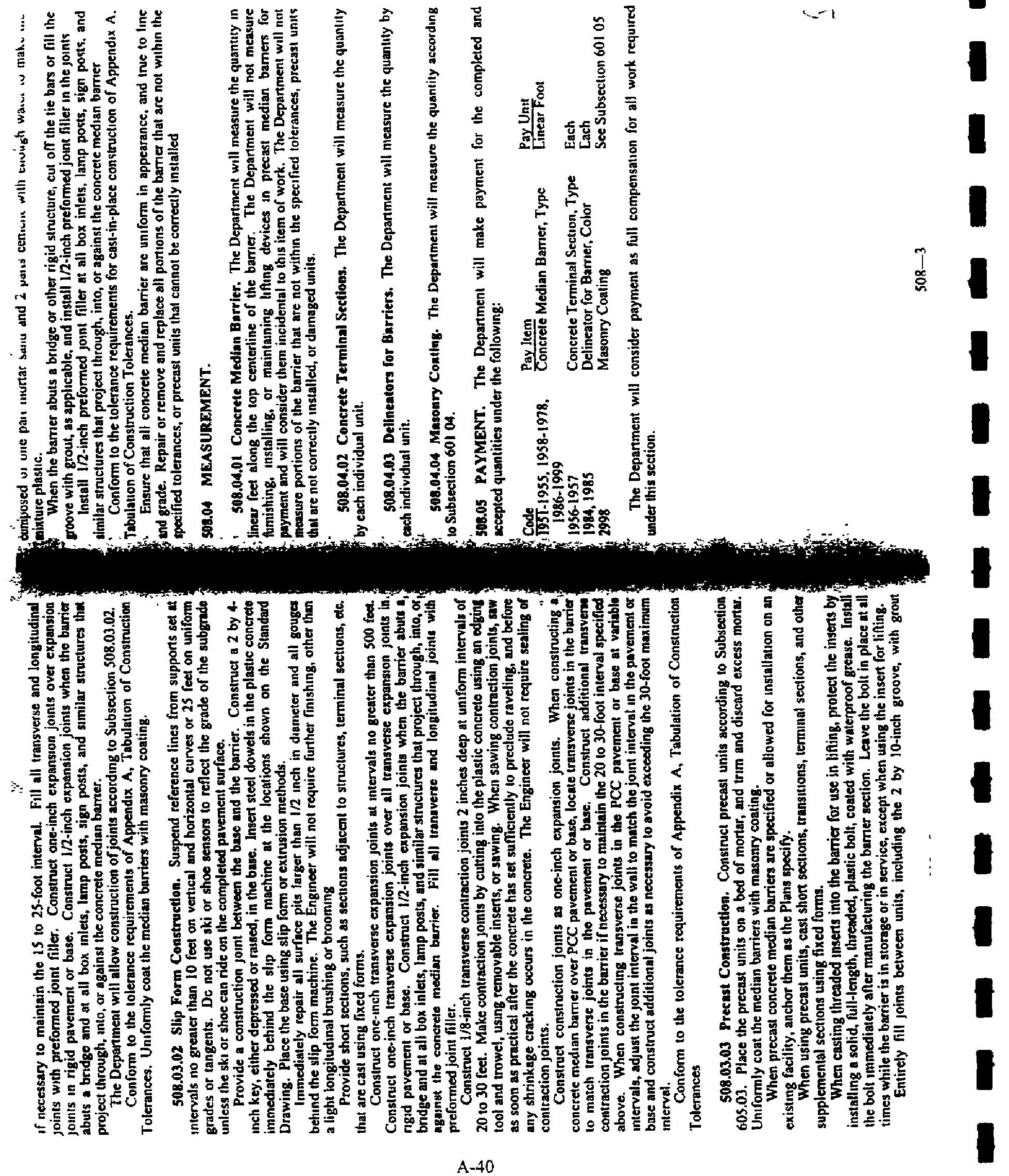


\section{STANDARD DRAWINGS}

\section{COMMONWEALTH OF KENTUCKY}

\section{TRANSPORTATION CABINET}

1998

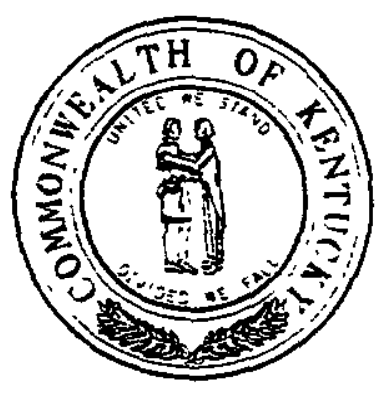

ISSUED BY KENTUCKY DEPARTMENT OF HIGHWAYS

FRANKFORT, KY.

GENTURY THANO- 


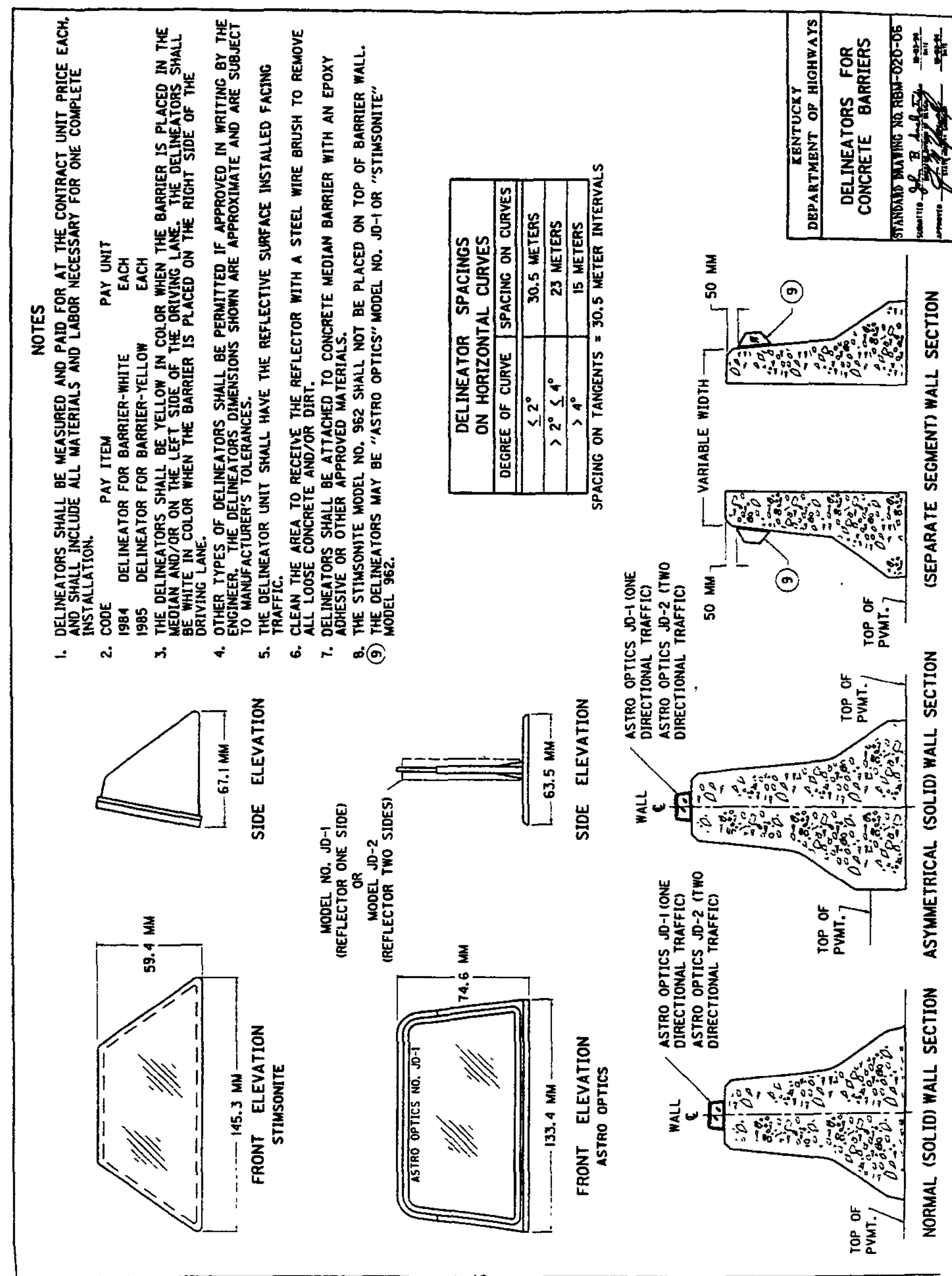




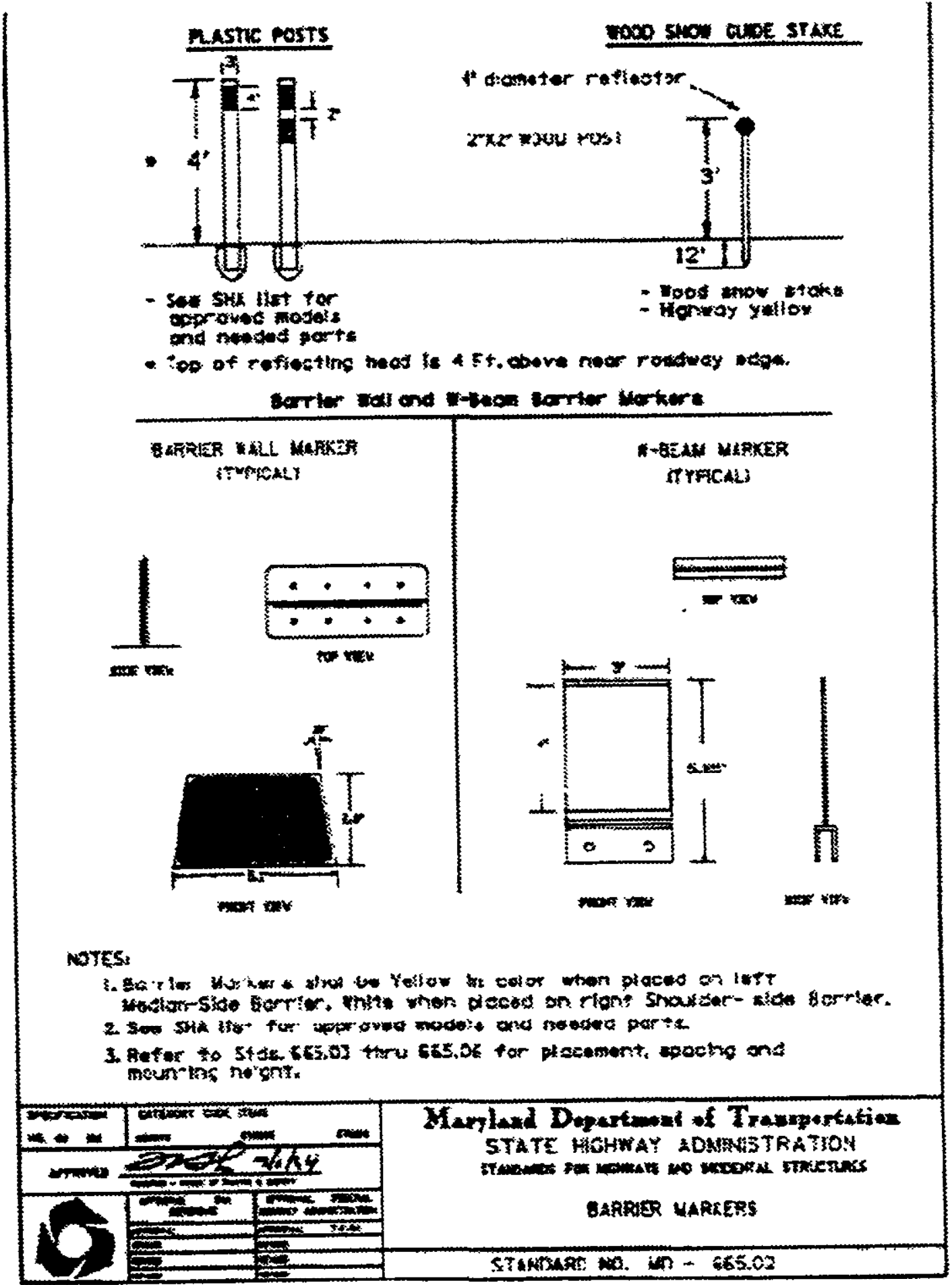




\section{Delneotion Preament}

satesis

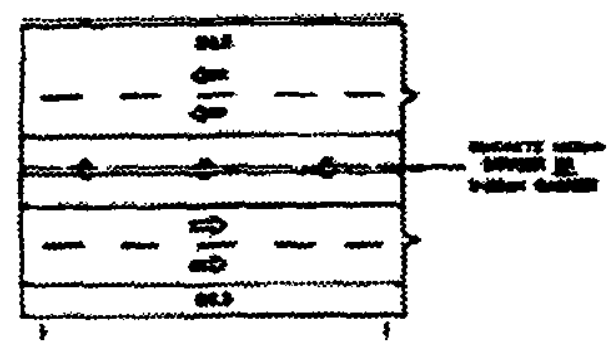

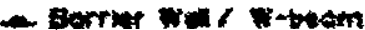

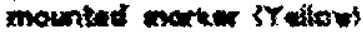

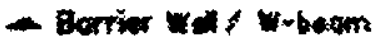

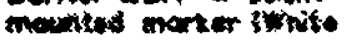

- Font morated diseator

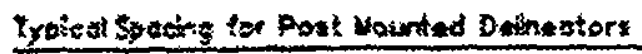

womine - 264

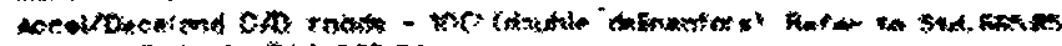

Surot - Reter 30 Std sestas

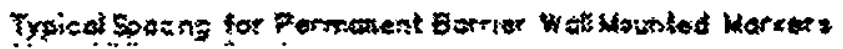

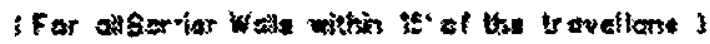

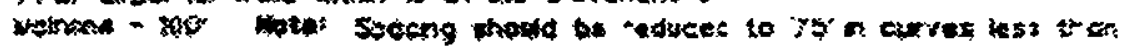

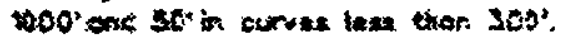

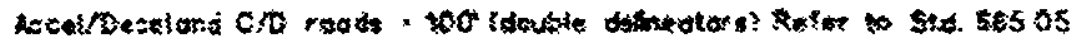

nomes Rerer to sti. 6es.ce

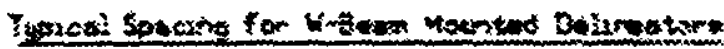

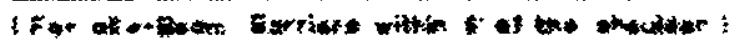

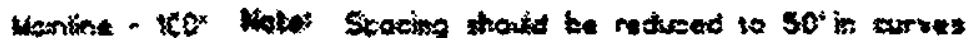

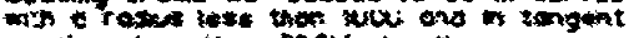

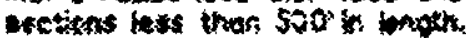

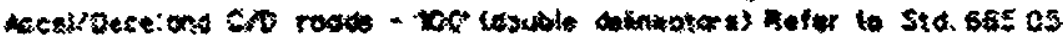

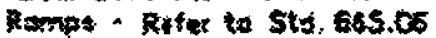

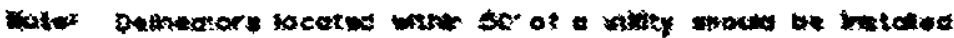

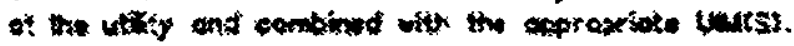

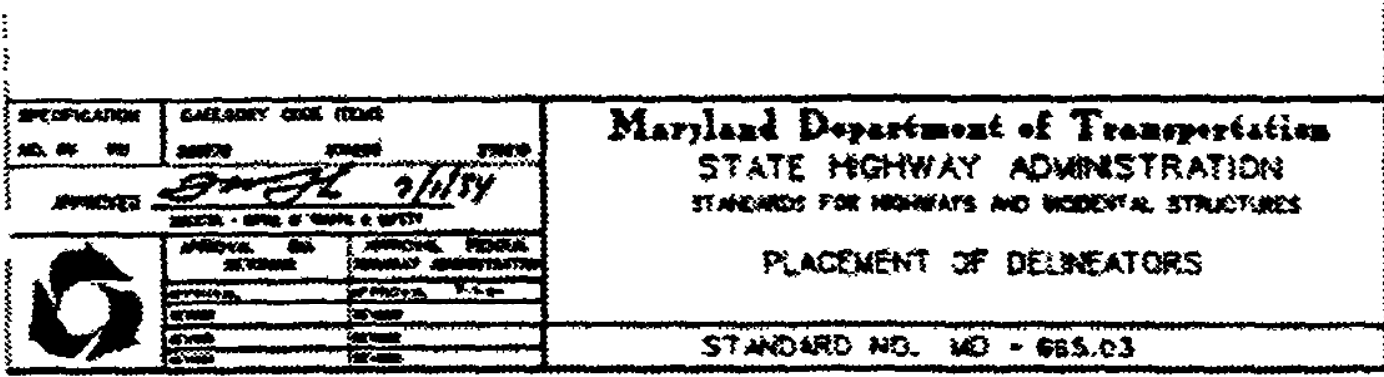




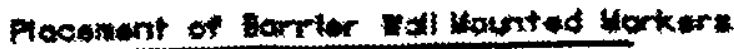

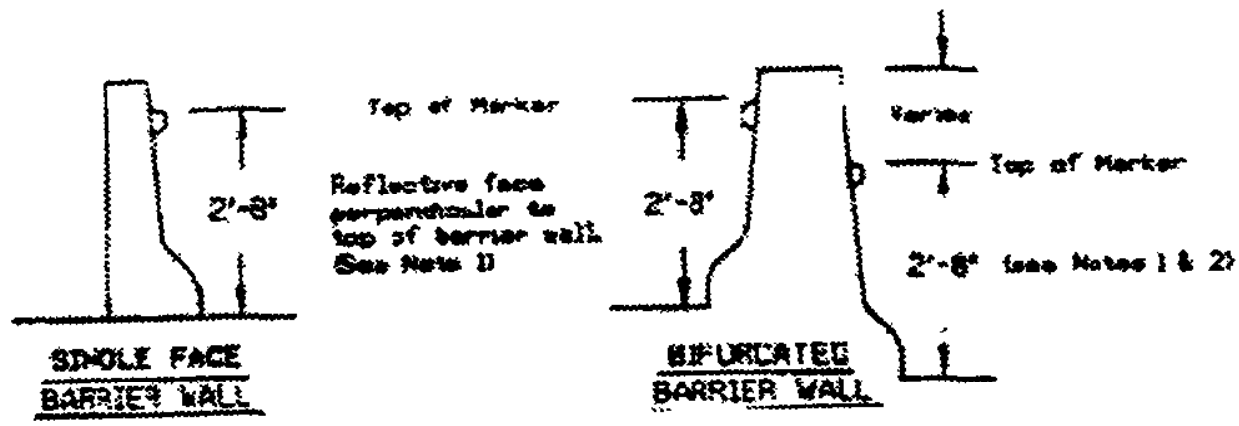

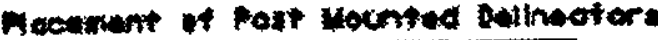

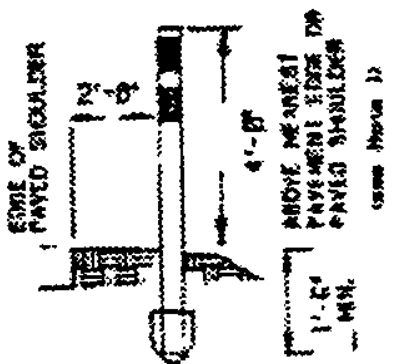

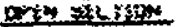
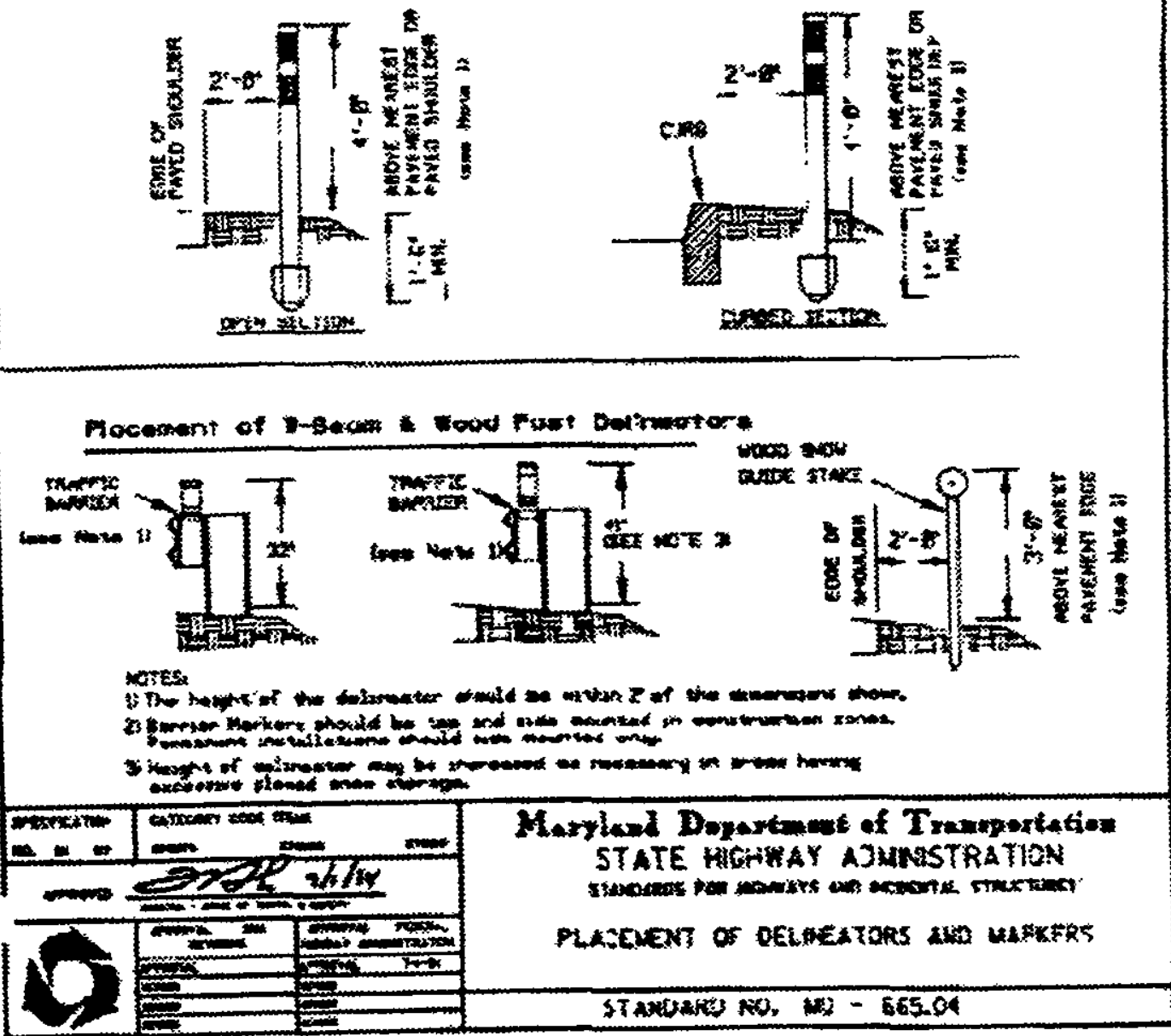


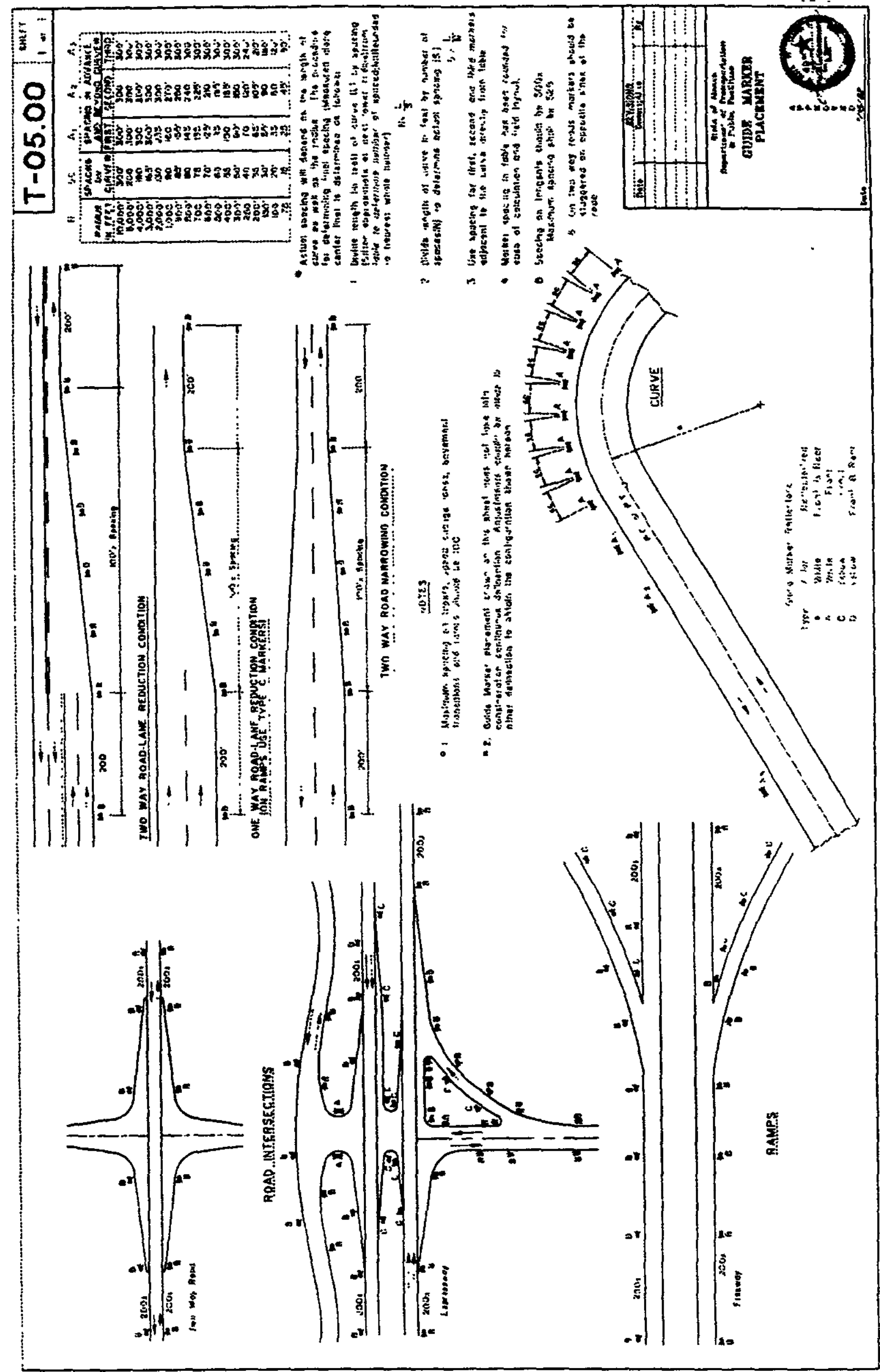


S- .2 Measurement will be made by the number of drum-like channelizers furnished and installed as specified. (Replacement barrels will also be measured for payment.) Payment will be made under Item 2563.603 (Channelizer Barrel) at the Contract bid price per each, which shall be compensation in full for all costs incidental thereto.

$\underline{\text { SP5-240 }}$

S- $\quad$ (2563) MEDIAN BARRIER DELINEATOR

This work shall consist of furnishing, installing and maintaining barriet delineators on median barriers in accordance with the provisions of Mn/DOT 2564, the details shown in the Plans, and the following:

S- .1 The reflectors shall be one of the following (7-7/8" X 4-1/2" in size) or an approved equal, or a substinute barrier at a closer spacing, as directed by the Engineer:

A) Davidson Portable Concrete Barrier Marker

Davidson Plastic Co.

18726 East Valley Hwy.

Kent, Washington 98032

B) Guardrall and Barrier Delineator, 965, Simsonite

Signals Products Division, Amerace Corp.

7542 North Natchez Avenue

Niles, Il 60648.

C) Reflexite Barrier Mount Delineator

Reflexite Corp.

315 South Street, P.O. Box 1628

New Britain, Conn. 06050

D) Duraflex Flexx 2020 Barrier Delineator

Duraflex Corp.

297 Margaret King Ave.

Ringwood, N.J. 07456

S- .2 Measurement will be made by the number of barrier delineators furnished and installed as specified. Payment will be made under Item 2563.603 (Median Barrier Delineator) at the Contract bid price per each, which shall be payment in full for all costs involved. 


\section{7-5.06.02 Narrow Bridges; One Lane Bridges}

A narrow bridge shall be defined as any of the tollowing:

- A bridge with a minimum driving surface width greater than $5.5 \mathrm{~m}$ (18 feet) and less than the roadway approach width (not including shoulders).

- A bridge where engineenng judgment of approach grades, curvatures, number of trucks or other considerations justıfies a narrow bridge classification.

Narrow bridges should be marked and delineated as shown in Figure 7.27.

A one-lane bndge is defined as any bridge having a clear opening width of $5.5 \mathrm{~m}$ (18 feet) or less. One-lane bridges shall be marked and delineated as shown in Figure 7.28.

\section{7-5.06.03 Cattle passesiLarge Culverts}

Cattle passes and larget culvers that meet one of the following descriptions are subject to the provisions of this subsection.

- headwalls are present and are not protected by guardrail, subject to engineenng judgement

- minimum width of $1 \mathrm{~m}$ (42 inches) and a maximum width of $6 \mathrm{~m}$ ( 20 feet). Large culverts ( $6 \mathrm{~m}$ [ 20 feet] or wider) may be treated as a bridge, subject to engineering judgement.

- any culvert with an end or opening that is within $2.5 \mathrm{~m}$ (8 feet) of the shoulder P.I. This $2.5 \mathrm{~m}$ ( 8 foot) distance $u$ as selected because it may allow a motorist to pull off of a narrow shouldered roadway if other conditions permit.

- other structures as determined by the district/division traffic engineer.

All drainage structures and cartle passes meeting the above criteria should be marked with Type 2 object markers as described in Section 3C-3 of the MN MUTCD and the following:

- The Type 2 Marker used shall be a $150 \times 300 \mathrm{~mm}$ (6" $\times 12^{\prime \prime)}$ marker constructed of $1.6 \mathrm{~mm}\left(0.062^{\prime \prime}\right)$ aluminum or other lightweight material such as fiberglass or flexible urethane sheeting. The marker shall use Yellow High Intensity Reflective Sheeting of a type compatible with the base material.

- On special flexible post designs that cannot accommodate the $150 \times 300 \mathrm{~mm}\left(6^{\mathrm{m}} \times 12^{\prime \prime}\right)$ marker, a $75 \times 300 \mathrm{~mm}$ (3" x 12") marker may be used.

- Two markers shall be mounted back-to-back on a flexible post or $3.0 \mathrm{~kg} / \mathrm{m}$ (2-pound) steel post. A flexible post is preterred due to tt's resistance to being knocked down by snowplows and farm equipment. Additionally, it provides better daytime visibility.

- The two-w ay marker assembly shall be installed on the near right side immediately in front of the struckure as shown in Figure 7.29.

The typical marking of cattle passes and large culvers not protected by guardral are shown in Figure 7.29.

\section{7-5.06.04 Guardrail}

All guardrals shall be delineated with the snowplou marker. A typical application of these object markers can be found in Figure 7.26.

\section{7-5.06.05 Islands and Interchange Gores}

A typical application of the placement of object markers on Islands or Interchange gores can be found in Char 7-5 and Figure 7.26.

\section{7-5.06.06 End of Roadway}

A typical placement of markings for a roadway that ends with no alternative vehicular path is shown in Figure 7.26 .

\section{7-5.06.07 Other Objects}

Objects located within the clear zone should be marked with the proper object marker. The clear zone should be determined as stated in Chapter 4 of Road Design Manual, Part I.

\section{7-6.00 DELINEATION}

\section{7-6.01 Purpose}

Delinearors, which are considered guide markers rather than warning devices, are effective aids for night driving. They may be used on long, continuous sections of highway or through short suretches where there are changes in vertical or horizontal alignment, paricularly where there is a lack of contrast between the pavement and shoulder. Delineators are placed or removed by maintenance personnel or by contract. Chart $7-6$ and Figure 7.30 display different types of delineators.

\section{7-6.02 Types and Materials}

Delineator types and the reflective sheetng they require are indicated in Chan 7-6. All but the cylinder style require wide angle VIP, Type $B$ reflective sheeting. Standard Number 4, a reflective sheeting designed to adhere to curved surfaces, is used on the cylinder style delineator. 
These delineators, with the exception of the cylinder style, are used to outhe changes in alignment, lane transitions, through lane and ramp alignments, and intersections. At intersections where $360^{\circ}$ retroreflectiviry is desirable, the cylinder type is used

Acrylıc, plastic. and prismatic reflectors are generally not specified for Mn/DOT applications.

\section{7-6.03 Delineator Colors}

Delineators shall conform to the color of pavement markıng they supplement.

\section{7-6.04 Delineator Location}

The detarls of height and location of delineators are shown in Figure 7.30 and stared below.

\section{7-6.04.01 Delineator Height and Lateral Placement}

Delineators, if used, should normalty be installed so that the mounung heignt to the bottom of the delineator is $1.2 \mathrm{~m}$ ( 4 feet) above the surface of the nearest traffic lane. They shall be no more than $3.6 \mathrm{~m}$ (12 feet), nor less than $0.2 \mathrm{~m}$ (2 feet), outside the roadway or pavement edge. On rodduass with shoulders. delineators should be installed $1.8 \mathrm{~m}$ ( $6 \mathrm{feet}$ ) outside the shoulder break. Along curbed sections of roadways. delineators shall be placed not less than $1.8 \mathrm{~m}$ (2 feet), nor more than $1.5 \mathrm{~m}$ (5 feet). from the curb face.

\section{7-6.04.02 Delineator Spácıng}

Delineators should be placed at a constant distance from the edge of the roadway except, where a guardrall or other obstruction Intrudes into the space between the pavement edge and the extension of the line of delineators. The delineators should then be in line with or inside the innermost edge of the obstruction. A typical delineator unstallation is shown in the $\mathrm{MN}$ MUTCD, Section 3D-5. and Figure 3-20.

A simple method for field personnel to determine the degree of curve or the radius of a curve is shown in Figure 7.31 .

\section{Along Honzontal Curves}

When applied on the approaches to and throughout honzontal curves, spacing should permit several delineators to always be visible along the curve ahead of the driver. Table III-1 in Section 3D-5 of the MN MUTCD shows the recommended spacing for delineators along honzontal curves. A typical layout for delineator spacing on horizontal curves is shown in Chart 7-8.

\section{Along Vertical Curves}

When applied on crest vertical curves. the spacing should permit a minimurn of three delinedtors to be visible from all points along the centerline of the curve dt an eye level of $1.2 \mathrm{~m}$ (4 feet) above the pavement.

\section{Along Tangent}

When applied delineators should be spaced $160 \mathrm{~m}$ (0.1 mile) apart along the through roadway, except along acceleration and deceleration lanes where the spacing should be as indicated in section 3D-5 of the MN MUTCD. Where normal spacing is interrupted by driveways, crosswalks, etc.; and where, under the normal spacing a delineator would fall within such an area, that delineator may be moved in either direction a distance not exceeding $25 \%$ of the normal spacing. If the delineator still falls within that area, it should be omitted.

\section{$7-6.04 .03$ Intersections}

A method of delineating untersections is shown in Figure 7.31.

\section{7-6.04.04 Divided-Highway Crossovers}

Delineation of divided-highuay crossovers is shown in Figure 7.32 .

\section{7-6.04.05 Interchanges}

Delineations of cloverleaf and diamond interchanges are shown in Figures 7.33 to 7.36 .

\section{7-6.04.06 Guardrall}

Three cable guardrail shall be delineated as shown in Standard Plate No. 8330 D which states that every endpost and every fourth intervening post shall have a $75 \mathrm{~mm}$ (3-inch) wide silver-white strip of reflective sheeting mounted on a flexible strip of aluminum which is mounted around the post approximately $190 \mathrm{~mm}$ (7.5 inches) from the top of the post. Platebeam guardrail delineation is under investigation.

\section{7-6.05 Deer Reflectors}

Each district/division may make the decision to remove existing deer reflectors based on any of the following conditions:

1. The existing installations are more than six years old and there is no intent of maintaining them due to replacement costs (lack of maintenance funds). complicated installation procedures, and a lack of staff.

2. The existing installations are a problem for maintenance actıvities (their lateral placement causes mowing and snow removal problems).

3. Writen documentation indicates that either the number of deer kilis has not been significantly deer reduced or the number of deer kills has actually increased. 


\section{7-7.00 REFERENCES}

1. Minnesota Department of Transportation, Minnesota, Manual on Lniform Traffic Control Devices, 1991.

2. American Association of State Highway Officials, A Policy on Geometric Design of Rural Highways, 1990.

3. State of Minnesota, Minnesota Statutes.

4. Minnesota Department of Transportation, Standard Signs Summary, 1997.

5. Minnesota Depanment of Transporation, Road Design Manual, 198?.

6. Minnesota Department of Transportation, Bicycle Transportation, Planning and Design Guidelines, June. 1996.

7. American Association of State Highway and Transportation Officials (AASHTO). Guide for the Des elopment of Bicycle Facilities. 1991. 


\section{7-5.06.02 Namrow Bridges/One Lane Bridges}

A narrow bridge shall be defined as any of the following:

- A bridge with a minimum driving surface width greater than $5.5 \mathrm{~m}$ (18 feet) and less than the roadway approach width (not including shoulders)

- A bridge where engineering judgment of approach grades, curvatures, number of trucks or other considerations justifies a narrow bndge classification.

Narrow bridges should be marked and delineated as shown in Figure 7.27.

A one-lane bridge is defined as any bridge having a clear opening wdth of $5.5 \mathrm{~m}$ (18 feet) or less. One-lane bndges shall be marked and delineated as shown in Figure 7.28 .

\section{7-5.06.03 Cattle passes/Large Culverts}

Cattle passes and larger culverts that meet one of the following descnptions are subject to the provisions of this subsection:

- headwalls are present and are not protected by guardrail, subject to engineering judgement

- minumum width of $1 \mathrm{~m}$ (42 inches) and a maximum width of $6 \mathrm{~m}$ (20 feet) Large culverts $(6 \mathrm{~m}$ [ 20 feet] or wider) may be treated as a bridge, subject to engineering judgement.

- any culvert with an end or opening that is within $2.5 \mathrm{~m}$ (8 feet) of the shoulder P.I. This $2.5 \mathrm{~m}$ (8 foot) distance was selected because it may allow a motorist to pull off of a narrow shouldered roadway if other conditions permit.

- other structures as determined by the district/diviston traffic engineer.

All drainage structures and cattle passes meeting the above criteria should be marked with Type 2 object markers as described in Section 3C-3 of the MN MUTCD and the following:

- The Type 2 Marker used shall be a $150 \times 300 \mathrm{~mm}$ (6" \& 12") marker constructed of $1.6 \mathrm{~mm}$ (0.062") aluminum or other lightweight material such as fiberglass or flexible urethane sheeting. The marker shail use Yellow High Intensity Reflective Sheeting of a type compatible with the base material.

- On special flexible post designs that cannot accommodate the 150 × $300 \mathrm{~mm}\left(6^{\prime \prime} \times 12^{\prime \prime}\right)$ marker, a 75 x $300 \mathrm{~mm}$ (3" x 12") marker may be used.

- Two markers shall be mounted back-to-back on a flexible post or $3.0 \mathrm{~kg} / \mathrm{m}$ (2-pound) steel post. A flexible post is preferred due to it's resistance to being knocked down by snowplows and farm equipment. Additionally, it provides better daytime visibility.

- The two-way marker assembly shall be installed on the near right side immediately in front of the structure as shown in Figure 7.29.

The typical marking of cattle passes and large culverts not protected by guardrail are shown in Figure 7.29.

\section{7-5.06.04 Guardrail}

All guardrails shall be delineated with the snowplow marker. A typical application of these object markers can be found in Figure 7.26 .

\subsection{Islands and Interchange Gores}

A typical application of the placement of object markers on Islands or Interchange gores can be found in Chart 7-5 and Figure 7.26.

\section{7-5.06 06 End of Roadway}

A typical placement of markings for a roadway that ends with no alternative vehicular path is shown in Figure 7.26 .

\section{7-506.07 Other Objects}

Objects located within the clear zone should be marked with the proper object marker. The clear zone should be determined as stated in Chapter 4 of Road Design Manual, Part I.

\section{7-6.00 DELINEATION}

\section{7-6.01 Purpose}

Delineators, which are considered guide markers rather than warning devices, are effective auds for night driving. They may be used on long, continuous sections of highway or through short stretches where there are changes in vertical or horizontal alignment, particularly where there is a lack of contrast between the pavement and shoulder. Delineators are placed or removed by maintenance personnel or by contract. Chart 7-6 and Figure 7.30 display different types of delineators.

\section{7-6.02 Types and Materials}

Delineator types and the reflective sheeting they require are indicated in Chart 7-6. All but the cylinder style require wide angle VIP, Type B reflective sheeting. Standard Number 4 , a reflective sheeting designed to adhere to curved surfaces, is used on the cylinder style delineator. 
These delineators, with the exception of the cylinder style, are used to outline changes in alignment, lane transitions, through lane and ramp alignments, and intersections. At intersections where $360^{\circ}$ retroreflectivity is desirable, the cylinder type is used.

Acrylic, plastic, and prismatic reflectors are generally not specified for Mn/DOT applications.

\section{7-6.03 Delineator Colors}

Delineators shall conform to the color of pavement marking they supplement.

\section{7-6.04 Delineator Location}

The details of height and location of delineators are shown in Figure 7.30 and stated below.

\section{7-6 04.01 Delineator Height and Lateral Placement}

Delineators, if used, should normally be installed so that the mountung height to the bottom of the delineator is $1.2 \mathrm{~m}$ ( 4 feet) above the surface of the nearest traffic lane. They shall be no more than $3.6 \mathrm{~m}$ (12 feet), nor less than $0.2 \mathrm{~m}$ ( 2 feet), outside the roadway or pavement edge. On roadways with shoulders, delineators should be installed $1.8 \mathrm{~m}$ ( 6 feet) outside the shoulder break. Along curbed sections of roadways. delineators shall be placed not less than $1.8 \mathrm{~m}$ ( 2 feet), nor more than $1.5 \mathrm{~m}$ ( 5 feet), from the curb face.

\section{7-6.04.02 Delineator Spacing}

Delineators should be placed at a constant distance from the edge of the roadway except, where a guardrail or other obstruction intrudes into the space between the pavement edge and the extension of the line of delineators. The delmeators should then be in line with or inside the innermost edge of the obstruction. A typical delineator installation is shown in the MN MUTCD, Section 3D-5, and Figure 3-20.

A simple method for field personnel to determine the degree of curve or the radius of a curve is shown in Figure 7.31.

\section{Along Horizontal Curves}

When applied on the approaches to and throughout horizontal curves, spacing should permit several delineators to always be visible along the curve ahead of the driver. Table III- 1 in Section 3D-5 of the MN MUTCD shows the recommended spacing for delineators along horizontal curves. A typical layout for delineator spacing on horizontal curves is shown in Chart 7-8.

\section{Along Vertical Curves}

When applied on crest vertical curves, the spacing should permit a minimurn of three delineators to be visible from all points along the centerline of the curve at an eye level of $1.2 \mathrm{~m}$ ( $t$ feet) above the pavement.

\section{Along Tangent}

When applied delineators should be spaced $160 \mathrm{~m}$ ( 0.1 mile) apart along the through roadway, except along acceleration and deceleration lanes where the spacing should be as indicated in section 3D-5 of the MN MUTCD. Where normal spacing is interrupted by driveways, crosswalks, etc; and where, under the normal spacing a delineator would fall within such an area, that delineator may be moved in either direction a distance not exceeding $25 \%$ of the normal spacing. If the delineator still falls within that area, it should be omitted.

\section{7-6.04.03 Intersections}

A method of delineating intersections is shown in Figure 7.31.

\section{7-6.04.04 Divided-Highway Crossovers}

Delineation of divided-highway crossovers is shown in Figure 7.32.

\section{7-6.04.05 Interchanges}

Delineations of cloverleaf and diamond interchanges are shown in Figures 7.33 to 7.36 .

\section{7-6.04.06 Guardrail}

Three cable guardrail shall be delineated as shown in Standard Plate No. $8330 \mathrm{D}$ which states that every endpost and every fourth intervening post shall have a $75 \mathrm{~mm}$ (3-inch) wide silver-white strip of reflective sheeting mounted on a flexible stnp of aluminum which is mounted around the post approximately $190 \mathrm{~mm}$ (7.5 inches) from the top of the post. Platebeam guardrail delineation is under investigation.

\section{7-6.05 Deer Reflectors}

Each district/division may make the decision to remove existing deer reflectors based on any of the following conditions:

1. The existing installations are more than six years old and there is no intent of maintaining them due to replacement costs (lack of maintenance funds), complicated installation procedures, and a lack of staff.

2. The existing installations are a problem for maintenance activities (their lateral placement causes mowing and snow removal problems).

3. Written documentation indicates that either the number of deer kills has not been significantly deer reduced or the number of deer kills has actually increased. 


\section{7-7.00 REFERENCES}

1. Minnesota Department of Transportation, Minnesota, Manual on Uniform Traffic Control Devices, 1991.

2. American Association of State Highway Officials, A Policy on Geometric Design of Rural Highways, 1990.

3. State of Minnesota, Minnesota Statutes.

4. Minnesota Department of Transportation, Standard Signs Summary, 1997.

5. Minnesota Department of Transportation, Road Design Manual, 1982.

6. Mirnesota Department of Transportation, Bicycle Transportation, Planning and Design Guidelines, June, 1996.

7. American Association of State Highway and Transportation Officials (AASHTO), Guide for the Development of Bicycle Facilities. 1991. 

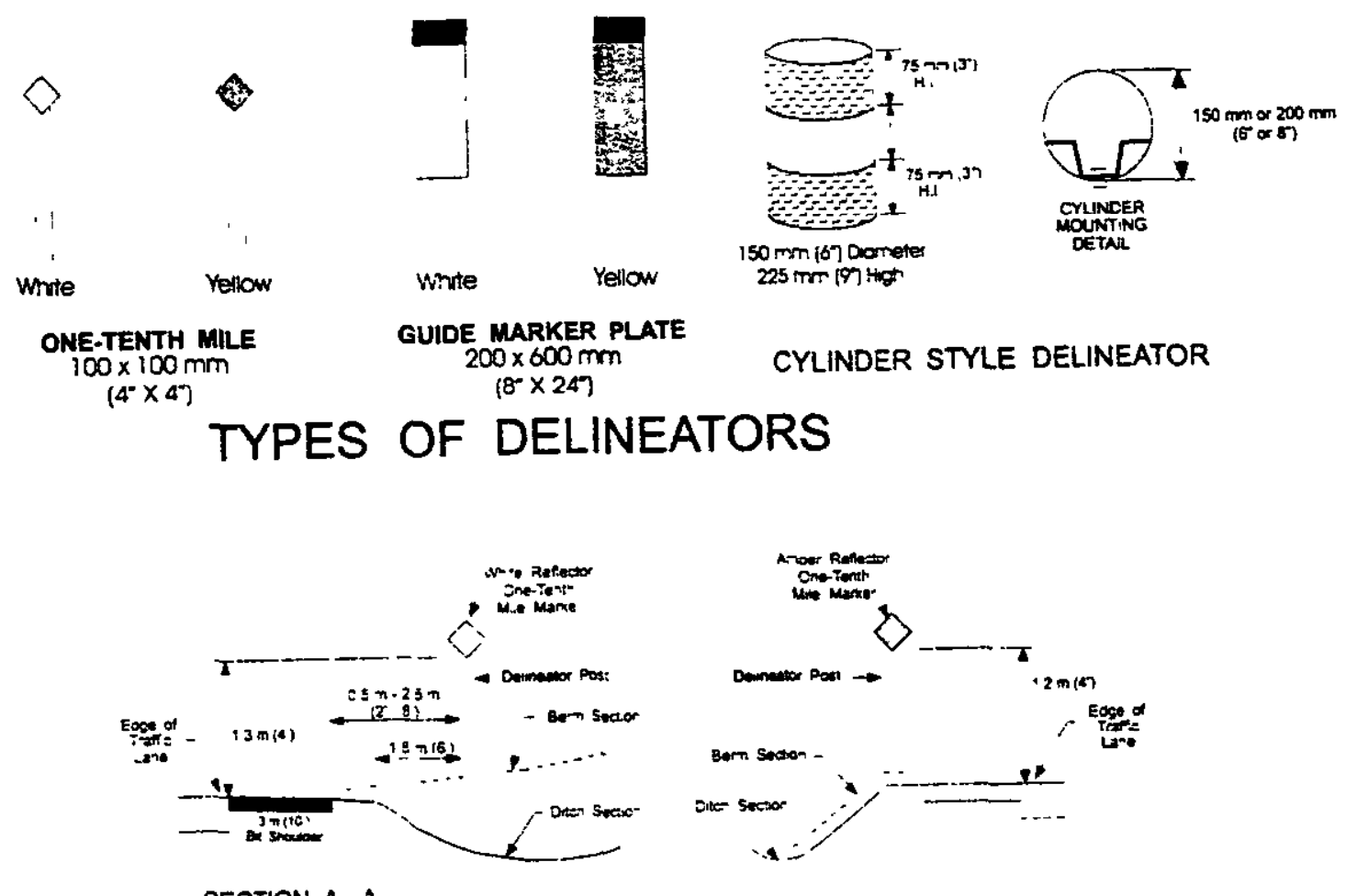

SECTION A - A For Figures 739 thru 742

SECTION B - B (LEFT ONLY) For Figures 739 thrs 742

\section{TYPICAL DELINEATOR PLACEMENT}

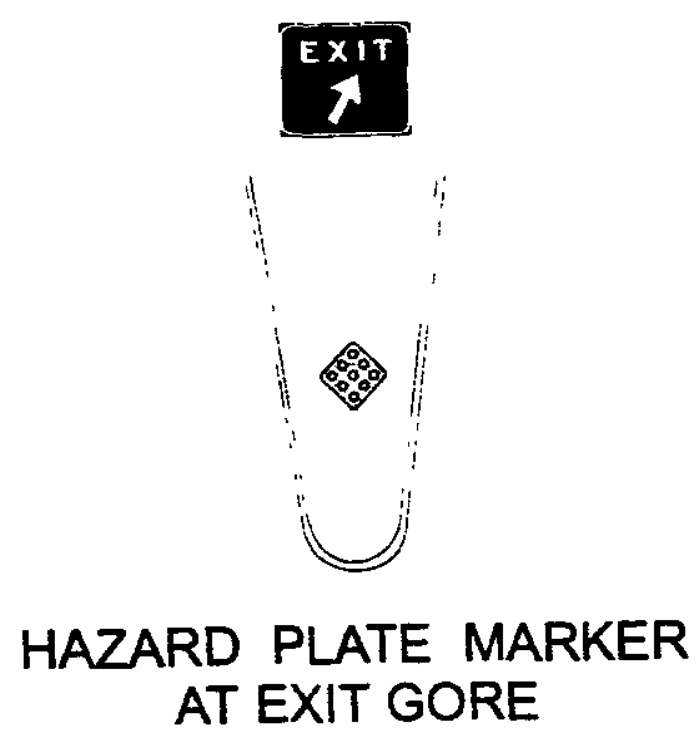

Text Ref.: 7-6.01

July 1,1999

DELINEATOR TYPES \& INSTALLATION 

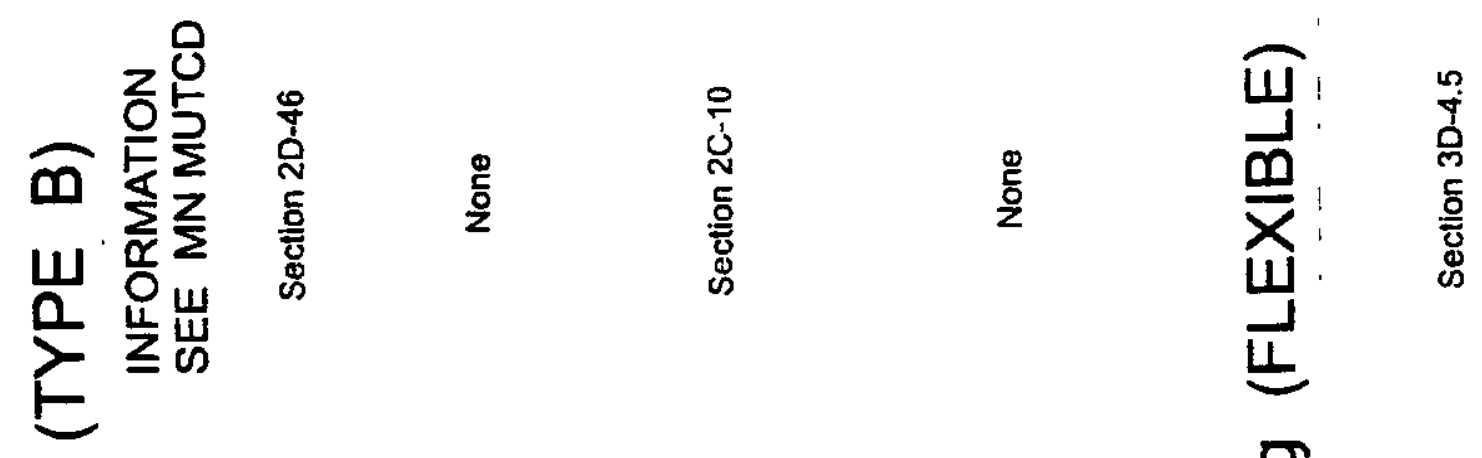

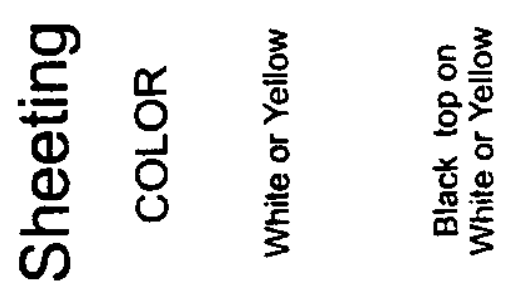
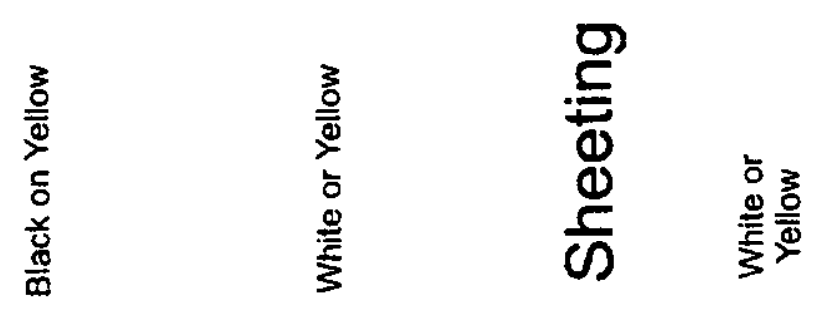

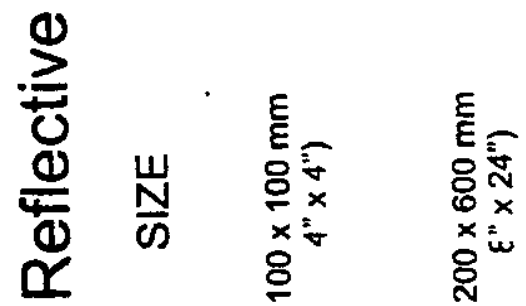
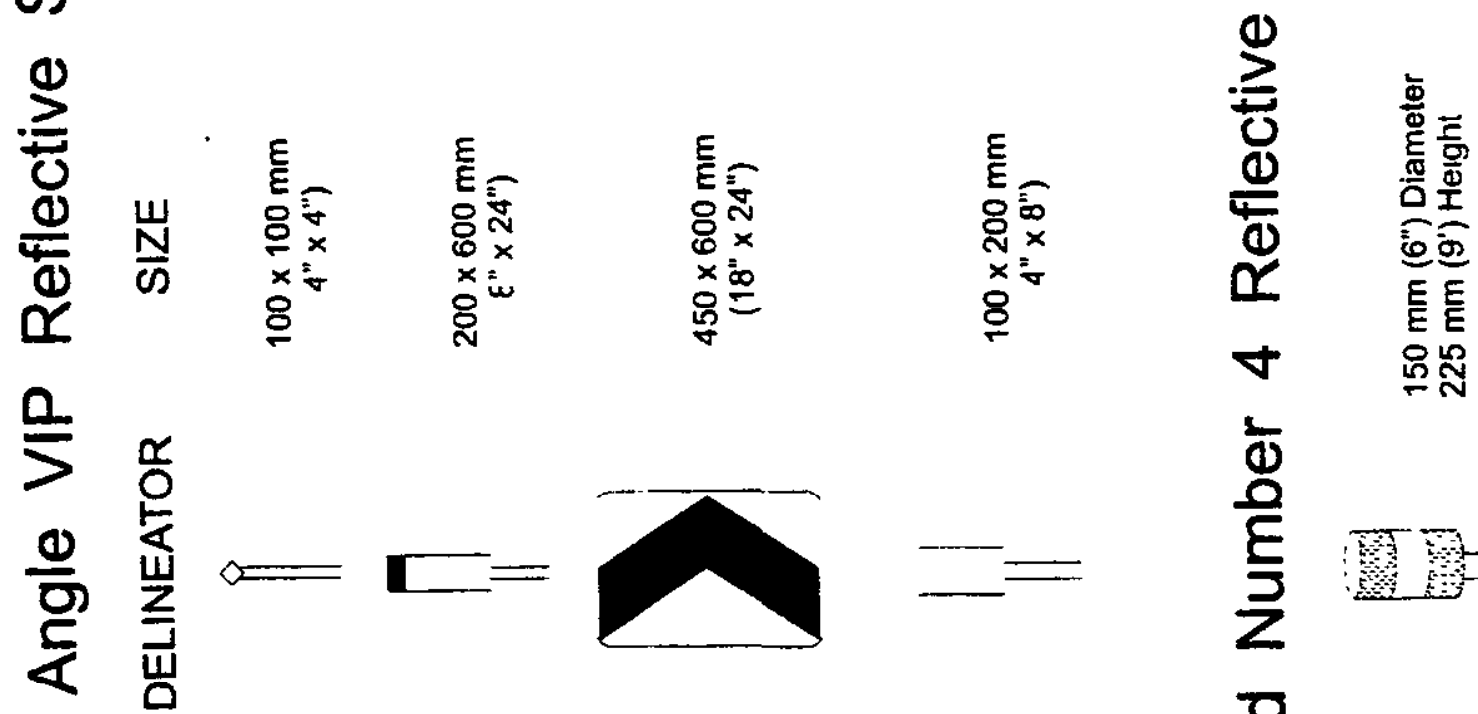

$\stackrel{0}{5}$
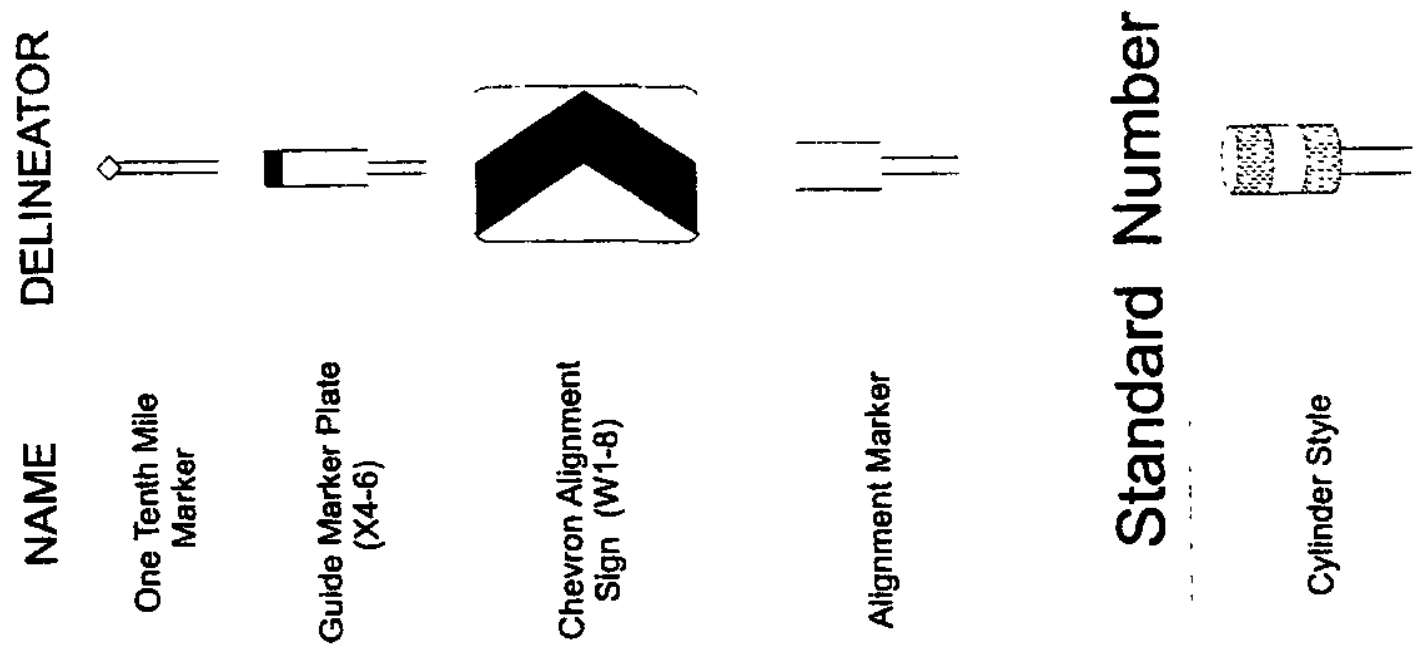

$\frac{\text { 음 }}{\frac{8}{0}}$

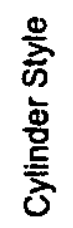

Text Ref.: 7-5.04

July 1,1998 


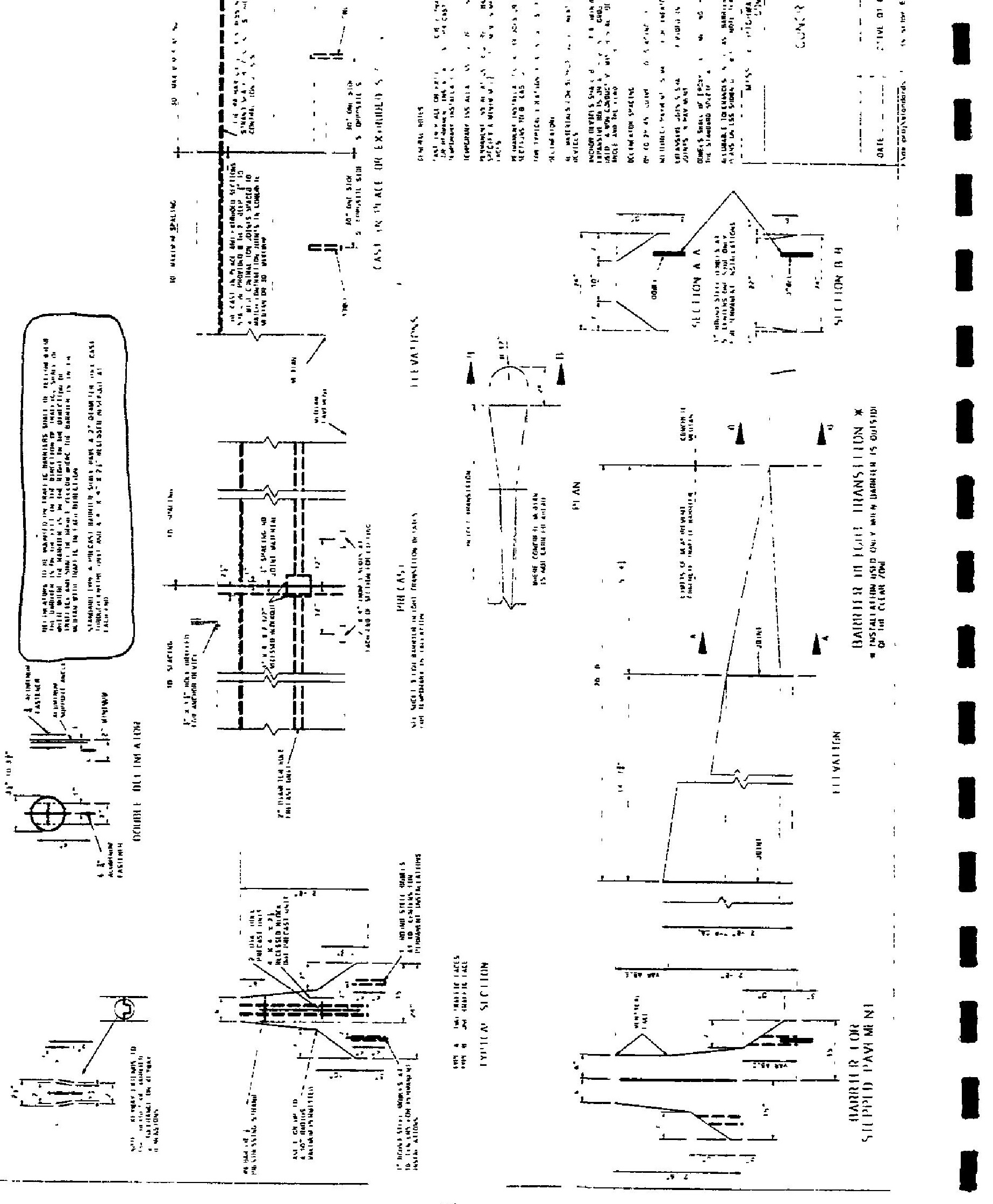




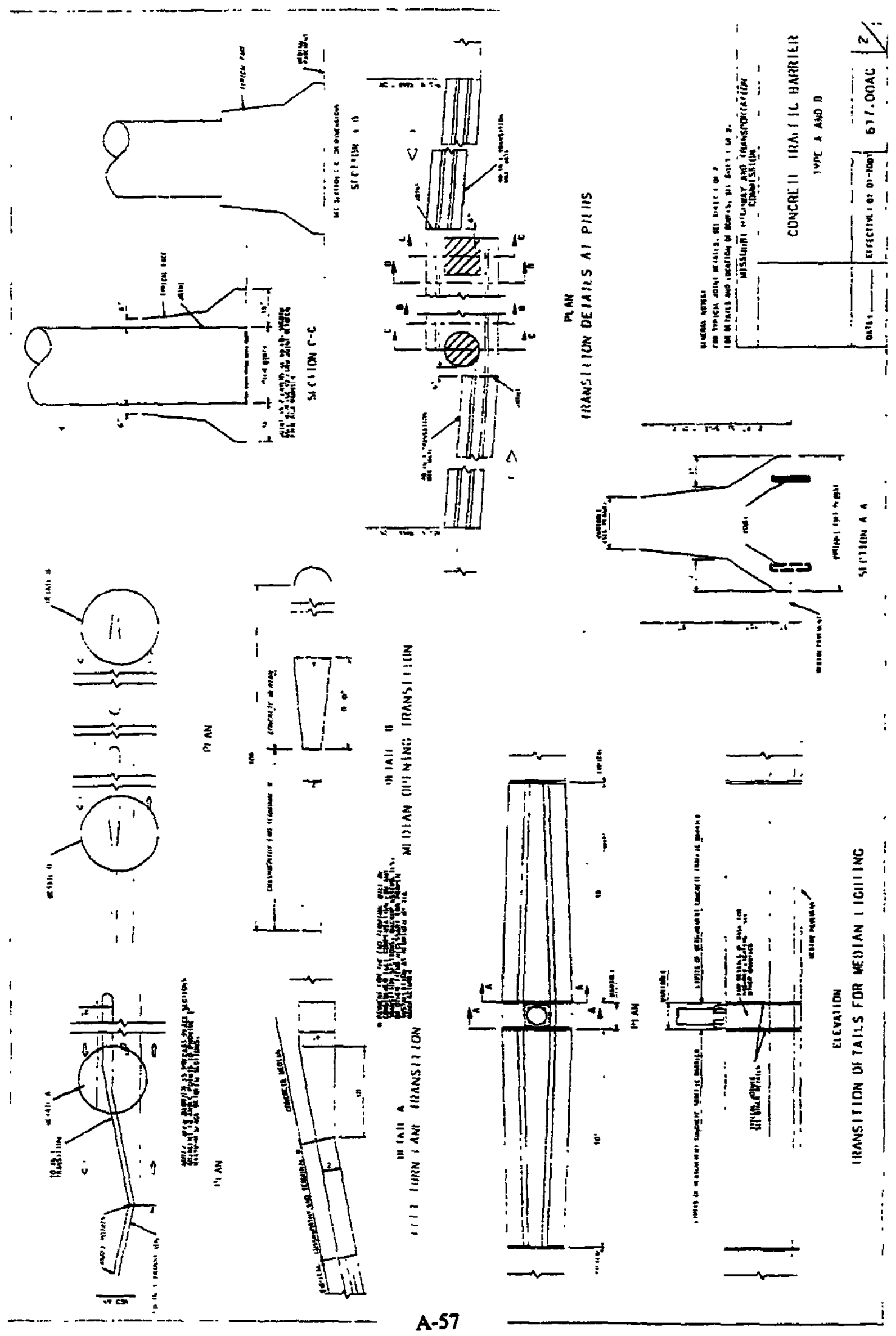




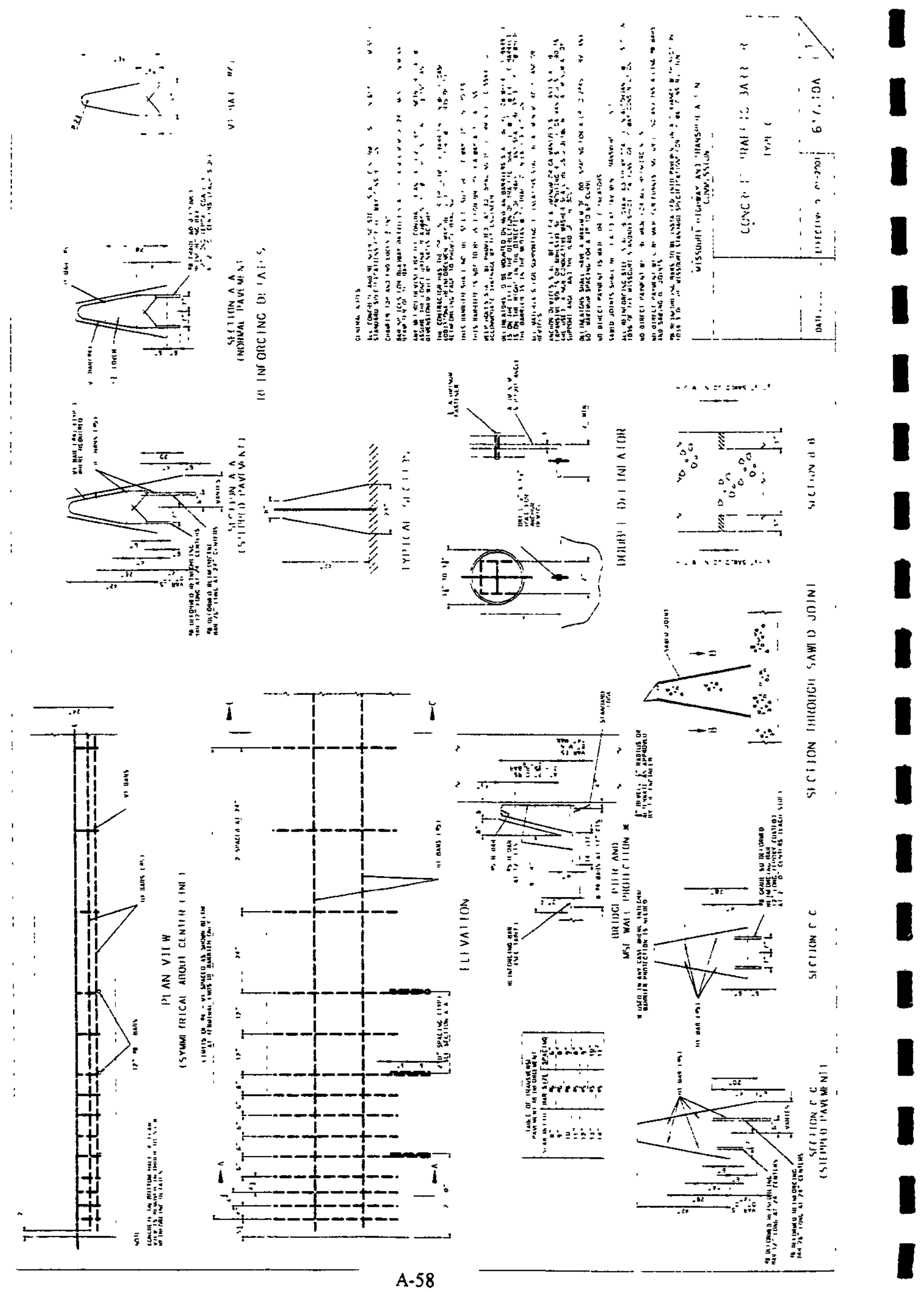




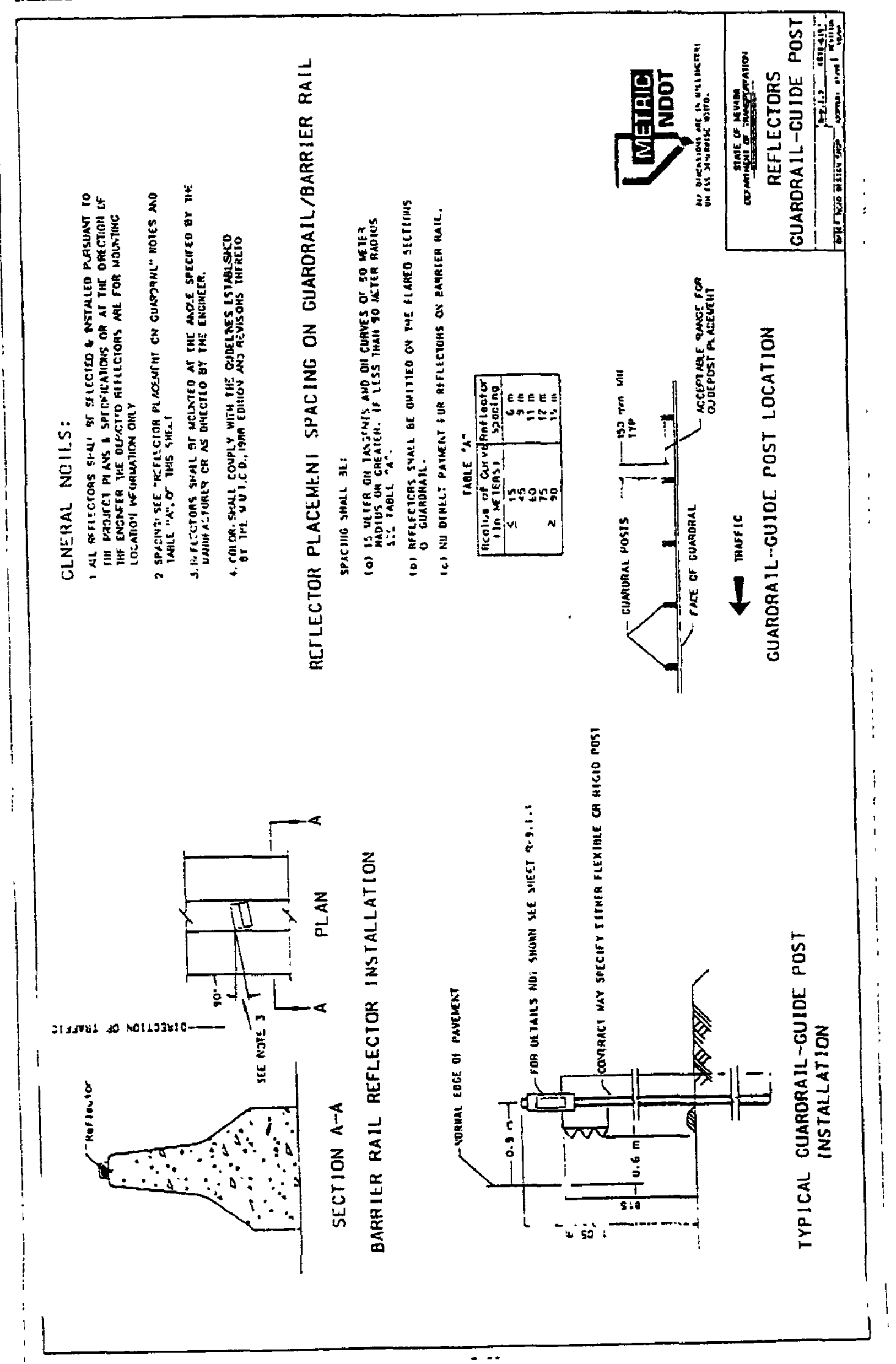


N.D.O.T.

\begin{tabular}{|c|c|c|c|c|c|c|}
\hline $\begin{array}{l}\text { Spece } \\
\text { Siumber. }\end{array}$ & Product Types & $\begin{array}{l}\text { Memifudurerta Name } \\
\text { Adites }\end{array}$ & Produet Name & Remarks & $\begin{array}{l}\text { Cerded } \\
\text { Effeetive } \\
\text { Date }\end{array}$ & $\begin{array}{l}\text { to } \\
\text { Nequber }\end{array}$ \\
\hline
\end{tabular}

$-$

\begin{tabular}{|c|c|c|c|c|c|}
\hline \multirow[t]{3}{*}{625.02 .02} & $\begin{array}{l}\text { REFLECITVE } \\
\text { MARKERS ON } \\
\text { PORTABLE } \\
\text { ARECAST } \\
\text { CONCRETE } \\
\text { BARRUER }\end{array}$ & 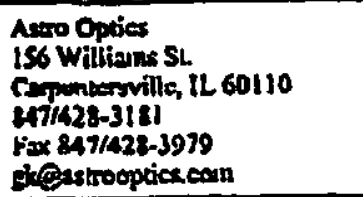 & $\begin{array}{l}\text { Fp-33 or Flei- } \\
\text { Tab Marta }\end{array}$ & $02 / 3 / 3$ & soli \\
\hline & & 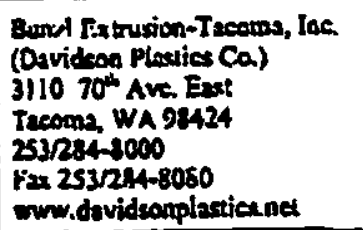 & PCAM-12 & $12 / 17 \%$ & 9015 \\
\hline & & 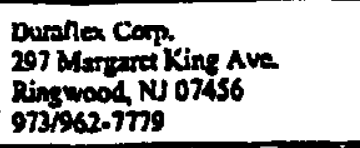 & $\begin{array}{l}\text { FLyXe arro } \\
\text { Wrts and } 76 \mathrm{~mm} \\
\text { Reflective } \\
\text { Shoting }\end{array}$ & $1217 / 97$ & solo \\
\hline 625.02 .02 & $\begin{array}{l}\text { BAREIER MARKER } \\
\text { DAUMS ON } \\
\text { CONCRETE } \\
\text { DARRIER RALS }\end{array}$ & 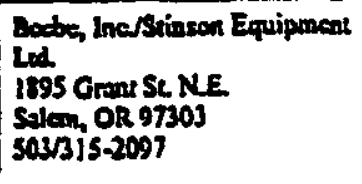 & 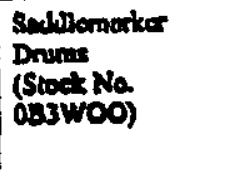 & $12 / 5 / 97$ & 5101 \\
\hline
\end{tabular}




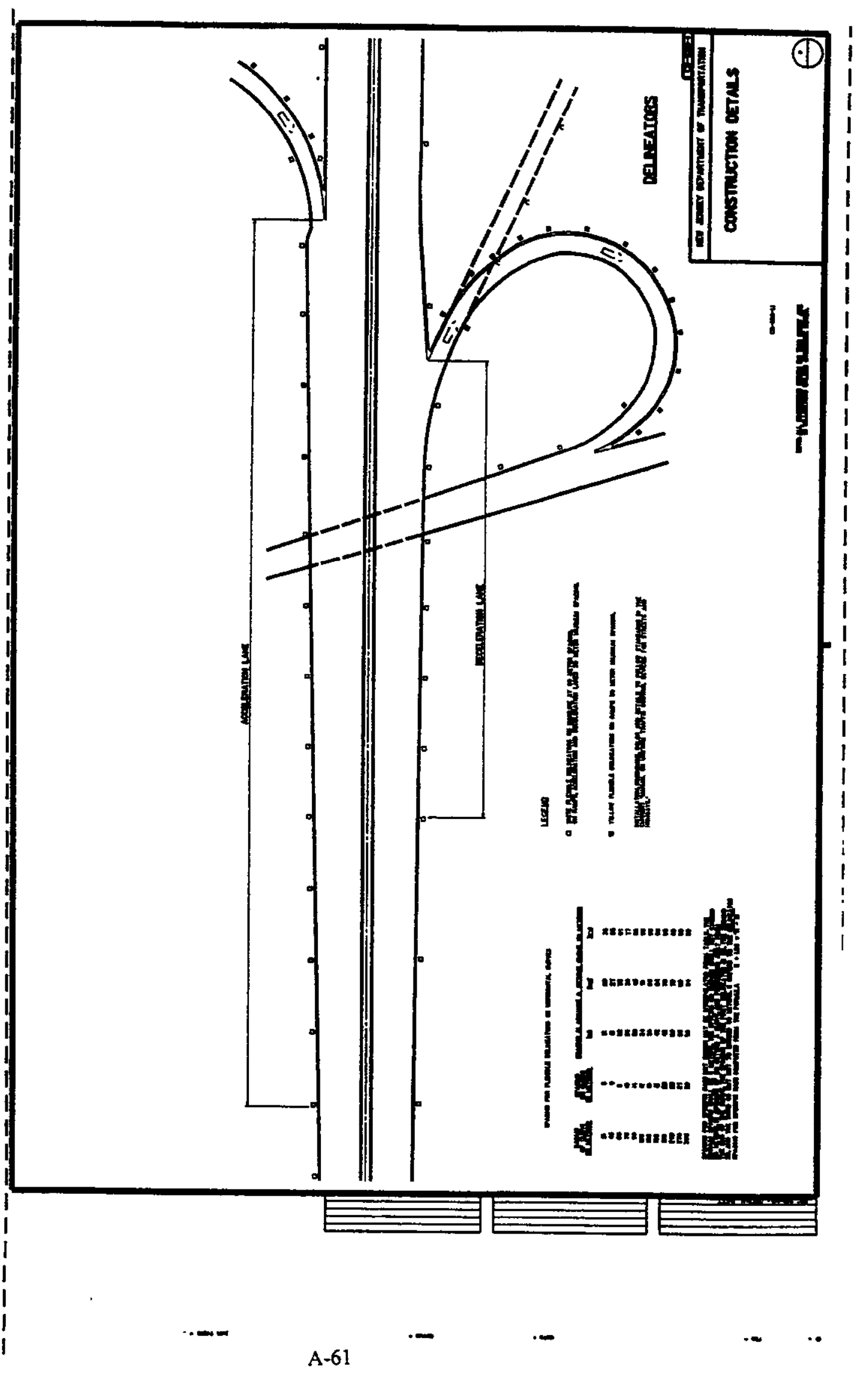




\subsection{Guide Rail Mounted Flexible Delineators.}

Flexible delineators shall be mounted on the spacer of beam guide rall using either a " $U$ " chamel base on the I-beam spacer or a flat base attached to a wood polymer, or other solid top spacer. The base shall be attached to the spacer using an adhesive recommended by the manufacturer of the base and panel. The first delmeator shall be placed on the bean guide rail end treatment, positioned so that the reflector area is facmg the direction of traffic, then subsequently every 25 meters (13 sections of guide rail) for tangent manline roadway, and every 13.5 meters (seven sections of gunde rail) for curved mainline roadways with radii less than 580 meters. If a parabolic flare in the beam guide rail exists, the second delineator shall be placed at the end of the flared section with subsequent delineators spaced as stated above. If the distance between the end of the beam guide rail is greater than 6 meters on curved mainline roadways, or 12 meters on tangent mainline roadways, a delineat or shall be installed on the last post or end treatment.

Retroreflective sheeting, Type IV-A shall be applied to the upper portion of the flexible delineator panel. The retroreflective sheeting shall cover a minimum area of 115 by 115 millimeters ( 115 by 230 millmeters for deceleration and acceleration lanes). The color shall be white when the delmeator is located on the right side to the direction of traffic and shall be yellow when the delineator is located on the left side to the direction of traffic

\subsection{Barrier Curb Mounted Flexible Delineators.}

The first lexible deluneator shall be placed at the beginning of the concrete barrier curb section, positioned so that the reflector area is facing the drection of traffic, then subsequently every 24 meters. If the distance between the end of the concrete barrier curb and the adjacent delmeator is greater than 12 meters, a delineator shall be installed on both sides of barrier curb openungs.

Concrete barrier curb mounted flexible delineators shall be attached to the side of the barrier curb, 75 millimeters from the top of the barrier, using a method recommended by the manufacturer of the delineator unit.

Retroreflective sheeting, Type IV-A shall be appled to the upper portion of the flexible delineator panel facing traffic and perpendicular to the top of the concrete barrier curb. The retroreflective sheeting shall cover an area of 90 by 90 millimeters. The color $\because \quad$ shall be white when the delineator is located on the right side to the direction of traffic and shall be yeliow when the dehneator is located on the lefi side to the direction of traffic

620.06 Method of Measurement.

\section{COMPENSATION}

Flexible delineators will be measured by the number of units.

620.07 Basis of Payment.

Payment will be made under.

$\begin{array}{ll}\text { Pay Item } & \text { Pav Unit } \\ \text { FLEXIBLE DELINEATORS, GROUND MOUNTED } & \text { UNIT } \\ \text { FLEXIBLE DELINEATORS, GUIDE RAI MOUNIED } & \text { UNIT } \\ \text { FLEXIBLE DELINEA TORS, BARRIER CURB MOUNTED } & \text { UNIT }\end{array}$

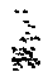

\section{SECTION 621 - CRASH CUSHIONS}

\section{$670100 \%$}

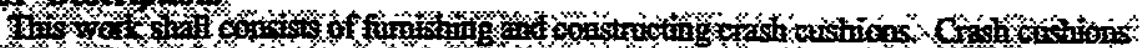

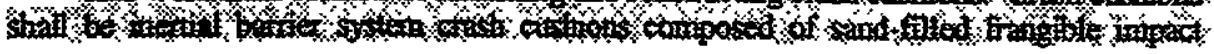


sign supports shall be adjusted by rotating the sign on the posts Stgns mounted on "U" post sign suppons shall be adjusted as specified in Subheading 2 of the second paragraph of Subsection 619.03

619.05 Cleaning Signs.

Before findl inspection, all sign faces and support surfaces shall be cleaned of all foretgn matter. Necessary measures shall be taken to provde that all signs, sign supports, and sign sites are in good condition and have a good appearance

\subsection{Method of Measurement.}

\section{COMPENSATION}

Signs of the various sizes will be measured by square meter.

Guide signs of the various types will be measured by the square meter.

\subsection{Basis of Payment.}

Payment will be made under:

$\begin{array}{ll}\text { Pay Item } & \text { PQy Untt } \\ \text { SIGNS } & \text { SQUARE METER } \\ \text { GUIDE SIGNS, TYPE GA, "U" POST SUPPORTS } & \text { SQUARE METER } \\ \text { GUIDE SIGNS, TYPE GA. BREAKAWAY SUPPORTS } & \text { SQUARE METER } \\ \text { GUIDE SIGNS, TYPE GA, NON-BREAKAWAY SUPPORTS } & \text { SQUARE METER } \\ \text { GUIDE SIGN PANELS, TYPE GO } & \text { SQUARE METTER } \\ \text { GUIDE SIGN PANELS, TYPE GOX } & \text { SQUARE METER }\end{array}$

Separate payment will not be made for posts for signs

Payment for sign support structures will be made in accordance with Section 509

Payment for sign illumination will be made in accordance whth Section 705

Payment adjustments for strength will be made in accordance with Subsection 914.02, Subpart F, and will be applied to the lot for those Pay Items specified in that Subpart.

\section{SECTION 620 - DELINEATORS}

\subsection{Description.}

This work shall consist of furnishing, assembling, and erecting flexible delineators

620.02 Materials.

\section{MATERLALS}

Materials shall conform to the following:

Retroreflectuve Sheetung.. .... $\ldots \ldots \ldots \ldots \ldots 1604$

Flexuble Delineators. ................................916 14

\subsection{Ground Mounted Flexible Delineators.}

\section{CONSTRUCTION}

Flexible delineator units shall be dnven vertically unto the ground to a minimum depth of 450 millimeters. Units shall be installed so that the plane face of the center of the reflective area is at an angle of zero degrees whth a perpendicular to the direction of traffic

Retroreflectve sheeting. Type IV-A shall be pre-applied to the front (surface facing traffic) of the unit by the manufacturer. The retroreflectuve sheetung shail cover a minimum area of 75 by 300 millimeters, beginning a maximum of 50 millimeters from the top of the post. The color shall be white when the delineator is located on the right side to the direction of traffic and shall be yellow when the delneator is located on the left side to the drection of traffic. 


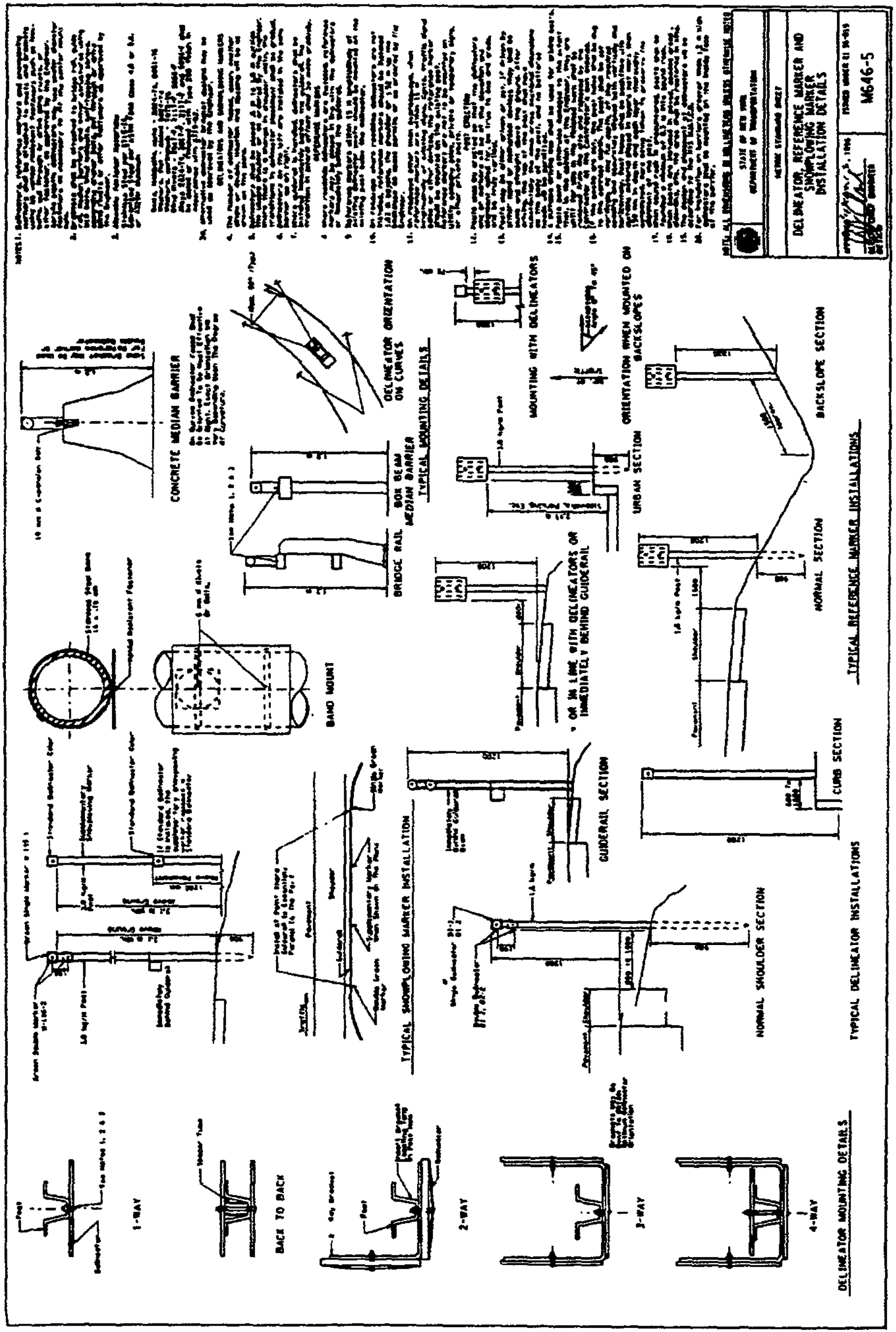


Base posts shall be punched on center line with a munimum of twelve 7/16-inch diameter holes on one inch centers. The first hole shall be one inch from the top. The bottom of the post shall be pointed for easy installation.

The sign post, base posts. retainer-spacer, and anchor plates shall be galvanized according to AASHTO M-232.

6 Structural Steel Posts. Structural steel posts shall be fabricated from material conforming to Section $834.01 \mathrm{~A}$. and shall be galvanized according to Sectuon 854 after fabrication

\subsection{DELINEATORS.}

A. Posts. Steel posts shall meet ASTM A-702.

Steel posts shall be galvanized according to AASHTO M-111 or be aluminum posts fabncated from aluminum alloy meeting ASTM B-308. Alloy 6061-T6

Posts shall have holes at one inch spacing the entire length of the post.

\section{B Reflectors.}

1. Reflective Sheeting. Type III reflectuve sheeting for delmeators shall be uhite or yellow adhesive coated, permanently adhered to aluminum or galvanuzed steel.

The reflective sheeung shall meet Section 89402 . Backing material shall meet Section 894.01.

The finished reflector shall show careful workmanship; be free of burrs, scratches. or damaged reflective sheeting; and have essentially a flat surface.

\section{Acrylic Plastic.}

a. Metal Parts. The housing shall be .020-inch ASTM B-209 3003-H14 or 5052-0 sheet aluminum formed to approximately 3-1/4 inches in diameter and .235-inch in depth to retain the acrylic reflector. The housing shall be provided with 4 embossed circular reinforcement ribs and marked with the manufacturer's name and part number

An aluminum grommet with a 3/16-inch inside diameter shall be expanded within the reflector mounting hole

b. Acrylic Plastic. The reflector shall be an acrylic plastic manufactured from methyl methacrylate. The reflector shall consist of a clear and transparent plastic face, whth a minimum of 7 square unches of reflective area, referred to as the lens. It shall have a heat sealable plastic coated metallic foil back fused to the lens under heat and pressure around the entire perimeter of the lens and the central mounting hole to form a unt permanently sealed against dust, water, and water vapor. The reflector shall be colorless, yellow, or red 
The lens shall consist of a smooth front surface free from projection or indentation other than the central mounting hole and identification with a rear surface bearing a prismatic configuration such that it will provide total internal reflection of light.

c. Optical Requirements. The optical requirements shall be as follows:

\section{Color}

Crystal or Silver Yellow Red

\section{Candelas per Foot-Candle per Square Foot Divergence Angle, -0.1 Degrees Entrance Angle, Deg.}

$\begin{array}{rl}0 & 20 \\ 119 & 47 \\ 71 & 28 \\ 29 & 11\end{array}$

The reflex reflector to be tested shall be located 100 feet from a single light source having an effective diameter of 2 inches; the light source shall be operated at approximately normal efficiency. The retum light from the reflector shall be measured by a photoelectric photometer having a minımum sensiuvity of $1 \times 10^{-7}$ foot candles per $\mathrm{mm}$ scale division. The photometer shall have a receiver aperture of 0.5 inch diameter, shielded to eliminate stray light. The distance from light source center to aperture center shall be 2.1 inches for $0.1^{\circ}$ observation angle. During testung. the reflector shall be spun to average the onentation effect. If a test distance other than 100 feet is used, the source and aperure dimensions and the distance between source and aperture shall be modified in the same proportion as the test distance.

Failure to meet the specific intensity minimum shall constimute failure of the refiector being tested; fallure of more than 2 reflectors out of 50 subjected to test shall constitute failure of the lot.

d. Durability. The durability tests shall be as follows:

(1) Seal Test. The following test shall be used to deternine if a reflector is adequately sealed against dust and water.

Submerge 50 samples in a water bath at room temperature. Subject the submerged samples to a vacuum of 5 inches for 5 minutes, then examine them for water intake. Failure of more than $2 \%$ of the number tested shall be cause for rejection.

(2) Heat Resistance Test. Thre reflectors shail be tested for 4 hours in a circulating air oven at $175^{\circ} \pm 5^{\circ} \mathrm{F}$. The test specimens shall be placed in a honzontal position on a grid or perforated shelf permitting free air circulation. At the conclusion of the test, the samples shall be removed from the oven and permitted to cool in air to room temperature. The samples, after exposure to beat, shall show no significant change in shape and general appearance when compared with unexposed control standards. No failures will be permitted.

C. Fasteners. Aluminum tension pin fasteners shall be an aluminum alloy meeting ASTM B-211 Alloy 2024-T4 or 6061-T6. The collar shall be aluminum alloy 
$89406 \mathrm{C}$

meeting ASTM B-211 Alloy 6061-T67 or 6061-T6. The fasteners shall conform to the Contract.

Steel tension pin fasteners shall be a medium carbon steel with a minimum shear strength of $70.000 \mathrm{psi}$ and a minimum tensile strength of $67,500 \mathrm{psi}$. They shall be galvanized according to AASHTO M-232 conforming to the Contract.

\subsection{SAMPLING AND TESTING.}

A. Base Metal. The Contractor shall furnish to the inspector a cenification as specified in Secuon 801.01.

B Solutions for Cleaning and Etching. The solutions used for cleaning and etching shall not vary more than $10 \%$ from the manufacturer's recommendation. In addition, all treatment tanks shall be charged with fresh chemicals at least once a year. Titration equipment shall be available for the inspector's use to check the solution strengths.

C. Inspection. All matenal and finished signs are subject to inspection ar the place of manufacture and shall be subject to final inspection at the time of erection. Test panels, 12 inches by 12 inches representative of any stage of production, shall be furnıshed upon the inspector's request. These panels shall be processed with the regular production run and witnessed by the inspector. All surfaces exposed to weatherng shall be free of any defects that may umpar the serviceability or detract from the general appearance or color matching of the sign. Signs with any defects or damage that would affect their appearance or serviceability will not be accepted. No repairs shall be made to the face sheet without the approval of the inspector. Signs not conforming in all respects to the requirements $w$ ill be rejected.

D Reflective Sheeting. The reflective sheeting shall be certified by the manufacturer that the minimum bnghtness values previously listed for each color, have been met. The color of each type shall be checked by the inspector using the standard color chans as specified.

1. Reflective Sheeting Flexibility. The Contractor shall furnish test specimens for each color of reflective sheeting according to AASHTO M-268. Type III and Type $\Gamma \mathrm{V}$ reflective sheeting shall be applied to a plate as specified in AASHTO M-268 and shall be fumished for each color. These test specimens shall be processed with the regular production run and witnessed by the inspector.

2. Inspection. The reflective sheeting packages shall be inspected before installation on sign backings. The Contractor shall provide access by the inspector and shall indicate the roll packages or flat packages to be used on a particular Project. The inspector will mark the roll of flat material and note the manufacturer 's date. All material used on that Project shall be used within one year of this date. If this date is past on the date of inspection, the roll shall be rejected.

E. Torque Control Nuts. The Contractor shall fumish to the inspector a certification, as specified in Section 801.01. If torque control nuts are chosen for use. 

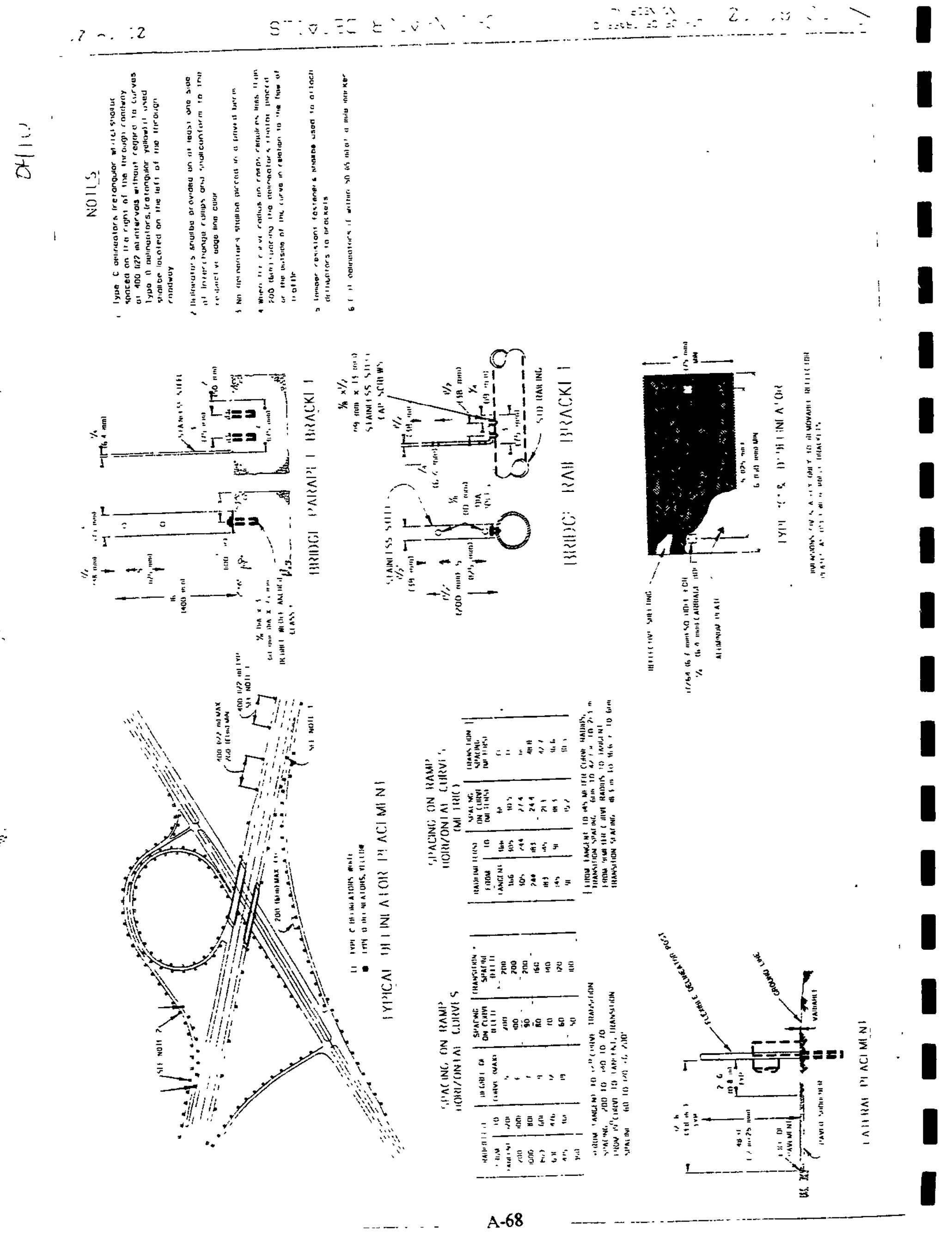


\section{Traffic Control Design Information Manual}

October 1999

IX. RAISED PAVEMENT MARKERS, DELINEATORS, BARRIER REFLECTORS AND OBJECT MARKERS

\section{A. Raised Pavement Markers}

Raised pavement markers (RPMs) should normally be included in new and resurfacing construction projects on State maintained roads and urban Interstates. They may also be included in the plans at other locations as specified in the RPM Program.

Standards and guidelines for RPMs are addressed in Sections 3A-10, 3B-1 5 and 3B16 of the OMUTCD, and RPM specifications are covered in Items 621 and 721. The SCDs TC-65.10, 65.11 and 65.12 incorporate the various installation details, and should be listed on the Title Sheet.

The plans shall call for the removal of existing RPM castings which would otherwise be abandoned and paved over, and their return to ODOT.

Testing procedures for RPMs are covered in Supplement 1062.

B. Delineators

Sections 3D and 4F-5 of the OMUTCD, AS 4C-7 and SCD TC-61.10 address current standards and guidelines conceming delineation on the rural state highway system. Delineator reflector color shall match that of the nearest edge line.

On divided highways, freeways and expressways inside cities, delineation should be provided on unlighted or partially lighted sections and may be considered on fully lighted sections.

Flexible posts are required on state maintained routes.

C. Barrier Reflectors (Permanert)

Barrier reflectors shall be erected on all new or reconstructed guard rail, new concrete barrier and new or reconditioned bridge parapets. Standards and specifications for barrier reflectors are covered in AS 4C-9 and CMS Items 626 and 720.04 .

Barrier reflector color shall match that of the nearest edge line. 


\section{Traffic Control Design Information Manual}

October 1999

D. Barrier Reflectors (Temporary)

These are used for maintaining traffic flow during construction. Although they are paid for under Item 614, they are identical to those described in AS 4C-9 and CMS Item 626.

E. Temporary Raised Pavement Markers

Temporary raised pavement markers are covered on SCD MT-101.20.

F. Object Markers

Object markers are covered in Sections $3 \mathrm{C}$ and $4 \mathrm{~F}-4$ of the OMUTCD.

Back To Table Of Contents 
POLICY ON

BARRIER REFLECTORS

i. FURFOSE

:nstallasicr of reflectors can be an effectlve nethod of celineating concrete or guardrall barriers along the rodeway and on bridges. Their purpose is to provide additional delineation and guidance during darkiess and/or adverse weather conditions.

The purpose of this polley is to provice guidellines for use in determining locations to be treated with barrier reflectors and establish standare installa:ion and malritenance practices.

i1. APPLICATION

This oolicy is applicable to a? h highweys on the rural state higliway systes and mey be applied to state and/or federally funded projects -egardiess of the type of existing or proposed pavenent marxings ard regardless of the presence of edge lires, refiectorlzed glare screers, ralsed Favenent ma-ke-s or highway lighting. However, these refiectors should not be installed: where standard post delineators in goed condition are alrady in olace along the barrler. where conditto-s mequire standard delineztors or where barrier replacemen: is sehecu ed within two years (except for temporary berriers in work zones).

\section{:!: PRINC:P.ES ANO GUIOELINES}

A. The use of berier reflectors should be co-sideres at the foliowing locations:

1. Identified Might barrier-iavolvenent Accident boca:iors arca Secsions.

These locations and sections are identified on the basis of night barrier-involvement accidents, and selezted by andys is of accident reccrds.

2. Potential Night Barrier-Invoivenent Accident Locations and Secticns.

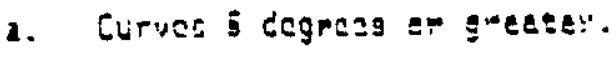
D. Entegr loengieng on ialun (21 feel or less) two-' ane nigrways.


SEVT Bv:Xe-9x Te ecos:er $7321 ; 4-5-01$ int-202\%,

c. Tangent sections and curves ilatter than 5 degrees on narrow two-lane highways.

\$. Concrete or guardrall barriers 10 feet or less from the near ecge of pavement.

e. Barriers with portions which encroach to within 10 feet of the traffic lane, e.g. at the epproach to a brtige end or pler. When ref.:ectorized, the entire length of barrier and no: just the encroaching pcrtion shou's be treated.

f. Portable concrete barriers and guardrail within
constructicn work zones, to include $G-R-E-A-T$ attenvation serminais.

8. Where the barrier is or a tangent section adjacent to a curve, deltheaston should be exterced through the curve with ralsed pavemen: me-xers, barrier refiectors or post delineators.

C. When the distance between successive treated sections is, or wiil ce,

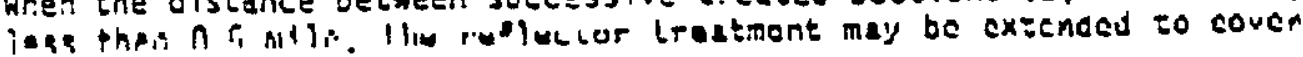
all barriers in the "gap".

IV. INSTALLATION

\section{A. Spacing}

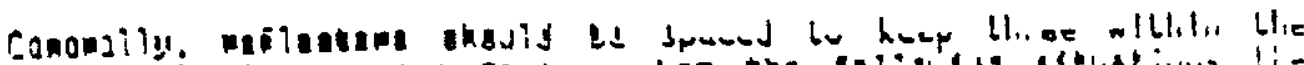

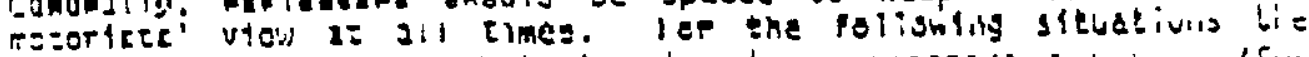

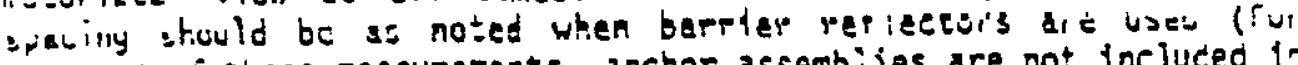
purposes of sthese measurements, anchor assembiies are not inciuced $1-$ the length of the berrferl:

1. Targent highway sections and curves fiatter than 5 degrees - ICO feet apart, excest as no:ec oelow in iten 3 ;

2. Curves 5 degrees or greater and izne reduction tasers (e.g. an interim concrete berrler used at the temporary termi-a: of a iresway) - 50 feet apart:

3. Tengent barriers and transition sections (frea ore offset distanes to a claser one) 200 feet or less in lergth is leart iprog rajlectori fer dircition, oen locuest et eseh ens and sie in : ne nitedio;

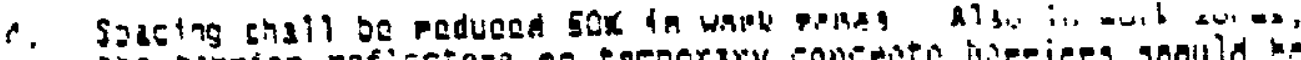

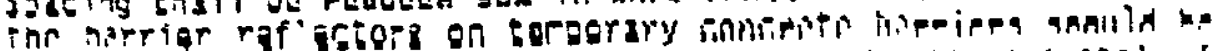
sujplestenteu oy ierge eylinarical retlecters lapproximately 6 ince ciateter $x \quad 22$ inch height), or other retroreflective devices o comoarajle size which will mainte in the desires ref lectivity in curved sectio-s, mounted on top of the bartier micwey beimeen the side-rourted barrler refiezors. Retlectorized giare streenirg is a'sc accaptabie. 


\section{B. MOLNTING}

1. On cancrete barrlers the height to the top of the reflactor should be 26 inches above the near edge of pavement; but the top of the refiector should not be less than 3 inches below the top of the concrate barrter.

2. On guartrail barriers the height of the reflector will depend on the type of cuardrail; however, it should be aporoximetely 21 inches above the near edge of pavenent. For bean guardrail, the

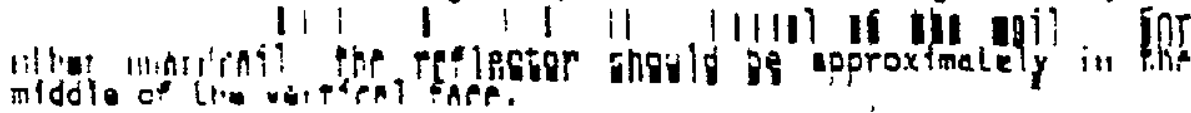

3. when thounzed on a plat surface, the terlestor faee ghould bo tllted upward from the vertical or plumb position 2 to 3 degrees to iacllita:e "rain washling" of the reflector face.

c. y-cirecioloni barter refleibur ilstallation may be usce on the outside of curves.

D. The color of the ourrier reflector shall be whise when used en barriers along the right side of the road and yellow for berriers on Lli:e le?:.

\section{REFLELTOQ MAIYTEYANC:}

To maintain sheir effectiveness, oarrter retiectors shou $d$ be mainlained in good condtiton by appropriate distric: fleld forces.

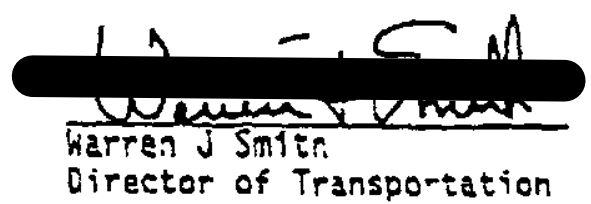




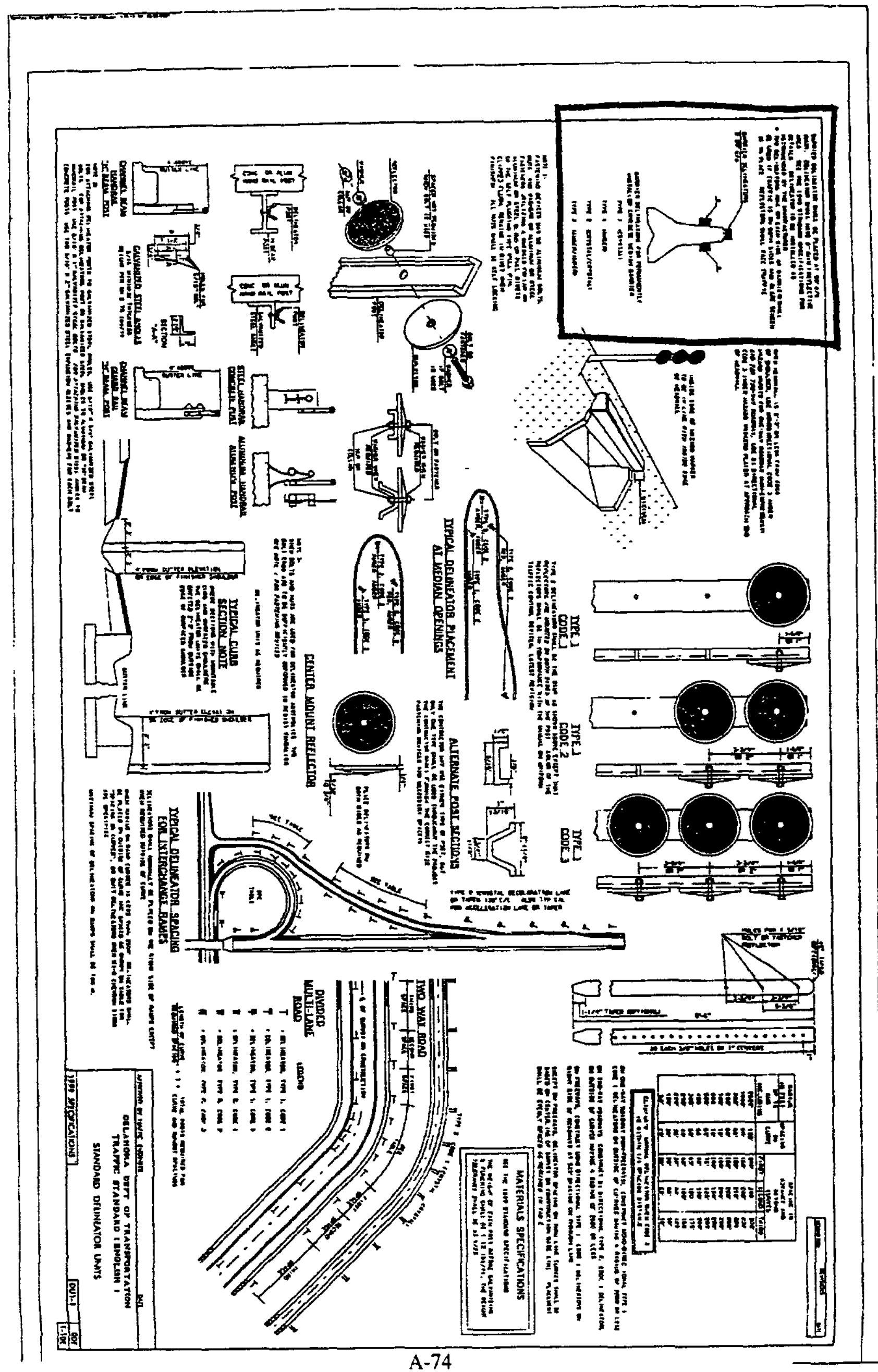




\section{FOR PERMANENT WALL}

BARRIER DELINEATOR SHALL BE PLACED AT $90^{\circ} \mathrm{c} / \mathrm{C}$ (MAX). DELINEATOR SHALL HAVE 6" (MIN.) REFLECTIVE AREA. SEE THE 1999 STANDARD SPECIFICATIONS FOR DETAILS. DELINEATOR TO BE INSTALLED AS RECOMMENDED BY THE MANUFACTURER.

* TWO DEL INEATORS (ONE ON EACH SIDE OF BARRIER) SHALL BE USED IF TRAFFIC IS ON BOTH SIDES AND GLARE SCREEN IS IN PLACE. REFLECTORS SHALL FACE TRAFFIC.

\section{BARRIER DELINEATORS}

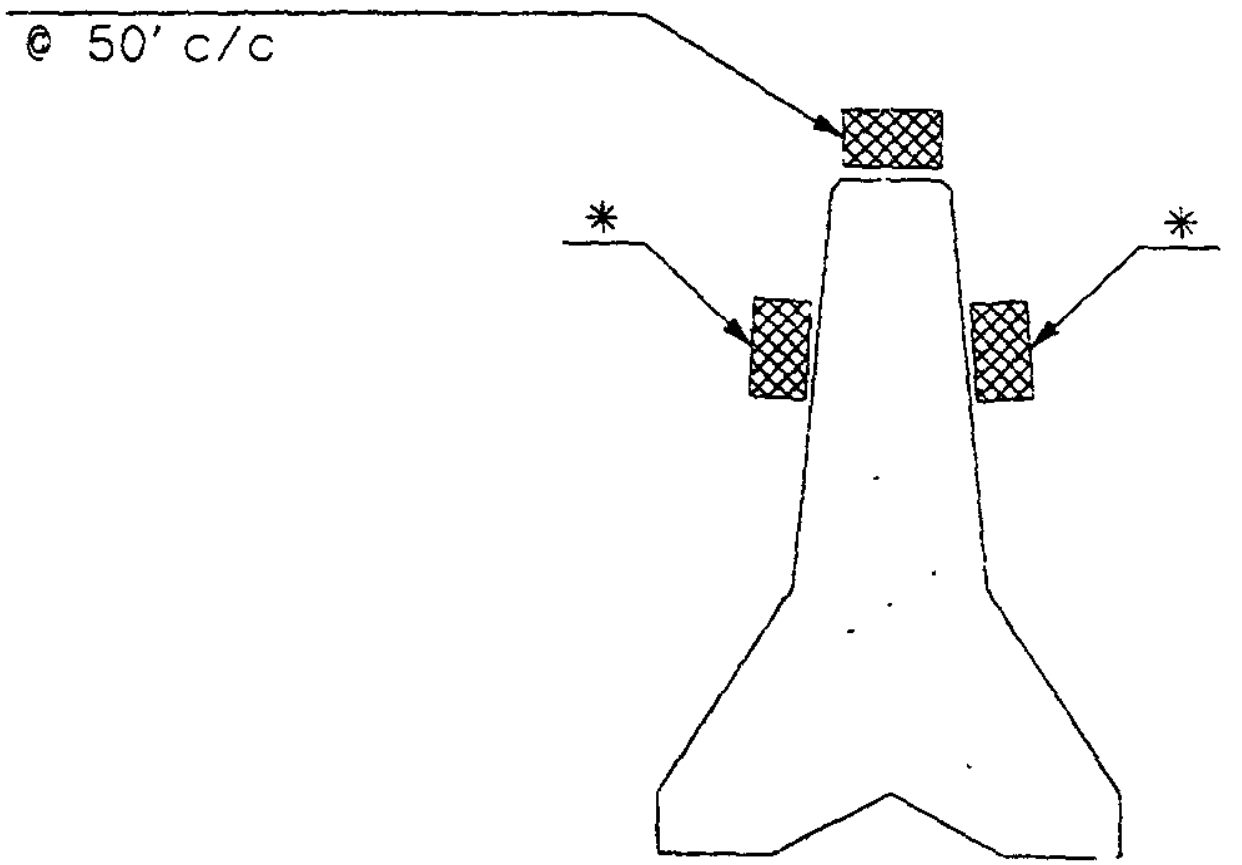

BARRIER DEL INEATORS FOR PERMANENTLY INSTALLED CONCRETE MEDIAN BARRIER

TYPE 1 (CRYSTAL)

TYPE 1 (AMBER)

TYPE 2 (CRYSTAL/CRYSTAL)

TYPE 2 (AMBER/AMBER) 


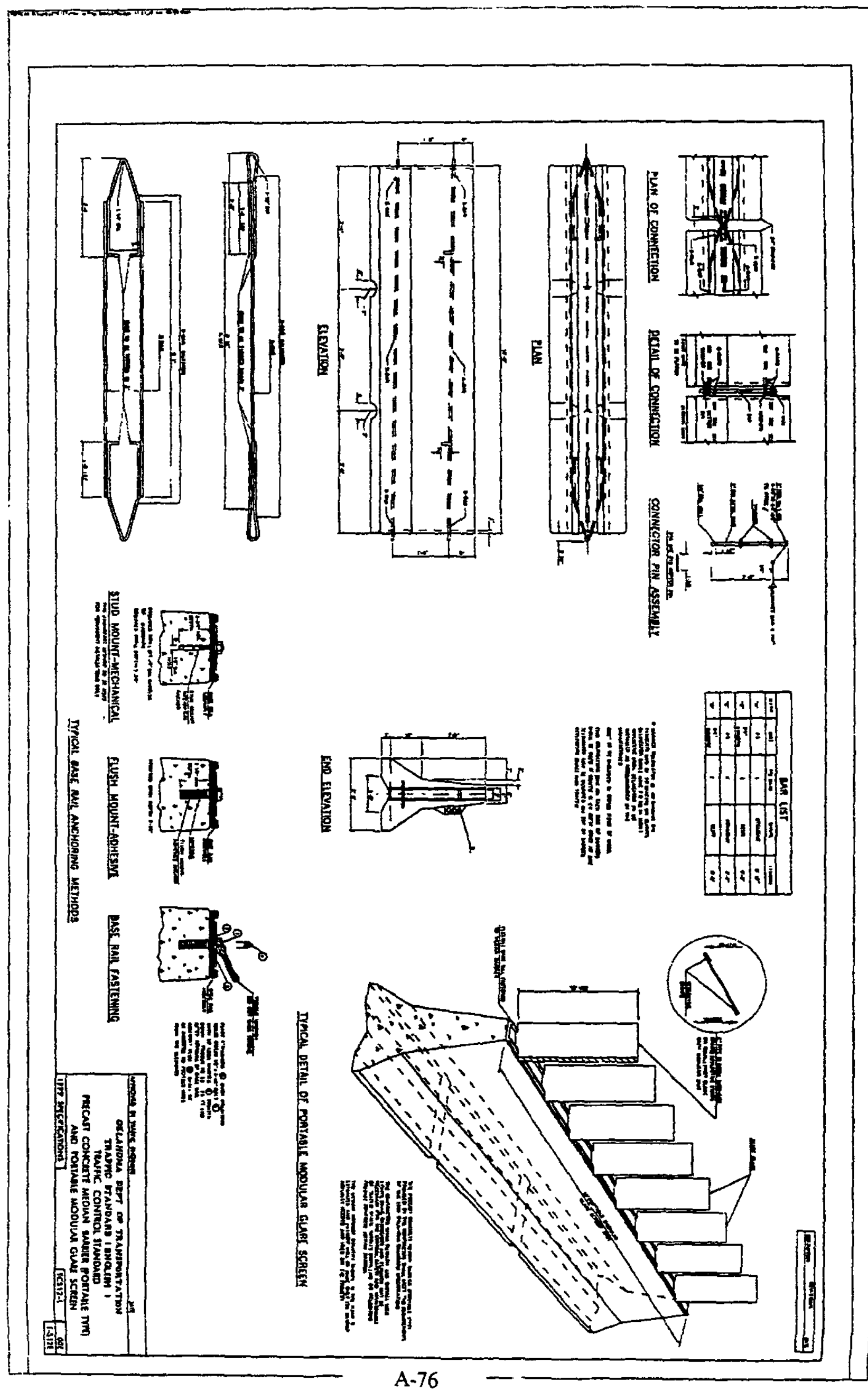




\section{FOR PORTABLE WALL \\ BARRIER DELUNEATOR @ 40' SPACING ON \\ TANGENTS AND @ 20. SPACING ON CURVES. \\ DELINEATOR SHALL HAVE 7.0 SQ. IN. (MIN.) \\ REFLECTNE AREA. DELINEATOR TO BE \\ INSTALLED AS RECOMMENDED BY THE \\ MANUFACTURER.}

MBLY

COST TO BE INCLUDED IN OTHER ITEMS OF WORK.

TWO DELINEATORS (ONE ON EACH SIDE OF BARRIER)

SHALL BE USED IF TRAFFIC IS ON EOTH SIDES OR ONE DELINEATOR MAY BE MOUNTED ON TOP OF BARRIER.

REFLECTORS SHALL FACE TRAFFIC

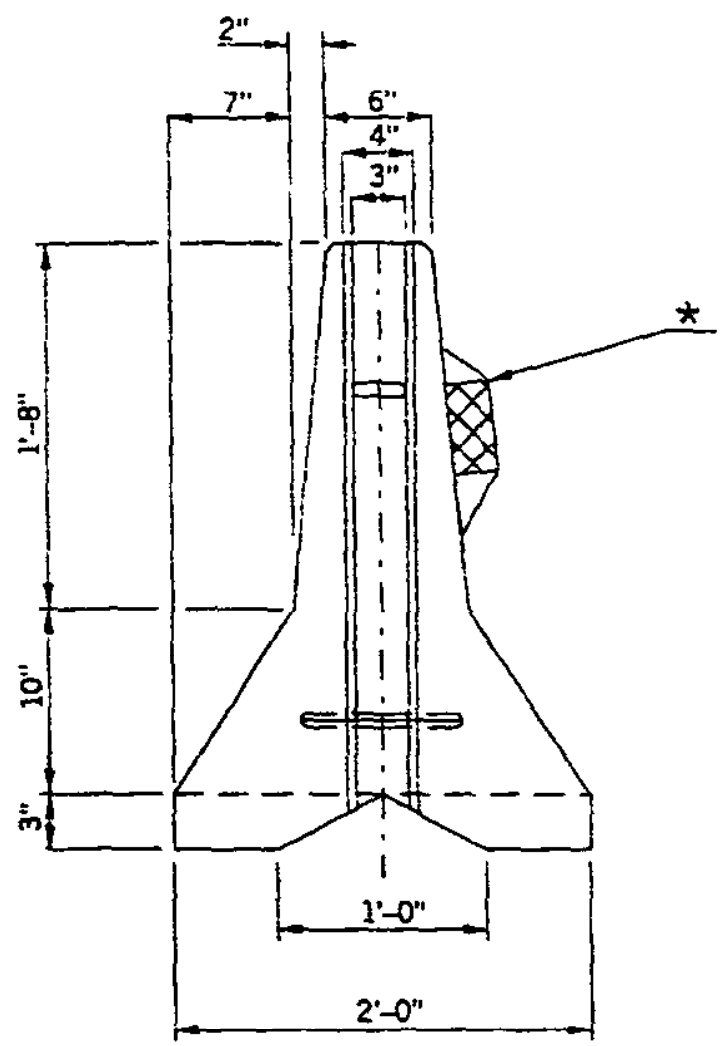

FLEXIELE

TO MEDI

END ELEVATION 


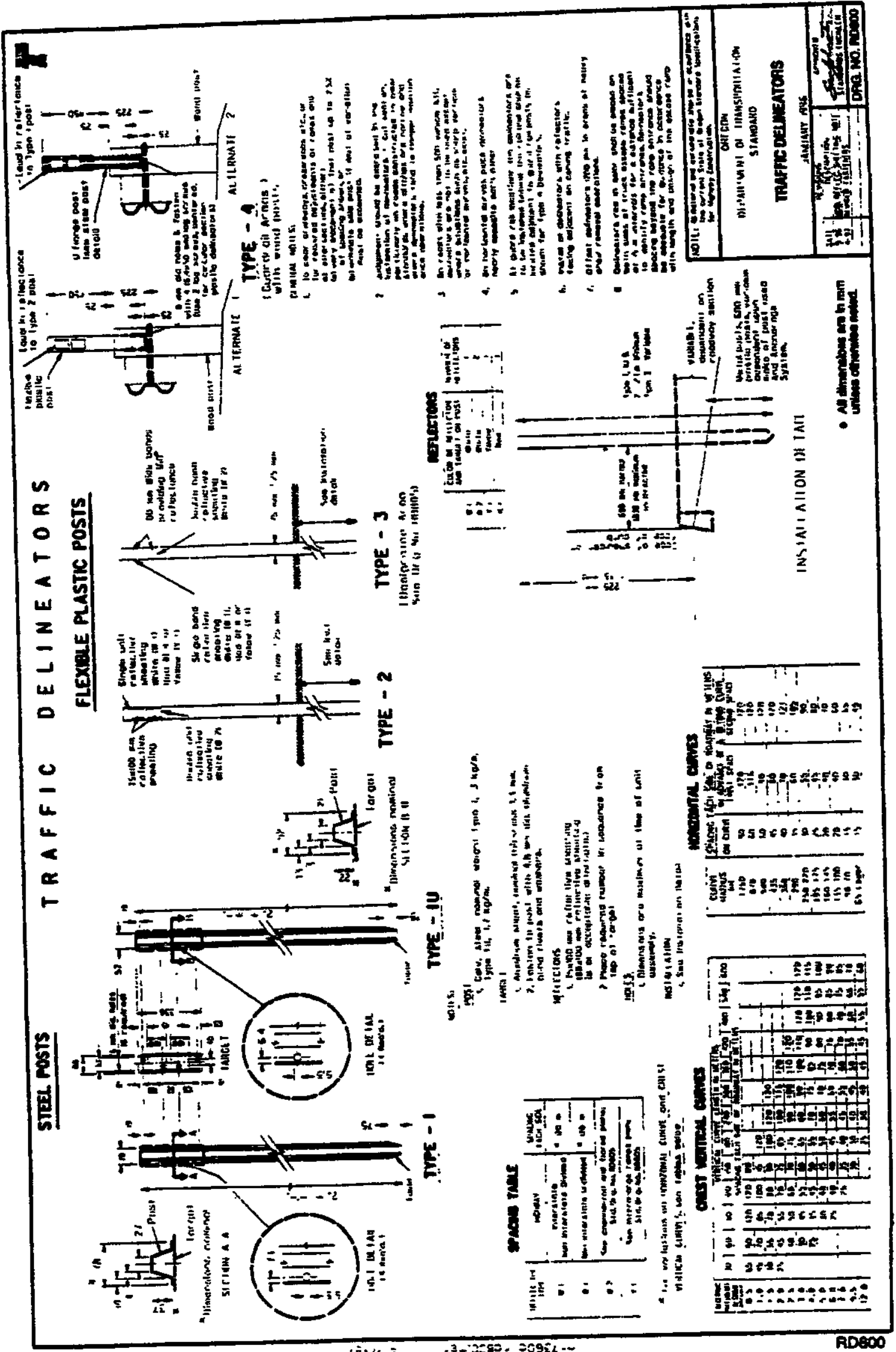




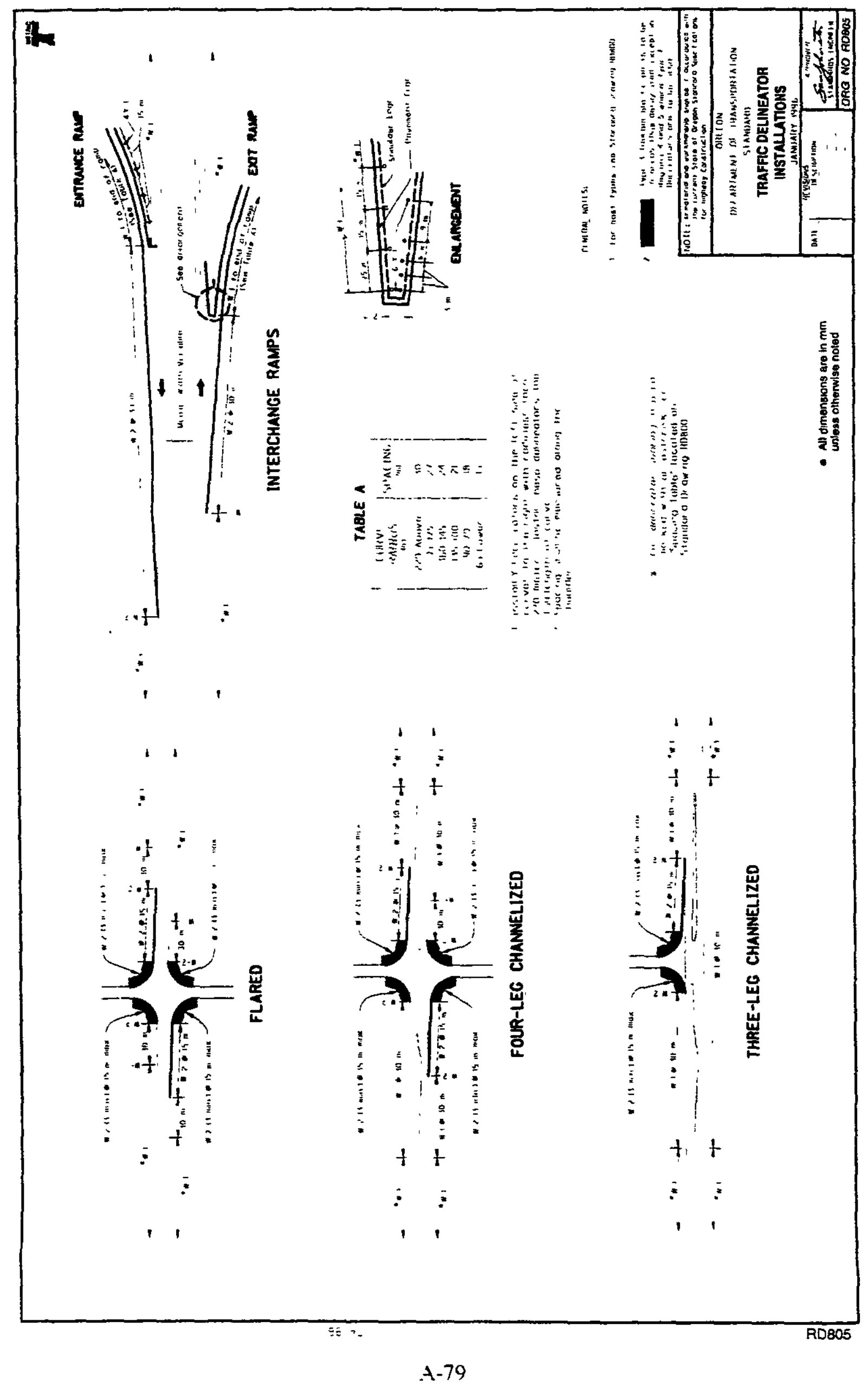




\section{Section 00840 - Delinetors}

\section{Description}

00840.00 Seope - This work consists of furnishing and installing delineators at locations shown or established.

Matertits

00s40.10 Dellnatore - Materials shall meet the following requirements:

Flexible Delineators 02850.30

Galvanized Support Posts .............................................................................................................02850.10

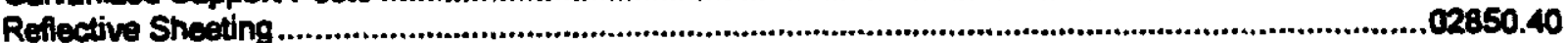

Target Members

00840.11 Dellneators At Guard Rall Locations - Delineators installed at guard rail locations shall be guard rail mounted (Type 4). Full length ground mounted delineators (Types 1 and 2) may be substituted.

00s40.12 Use of Salveged Materials - Delineator components salvaged from wisting or tenporary delineators may be reused in new permanent delineator installations providing they are of the current decign, conform to these spectications and are free of damage which would impar their appearance or serviceabiltty.

Sutability of salvaged materials proposed for reuse will be determined by the Engineer.

\section{Construction}

00840.40 Lines, Grades and Preparation Work - Install delineator posts to the lines, gredes and spacings shown and as established. To avoid difficult installation at any individual post site, the spacing may be varied $5 \%$ in either direction and deviate from line by $150 \mathrm{~mm}$ in either direction as approved. Remove vegetative growth, litter and debris from the post sites.

00840.41 Installation of Dalinastor Posts - Drive or set the delineator post firmly in the ground so it meets the impact resistance requirements according $1002850.30(\mathrm{cos})$. Post depths may very from that recommended by the manufecturer. Posts set in sandy, gravelly or other unconsolidated material may need to be longer to provide adequate anchorage. Posts may be shortmed to avoid unnecessary penetretion in solid rock or in large rock fragments, as approved by the Engineer. If set in rock. drill a $230 \mathrm{~mm}$ deep hole, $25 \mathrm{~mm}$ greater in diameler than the large dimension of the post, and grouted in place with a fine mortar groutt The posts shall be vertical and firm. Remove and discard posts which become split, cracked, twisted, bent, of the tops become badly misshapen due to installation and replace with undamaged posts.

Firmly attach guard rail mounted defineators to guard rail posts as shown.

00840.42 Torget Members - Assemble, fasten, set and align target members and reflective material appropriate to the type and color of delineators involved as shown or directed. All fastenings shall be tight. Attach the reflective sheeting to the posts by an approved positive means which has adequate strength to provent loss of the reflective material during the life of the post or tared.

\section{Finiahing and Glan Up}

00840.70 Gonoral - Repair and restore exposed damaged surfeces of installed delineators es directed. Replace parts of delineators showing damage beyond repair with now parts. 
Remove and dispose of excess excavated materials and litter and debris resulting from the operations according to 00310.43. Replace fouled stone bases with clean materlal of the kind which became fouled. Clean traveled surfaces and finish areas disturbed by the operations to the lines, slopes and conditions of the current project.

\section{Measurement}

00840.80 Unit Basis - The quantities to be paid for will be the actual number of each type of delineators furnished, installed, and accepted regardless of color or number of reflectors, measured as units in place

Required preparation work, earthwork, grouting, backfilling, reparr, restoration replacement, and cleaning up are considered as incidental to delineator installation and no separate measurement for this work will be made

\section{Payment}

00840.90 Unit Basis - The accepted pay quantities will be pald for at the contract unit price per each for the pay item "Delıneators, Type _.". Payment will be payment in full for furnıshing and placing all materials, including all equipment, tools, labor, and incidentals necessary to complete the work.

In the pay item the type of delineator will be inserted with a separate pay item provided for each type

The pay item "Delineators, Type 4" will apply to all guard ral mounted delineators and also for ground mounted delineators substituted. 


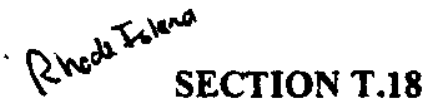

DELINEATORS AND HAZARD MARKERS

T.18.01 DESCRIPTION. This work shall consist of furnishing and erecting delineators and hazard markers of the type and design as indicated on the Plans and/or as directed by the Engineer, all in accordance with these Specifications. This work also includes the provision of flexible delineator posts.

T.18.02 MATERIALS. Single or multi-reflector delineators, reflectorized sheeting, and posts shall conform to the applicable requirements of SECTION M.16; SIGNS AND SIGN SUPPORTS, of these Specifications.

T.18.02.1 Flexible Delineator Posts. The delineators shall be manufactured from a flerible material which meets the following requirements:

a. Height. The overall dimensions of the delineator post shall be such that when installed in accordance with the manufacturer's instructions, the top of the post shall be 48 -inches above the final surface.

b. Delineator Posts shall remain flexible at temperatures between $0^{\circ} \mathrm{F}$ and $140^{\circ} \mathrm{F}$ and shall be durable, resistant to impact, ultraviolet light, ozone hydrocarbons and other atmospheric weathering. Posts shall be white or yellow in accordance with details indicated on the Plans.

c. Posts may be either a one-piece system or a two-piece system. When a two-piece system is used, the post portion shall be readily replaceable without removing or partially removing, the anchor and without displacing the soil around the anchor.

f. Surfaces. Rnth the front and back surfaces of the delineator shall be smooth surfaces cadable of acceding 